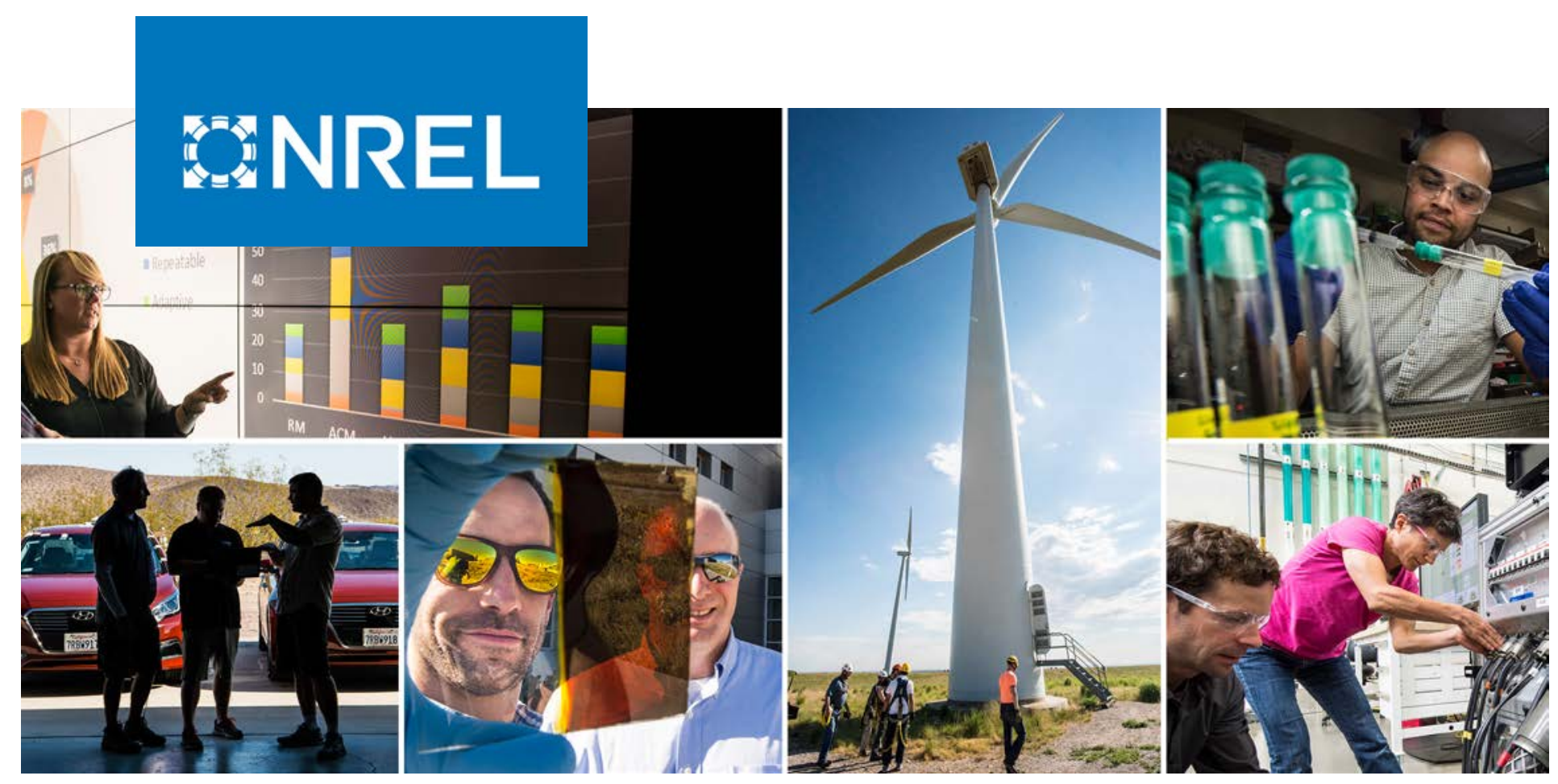

\title{
Microgrids for Energy Resilience: A Guide to Conceptual Design and Lessons from Defense Projects
}

Samuel Booth, ${ }^{1}$ James Reilly, ${ }^{1}$ Robert Butt, ${ }^{1}$ Mick Wasco, ${ }^{2}$ and Randy Monohan ${ }^{2}$

1 National Renewable Energy Laboratory

2 United States Marine Corps

NREL is a national laboratory of the U.S. Department of Energy Office of Energy Efficiency \& Renewable Energy

Operated by the Alliance for Sustainable Energy, LLC

This report is available at no cost from the National Renewable Energy Laboratory (NREL) at www.nrel.gov/publications.
Technical Report

NREL/TP-7A40-72586

Revised January 2020 


\title{
GNREL
}

\section{Microgrids for Energy Resilience: A Guide to Conceptual Design and Lessons from Defense Projects}

Samuel Booth, ${ }^{1}$ James Reilly, ${ }^{1}$ Robert Butt, ${ }^{1}$ Mick Wasco, ${ }^{2}$ and Randy Monohan ${ }^{2}$

\author{
1 National Renewable Energy Laboratory \\ 2 United States Marine Corps
}

\section{Suggested Citation}

Booth, Samuel, James Reilly, Robert Butt, Mick Wasco, and Randy Monohan. 2019. Microgrids for Energy Resilience: A Guide to Conceptual Design and Lessons from Defense Projects. Golden, CO: National Renewable Energy Laboratory. NREL/TP-7A40-72586. https://www.nrel.gov/docs/fy19osti/72586.pdf.

NREL is a national laboratory of the U.S. Department of Energy Office of Energy Efficiency \& Renewable Energy Operated by the Alliance for Sustainable Energy, LLC

This report is available at no cost from the National Renewable Energy Laboratory (NREL) at www.nrel.gov/publications.

Contract No. DE-AC36-08GO28308
Technical Report NREL/TP-7A40-72586

Revised January 2020

National Renewable Energy Laboratory 15013 Denver West Parkway Golden, CO 80401 303-275-3000 • www.nrel.gov 


\section{NOTICE}

This work was authored in part by the National Renewable Energy Laboratory, operated by Alliance for Sustainable Energy, LLC, for the U.S. Department of Energy (DOE) under Contract No. DE-AC36-08G028308. Funding provided by U.S. Department of Defense. The views expressed herein do not necessarily represent the views of the DOE or the U.S. Government.

This report is available at no cost from the National Renewable Energy Laboratory (NREL) at www.nrel.gov/publications.

U.S. Department of Energy (DOE) reports produced after 1991 and a growing number of pre-1991 documents are available free via www.OSTI.gov.

Cover Photos by Dennis Schroeder: (clockwise, left to right) NREL 51934, NREL 45897, NREL 42160, NREL 45891, NREL 48097, NREL 46526.

NREL prints on paper that contains recycled content. 


\section{Errata}

This report, originally published in May 2019, has been revised in January 2020 to address additional comments from our DoD, DON, and USMC partners to ensure this report provides an accurate representation of the work completed. Some of the more significant revisions were completed to;

- Provide clarification on processes for requirements definition undertaken by NREL and USMC staff.

- Expand on the laboratory and factory testing completed as part of this effort.

- Provide more specific focus on alternative financing mechanisms and the process for energy resilience valuation investigated as part of this effort.

- Expand on the valuation framework for economic cost savings coupled with energy resilience benefits to specific missions. 


\section{Acknowledgments}

The National Renewable Energy Laboratory thanks the United States Marine Corps and the United States Navy for the opportunity to partner with them on microgrid projects. In particular, we thank the Marine Corps Air Station (MCAS) Miramar public works team, the Marine Corps Energy Headquarters Office, and Naval Facilities Engineering Command for their support of this work. Mark Rodriguez from the Naval Facilities Engineering Command (NAVFAC) electrical engineering division also deserves a special thank you for his dedication to the Miramar microgrid projects along with many other team members who contributed lessons learned, including Anh Chung, Gilbert Geluz, Alfonso Jo, Kenneth Me, Laura Nelson, and John Thomas from NAVFAC as well as Craig Der Ananian, Robert Hillman, and Mark Hall from the joint venture of Schneider Electric and Black and Veatch, and Gregg Tomberlin from NREL. We would also like to thank Mike Meshek, Kate Anderson, Tim Tetreault, Mike Callahan, and Jeff Marqusee for their reviews, input, and editing of this report. 


\section{List of Abbreviations and Acronyms}

A

$\mathrm{AC}$

ANSI

BEMS

BESS

DoD

DoDI

DOE

EPRI

ERCIP

ERDC CERL

ES

ESPC

ETT

EUL

FAT

FO

FOC

GUI

HMI

ICMP

IEEE

IP

IT

$\mathrm{kVA}$

kVAR

$\mathrm{kW}$

LAN

MV

MW

NAVFAC

NEMA

NFPA

NIPRnet

NIST

NREL

O\&M

OSD

MAC

MCAS

MILCON

MVA

PCC

PF ampere

alternating current

American National Standards Institute

building energy management systems

battery energy storage system

U.S. Department of Defense

DoD Instruction

U.S. Department of Energy

Electric Power Research Institute

Energy Resilience and Conservation Investment Program

Engineer Research and Development Center Construction Engineering

Research Laboratory

ethernet switch

energy savings performance contract

electrical testing technician

enhanced use lease

factory acceptance testing

fiber optics

fiber optic cables

graphical user interface

human-machine interface

Internet Control Message Protocol

Institute of Electrical and Electronics Engineers

internet protocol

information technology

kilovolt-ampere

kilovolt-ampere reactive

kilowatt

local area network

medium voltage

megawatt

Naval Facilities Engineering Command

National Electrical Manufacturers Association

National Fire Protection Association

Non-classified Internet Protocol Router Network

U.S. National Institute of Standards and Technology

National Renewable Energy Laboratory

operation and maintenance

Office of the Secretary of Defense

media access control

Marine Corps Air Station

military construction

million volt-amperes

point of common coupling

power factor 


$\begin{array}{ll}\text { PID } & \text { proportional-integral-derivative controller } \\ \text { PLC } & \text { programmable logic controller } \\ \text { POD } & \text { point of delivery } \\ \text { PPA } & \text { power purchase agreement } \\ \text { PPC } & \text { power plant controller } \\ \text { PQ } & \text { power quality } \\ \text { PV } & \text { photovoltaics } \\ \text { RBAC } & \text { role-based access control } \\ \text { RFP } & \text { request for proposals } \\ \text { RMF } & \text { risk management framework } \\ \text { RTU } & \text { remote terminal units } \\ \text { SAIDI } & \text { system average interruption duration index } \\ \text { SAIFI } & \text { system average interruption frequency index } \\ \text { SAT } & \text { site acceptance testing } \\ \text { SCADA } & \text { supervisory control and data acquisition } \\ \text { SPIDERS } & \text { Smart Power Infrastructure Demonstration for Energy Reliability } \\ \text { SRM } & \text { and Security } \\ \text { TCP } & \text { Sustainment, Restoration, and Modernization } \\ \text { TRL } & \text { Transmission Control Protocol } \\ \text { UESC } & \text { technology readiness level } \\ \text { UDP } & \text { utility energy service contracts } \\ \text { UFC } & \text { User Datagram Protocol } \\ \text { UFGS } & \text { Unified Facilities Criteria } \\ \text { UMCS } & \text { Unified Facilities Guide Specifications } \\ \text { UPS } & \text { utility monitoring and control system } \\ \text { V } & \text { uninterruptible power supply } \\ \text { VAR } & \text { volt } \\ \text { VLAN } & \text { volt ampere reactive } \\ & \text { virtual local area network } \\ & \end{array}$




\section{Executive Summary}

The U.S. Department of Defense (DoD) has long recognized the strategic value of energy to its missions, and the energy resilience of DoD installations has become of increasing concern. Department of Defense Instruction $4170.11^{1}$ requires installations to be more energy resilient, and as a result, many installations are pursuing microgrids to meet their energy resiliency goals and requirements.

This report provides a resource for stakeholders involved in analyzing and developing microgrid projects at DoD installations. It builds on experience and lessons from the U.S. Department of Energy's (DOE) National Renewable Energy Laboratory (NREL) in supporting numerous DoD projects, including the microgrid at Marine Corps Air Station Miramar. ${ }^{2}$ The report is structured following NREL's microgrid design process. Figure ES-1 outlines the five steps in the microgrid design process and subcomponents.

\begin{tabular}{|c|c|c|c|c|}
\hline $\begin{array}{l}\text { Step One } \\
\text { Scoping \& } \\
\text { Planning }\end{array}$ & $\begin{array}{l}\text { Step Two } \\
\text { Data } \\
\text { Collection }\end{array}$ & $\begin{array}{c}\text { Step Three } \\
\text { Conceptual } \\
\text { Design }\end{array}$ & $\begin{array}{l}\text { Step Four } \\
\text { Project } \\
\text { Development }\end{array}$ & $\begin{array}{c}\text { Step Five } \\
\text { Implementation }\end{array}$ \\
\hline $\begin{array}{l}\text { - Project Team } \\
\text { - Background } \\
\text { Information } \\
\text { - Stakeholders } \\
\text { - Priority } \\
\text { Missions \& } \\
\text { Loads } \\
\text { - Risks/Threats } \\
\text { - High Level } \\
\text { Goals } \\
\text { - Performance } \\
\text { requirements }\end{array}$ & $\begin{array}{l}\text { - Total Loads \& } \\
\text { Critical Loads } \\
\text { - Electrical } \\
\text { Infrastructure } \\
\text { - Existing } \\
\text { Generation \& } \\
\text { Future Potential } \\
\text { - Controls \& } \\
\text { - Communications } \\
\text { - Energy Costs } \\
\text { - Historical } \\
\text { Reliability }\end{array}$ & $\begin{array}{l}\text { - Boundaries \& } \\
\text { Architecture } \\
\text { - Generation } \\
\text { Analysis \& } \\
\text { Selection } \\
\text { - Controls \& } \\
\text { Communications } \\
\text { - Design Constraints } \\
\text { \& Requirements } \\
\text { - Technical \& } \\
\text { Economic } \\
\text { Modeling } \\
\text { - Implementation } \\
\text { Options }\end{array}$ & $\begin{array}{l}\text { - Acquisition \& } \\
\text { Operating } \\
\text { Strategies } \\
\text { - Funding or } \\
\text { Financing } \\
\text { - Project } \\
\text { Refinement } \\
\text { - Request for } \\
\text { Proposal } \\
\text { Development } \\
\text { - Solicitation } \\
\text { - Contractor } \\
\text { Selection }\end{array}$ & $\begin{array}{l}\text { - Post Award } \\
\text { - Engineering Design } \\
\text { - Construction \& } \\
\text { Functional Testing } \\
\text { - Commissioning \& } \\
\text { Performance } \\
\text { Testing } \\
\text { - Operations \& } \\
\text { Maintenance }\end{array}$ \\
\hline
\end{tabular}

\section{Figure ES-1. NREL's microgrid design process}

For each step in the process this report provides practical information for DoD stakeholders, including information to gather, analysis to be conducted, available tools, examples from DoD projects, and lessons learned. Specific examples of the types of information provided include:

- A table highlighting potential project stakeholders

- A summary of project requirements from the Miramar microgrid project

- Information on the key items to analyze in electrical drawings

- Lessons learned from microgrid project procurement and implementation.

The goal of this report is to outline a process to improve the quality, reduce the cost, and increase the speed and scale of DoD's energy resiliency infrastructure investments.

1 For more information see: https://www.esd.whs.mil/Portals/54/Documents/DD/issuances/dodi/417011p.pdf

2 For simplicity this report will utilize Miramar to refer to Marine Corps Air Station Miramar 


\section{Table of Contents}

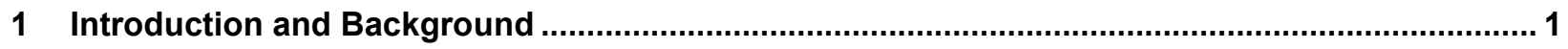

1.1 Energy Resilience Definitions for DoD Installations...................................................... 1

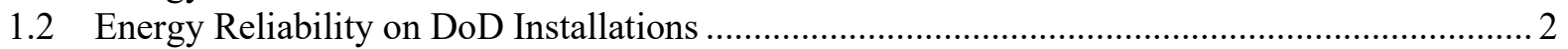

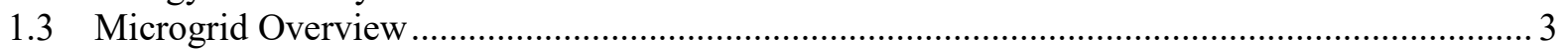

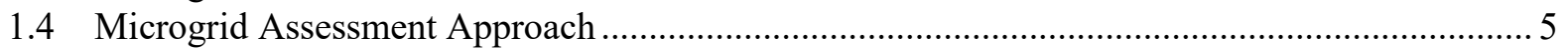

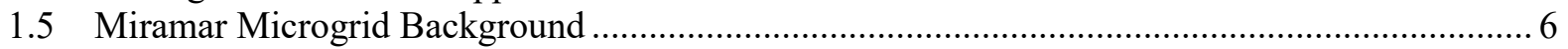

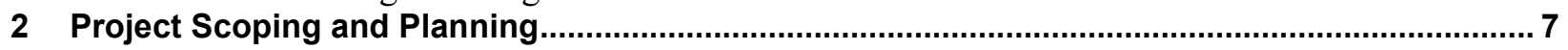

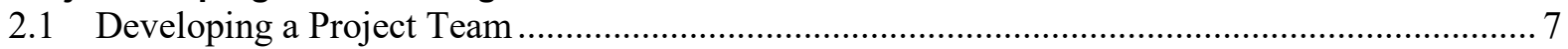

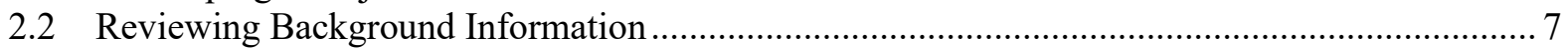

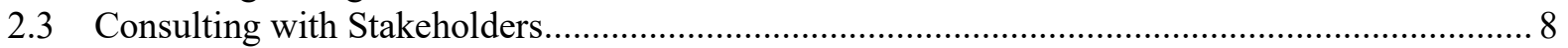

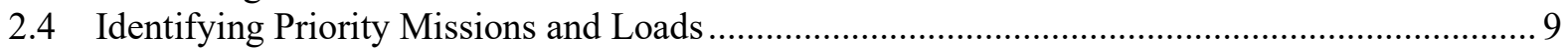

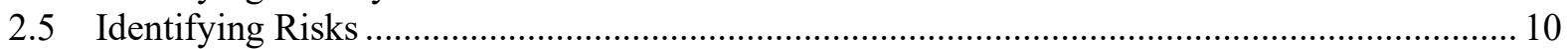

2.6 Defining High-Level Goals and Requirements ........................................................ 10

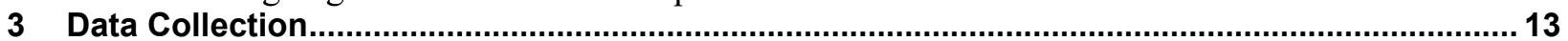

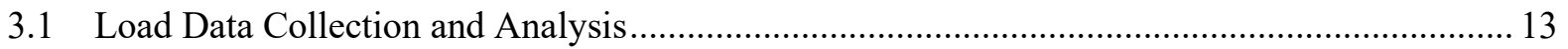

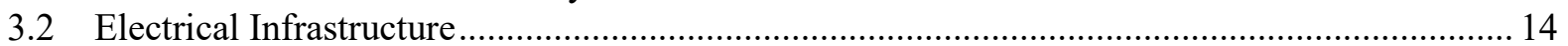

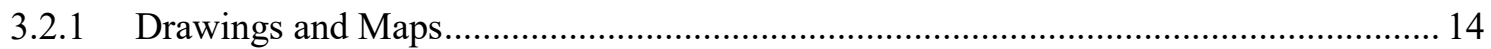

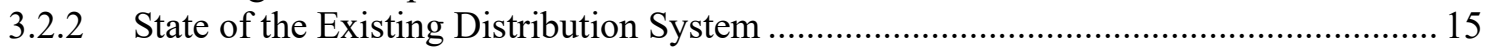

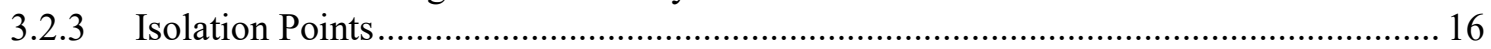

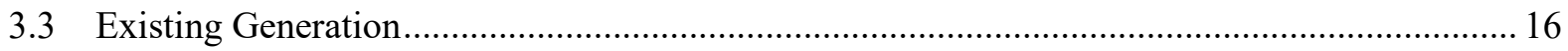

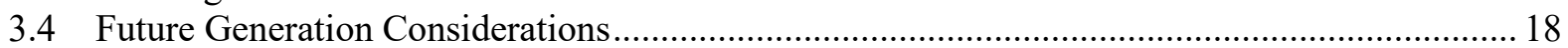

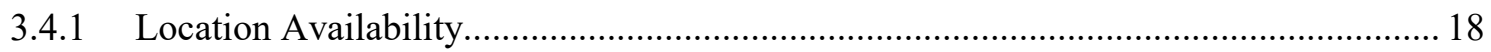

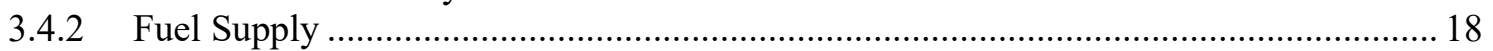

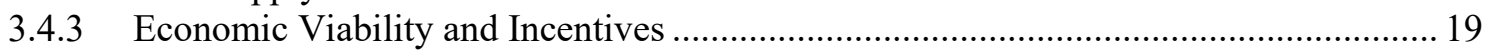

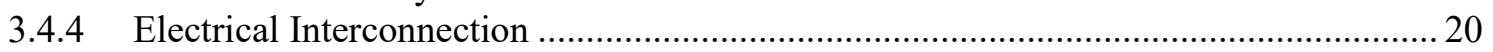

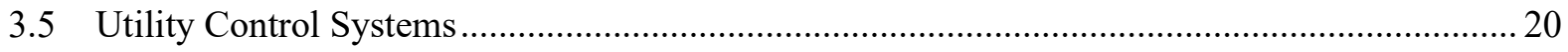

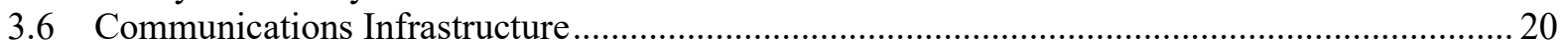

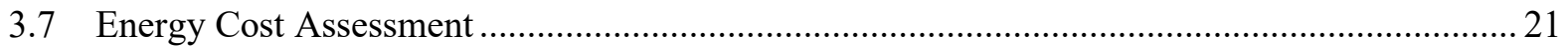

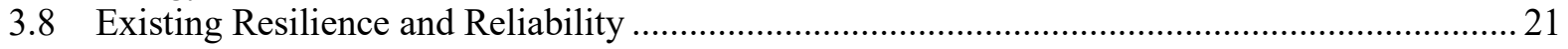

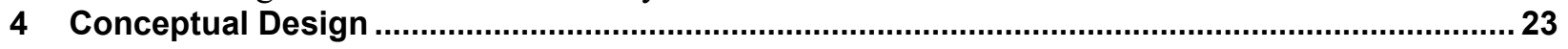

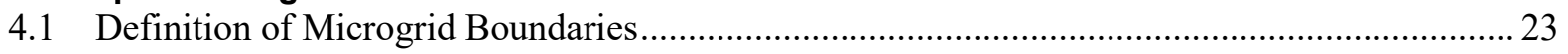

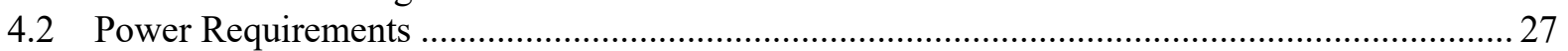

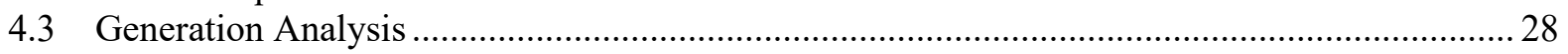

4.3.1 Existing Prime Power Dispatchable Generation and Variable Generation ..................... 30

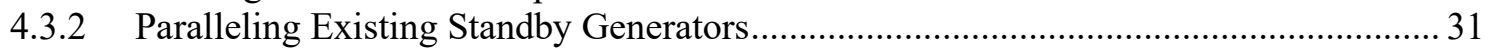

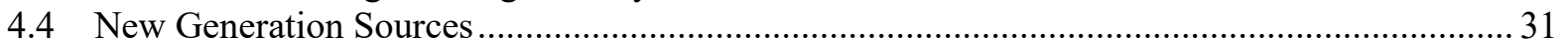

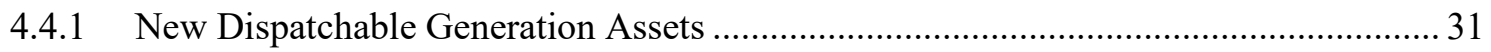

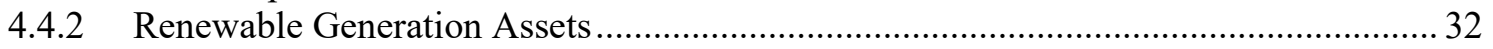

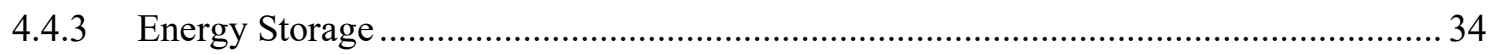

4.4.4 Matching Generation and Load........................................................................ 34

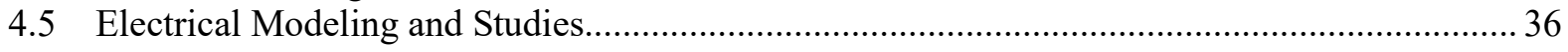

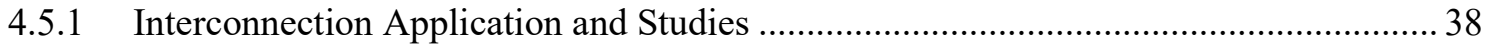

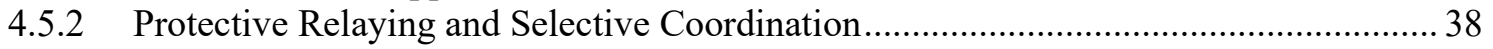

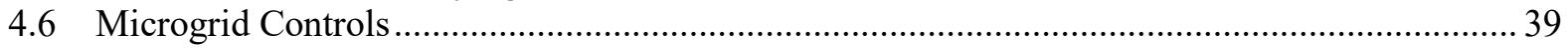

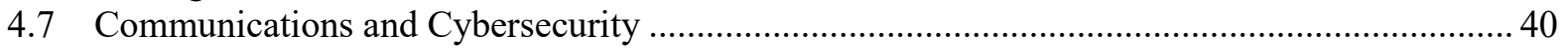

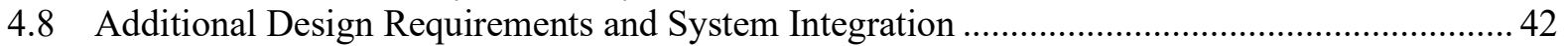

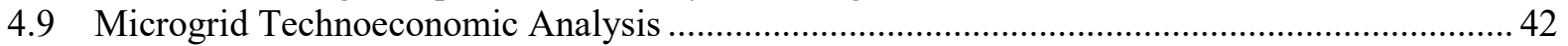

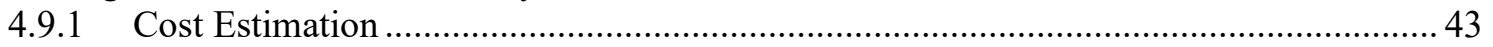

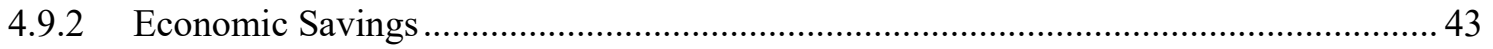




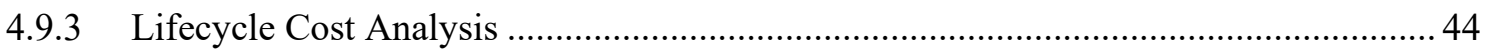

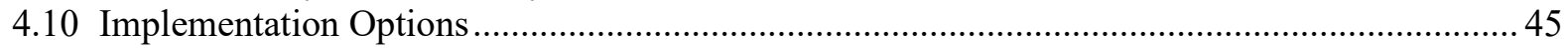

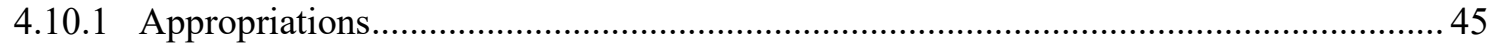

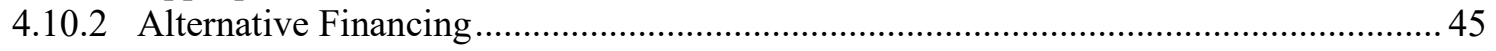

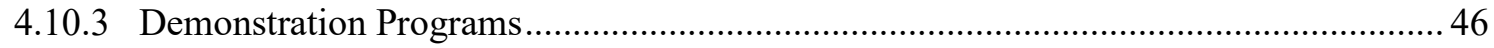

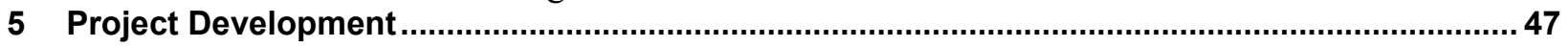

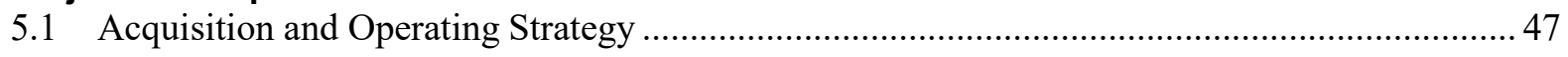

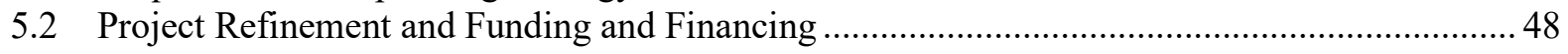

5.3 Solicitation, Selection, and Award: Lessons Learned .............................................................. 48

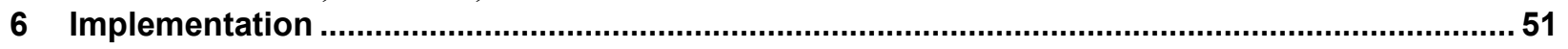

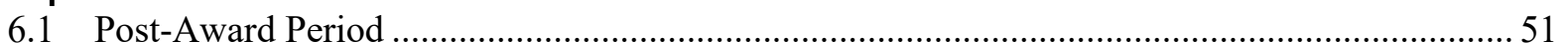

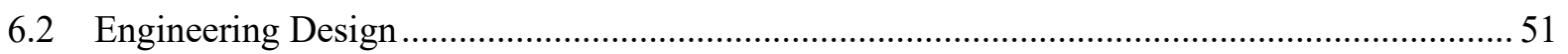

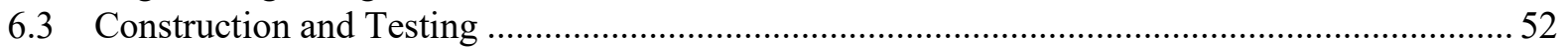

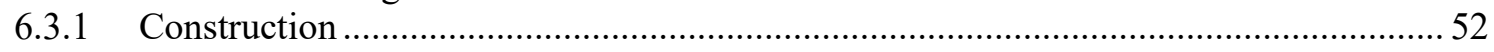

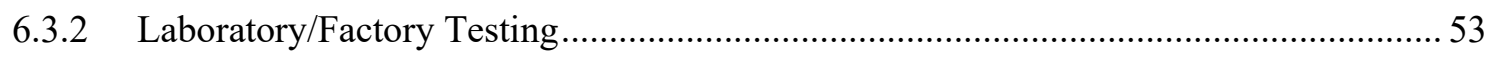

6.3.3 Site Acceptance Testing (Non-Energized) ......................................................... 54

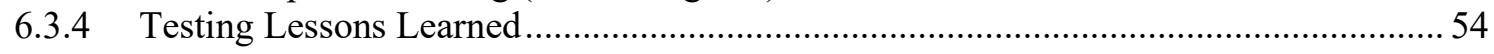

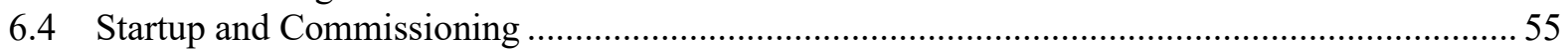

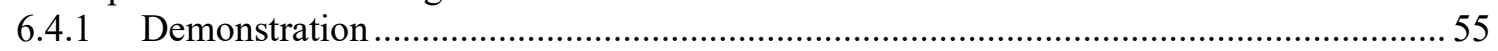

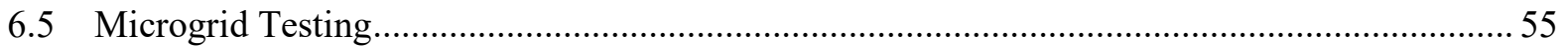

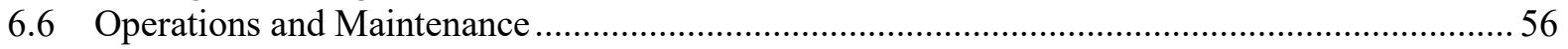

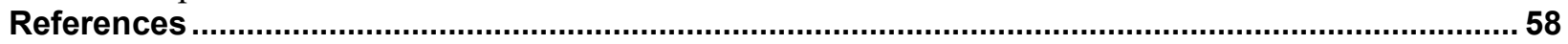

Appendix A. Example Data Request from NREL Microgrid Project .........................................60

Appendix B. Reactive Power, Harmonic Distortion, and Control Modes ..................................62

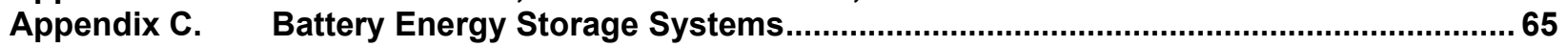

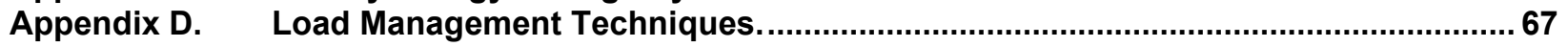

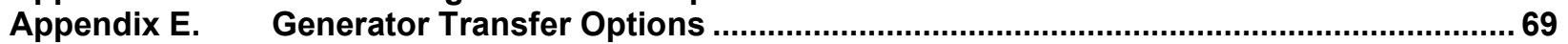

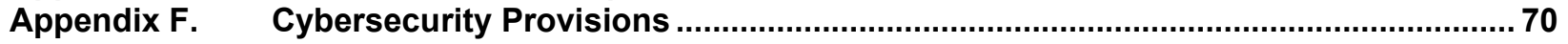




\section{List of Figures}

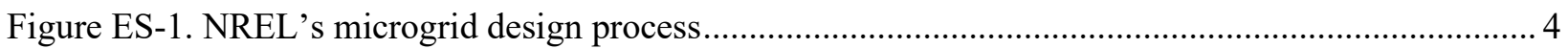

Figure 1: Reported DoD Utility Disruptions by Fiscal Year .......................................................... 3

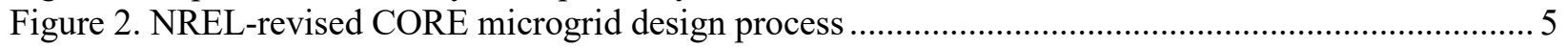

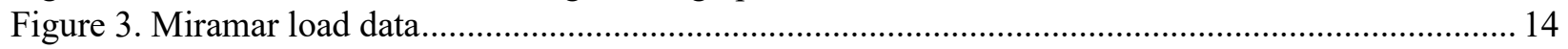

Figure 4. Examples of types of common DoD microgrids ............................................................... 24

Figure 5. Power output data and control signals from PV at Miramar during islanding test..................... 33

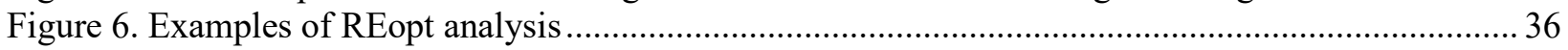

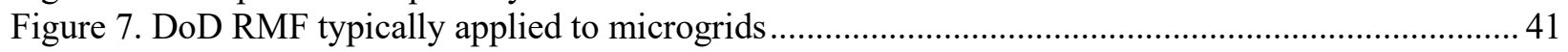

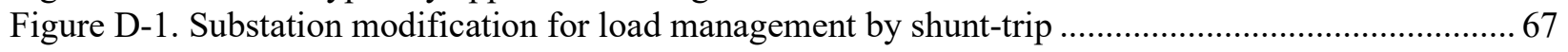

Figure D-2. Draw-out style power circuit breakers for load control..................................................... 68

Figure E-1. Typical automatic transfer switch scheme for standby diesel generator................................ 69

Figure E-2. Paired circuit breakers for standby diesel generators to support load/generation management

\section{List of Tables}

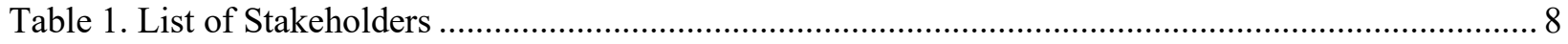

Table 2. Major Components of an Electrical Drawing that are Relevant to Microgrid Assessments......... 15

Table 3. General Characteristics of Microgrids Operating in Islanded Mode with Renewable Energy ..... 29

\section{List of Text Boxes}

Text Box 1. Example of Load Prioritization Strategy for Miramar Installation Microgrid ......................... 9

Text Box 2. Example of Microgrid Requirements at Miramar ................................................................. 11

Text Box 3. Example of Upgrades Required Before Pursuing a Microgrid ............................................ 16

Text Box 4. Examples and Considerations for Natural Gas Based Microgrids .......................................... 19

Text Box 5. Examples and Definitions of Loads Covered in Microgrids Listed by Increasing Boundary

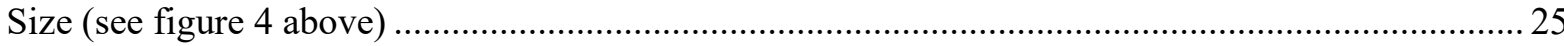

Text Box 6. Example of a Cost Analysis of New Isolation Points versus Additional Generation ............. 26

Text Box 7. Example of Microgrid Modeling for Miramar........................................................................ 38

Text Box 8. RMF Examples for Miramar and Otis Air National Guard Base ESTCP Projects................ 42

Text Box 9. Examples of Microgrid Testing …….............................................................................. 54 


\section{Introduction and Background}

The U.S. Department of Defense (DoD) has long recognized the strategic value of energy to its missions. The energy resilience of DoD installations has become a growing concern over the last decade as DoD missions have become increasingly reliant on systems that require electricity, such as computing equipment; industrial controllers; communications equipment; and mechanical heating, cooling, and ventilation systems. One strategy for improving the electrical energy resilience ${ }^{3}$ of an installation involves building a microgrid to serve as a backup power system in the event of a grid outage caused by an attack, equipment failure, or other contingency situation. ${ }^{4}$ A microgrid is a group of interconnected loads and distributed generation that act as a single controllable electrical entity and can operate in both grid-connected and isolated modes (Ton and Smith, 2012). Microgrids can add additional resiliency beyond the current DoD practice of building level backup generators.

This report provides (1) an overview of the microgrid planning, assessment, and design process for DoD installations and (2) is a resource for energy managers, policymakers, contractors, and other stakeholders involved in microgrid projects. The report builds on experience and lessons from the U.S. Department of Energy's (DOE) National Renewable Energy Laboratory (NREL) in supporting the Miramar microgrid project and numerous other DoD, DOE, and international microgrid projects.

\subsection{Energy Resilience Definitions for DoD Installations}

The DoD policy on energy resilience-Department of Defense Instruction (DoDI) 4170.11 (2018 update) requires that installations act to ensure they are energy resilient, and it provides several key definitions and guidelines that serve as a basis for this report, including: ${ }^{5}$

- Installation energy resilience is defined as "the ability to prepare for and recover from energy disruptions that impact mission assurance on military installations."

- Critical energy requirements are defined as "critical mission operations on military installations or facilities that require a continuous supply of energy in the event of an energy disruption or emergency."

- The following requirement is also included in the instruction: "DoD Components shall take necessary steps to ensure energy resilience on military installations. DoD Components shall plan and have the capability to ensure available, reliable, and quality power to continuously accomplish DoD missions from military installations and facilities." A requirement to determine critical loads is also included in the instruction: "DoD Components shall determine their critical energy requirements and conduct an engineering facility energy load analysis for these requirements when metering data is not unavailable. These critical energy requirements shall be reviewed and updated on an annual basis"

3 This report focuses on electrical energy resilience, as this is energy source of primary concern to most DoD installations and missions. However, in some cases, energy sources such as thermal energy could be more critical. 4 For simplicity, this report will refer to all potential outage scenarios as contingency situations.

5 For more information, see DoD (2018). 
- The instruction also provides several options for resilience; though it is focused on microgrids, it allows for many solutions, including building-level generators, alternative or renewable energy technologies, microgrids, and energy storage, as well as mission alternatives such as reconstitution elsewhere.

Though DoDI 4170.11 does provide clear instructions for installations in terms of energy resilience requirements, it does not provide detailed information about how to conduct many of the required assessments. The guidelines provided in this report can be used as complement to the instruction, and it provides information for DoD installations on the critical components of microgrid assessment, design, and implementation.

It should be noted that each of the DoD services also have their own instructions and policies for energy resilience. For example, the Army has a directive titled, Installation Energy and Water Security Policy (Secretary of the Army 2017). The directive instructs Army installations to develop strategies to be capable of independently providing energy and water needs for 14 days, thus providing additional guidance in complement to the DoD instruction. ${ }^{6}$ The Navy has an Energy Security Framework (NAVFAC 2017) that for example targets 7 days of fuel storage and provides a power benchmark for Naval Shipyards of $99.9886 \%$ utility availability. The Air Force Energy Flight Plan (U.S. Air Force 2017) has goals for improved resiliency, optimized demand, and assured supply.

\subsection{Energy Reliability on DoD Installations}

Improving resiliency for installations requires an understanding of the current status of electrical supply reliability. Reliability and resiliency are not the same thing, reliability refers to a measurement of the number and duration of electrical outages for an installation. Historical reliability can be proxy for predicting the likelihood of future outages and can set a baseline for potential improvements that a microgrid could provide. ${ }^{7}$ Resiliency refers to the ability of an installation to respond to and recover from a contingency situation.

Annual reporting on Department of Defense energy management is required by Title 10, U.S.C. $\S 2925$ (a)(2), including the reporting of utility outages at military installations. The annual DoD outage statistics are published in the Department of Defense Annual Energy Management and Resilience Report. (ODASD IE 2018, 2017, \& 2016) The number of utility outages reported per year which includes electricity, water, and gas that last 8 hours or longer are shown in Figure 1 below.

6 For more information see, Secretary of the Army (2017).

7 Past energy supply reliability is not always a reliable predictor of future performance as certain things such as the utility regulatory environment and the conditions of the bulk electrical system may have changed or items such as the typical weather may be different in future scenarios. 


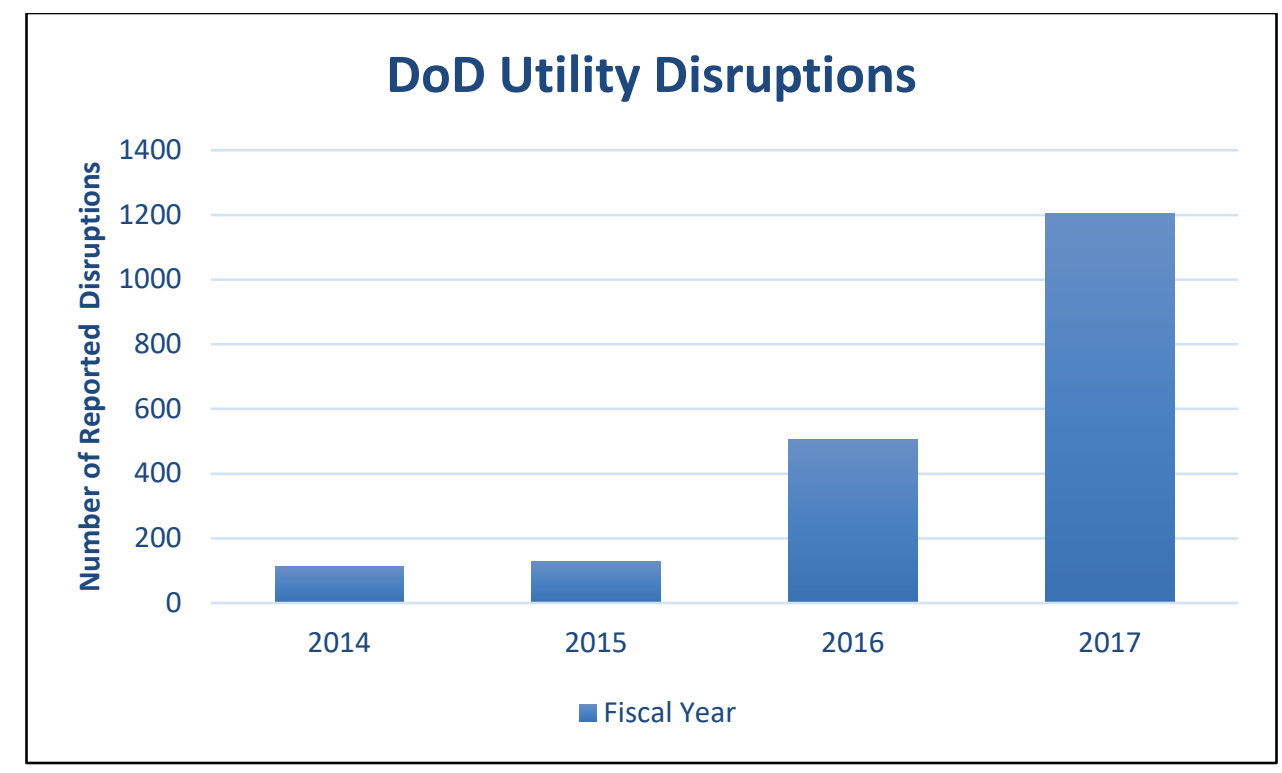

Figure 1: Reported DoD Utility Disruptions by Fiscal Year

(Data Sourced from DoD Annual Energy Reports)

Further information from the most recent report is summarized below. (ODASD IE 2018) DoD components reported approximately 1,205 utility outages that lasted eight hours or longer in Fiscal Year (FY) 2017. However, the increase in outages from FY16 to FY17 is estimated to be from increased reporting of outages by installations, rather than a substantial increase in the number of outages with 72 percent of these outages being electrical outages. In FY 2017, equipment failure (e.g., reliability or mechanical issues) accounted for $43 \%$ of the reported utility outages, $35 \%$ were caused by planned maintenance, and $15 \%$ were caused by acts of nature (e.g., weather, storms). The remaining 7\% were considered "other" because they did not fall under these categories.

Some of the DoD services and other government agencies have also attempted to analyze outage data. Based on information from the Navy's maintenance management system, Navy bases experienced more than 900 outages in FY 2015, for bases in the Atlantic region, the average duration of an outage was around 15 hours; for bases in the Navy's Pacific region, the average duration was close to 32 hours (Marqusee, Schultz, \& Robyn, 2017). The Government Accountability Office also gathered information from 20 installations on utility disruptions and 18 of them reported that they had experienced a disruption that lasted 8 hours or longer between 2012 and 2014, they also reported 150 total utility disruptions of which about 110 were electric utility disruptions. (Marqusee, Schultz, \& Robyn, 2017)

\subsection{Microgrid Overview}

Microgrids can enhance energy resiliency by providing energy surety (i.e., loads have certain access to energy) and survivability (i.e., energy is resilient and durable in the face of potential damage).

Microgrids are typically composed of distributed energy resources that can provide independent power to designated critical loads upon loss of their primary source of energy. However, a 
microgrid is distinct from an emergency back-up system in that a microgrid can interact with the utility (primary) grid and operate in either grid-connected or islanded mode. Microgrids are typically managed through a central controller that monitors the system operating parameters, coordinates distributed energy resources, balances and controls electrical loads, and is responsible for disconnection and reconnection of the microgrid to the primary grid. Microgrids without a central controller are less common but technical feasible as well, typically in these systems each distributed energy resource has an individual controller and the individual controllers act in a coordinated manner.

Microgrids can be an effective option for increasing a military installation's energy resilience, since they provide a functional electric power system that can operate independently of the main grid. The electrical grid provides primary power, the microgrid can provide secondary dispatchable power in the event of a grid failure (in addition to other services), and the building emergency diesel generators then only provide power directly to their respective building loads in the event of a failure of the primary grid and the microgrid. Microgrids have many advantages over building-level diesel generators:

- They provide more reliable power because they are a networked solution with more redundancy than a single building level backup generator. They are also often more reliable because microgrid components can be used in both grid-connected and off-grid operation. This allows for more frequent use and testing compared to diesel generators that may be rarely used, tested, or maintained.

- Microgrids can share load across generators, which increases overall system efficiency and allows for powering more load with the same amount of fuel than individual generators. Sharing load also avoids a potential technical issue commonly known as wet stacking (in which unburned fuel passes into the exhaust system), which can arise from continuous operation of generators at low loads.

- The increased system efficiency of microgrids can extend the length of time a site can be powered with a given amount of fuel during an extended grid outage.

- Microgrids are more flexible to changing critical loads and mission requirements during a contingency situation. A microgrid can send power to different loads or buildings, as compared to a generator which is tied to specific loads. This allows installations to more easily respond to unforeseen power needs during a contingency situation.

- Microgrids can more easily incorporate variable renewable energy sources, as they provide a larger system in which to balance variable generation and load.

- Microgrids can provide cost savings from operation during grid connected modes.

While there are many advantages, microgrids do have some potential disadvantages in comparison to building-level diesel generators:

- Potentially higher upfront capital costs depending on site specific requirements and existing infrastructure.

- They are more complex systems and require more specialized skills to operate and maintain.

- They include more controls and communications with a larger overall footprint and may have a higher cyber-security risk. 


\subsection{Microgrid Assessment Approach}

The process used to perform microgrid designs at NREL is the Continuously Optimized Reliable Energy (CORE) microgrid design process. (NREL 2013) It attempts to provide the optimal microgrid solution by balancing priorities related to energy resiliency, economic value, and clean energy. The process was first developed in 2012 and updated over time based on best practices and methodologies from other DOE and DoD laboratories and engineering firms, input from stakeholders, and lessons learned during microgrid project execution. Some of the publicly available processes focused on microgrid design that were incorporated are listed below, along with a key takeaway from each:

- Sandia National Laboratory methodology (Jensen et al. 2015): System requirements and threats should be defined early in the process.

- U.S. Army Corps of Engineers process for SPIDERS (ERDC CERL 2011): DoD procurement is unique and requires specific procurement-related considerations.

- Black \& Veatch (2016): Project economics should be constantly refined, and multiple design iterations may be necessary prior to final conceptual design.

- Concurrent Technologies Corporation: Energy Security Assessment: ${ }^{8}$ Extensive stakeholder engagement, including interviews with individual mission owners and installation support staff are necessary to ensure reliability and resilience capabilities are aligned with needs.

The updated CORE process is shown in Figure 2 and is followed as the structure for this report.

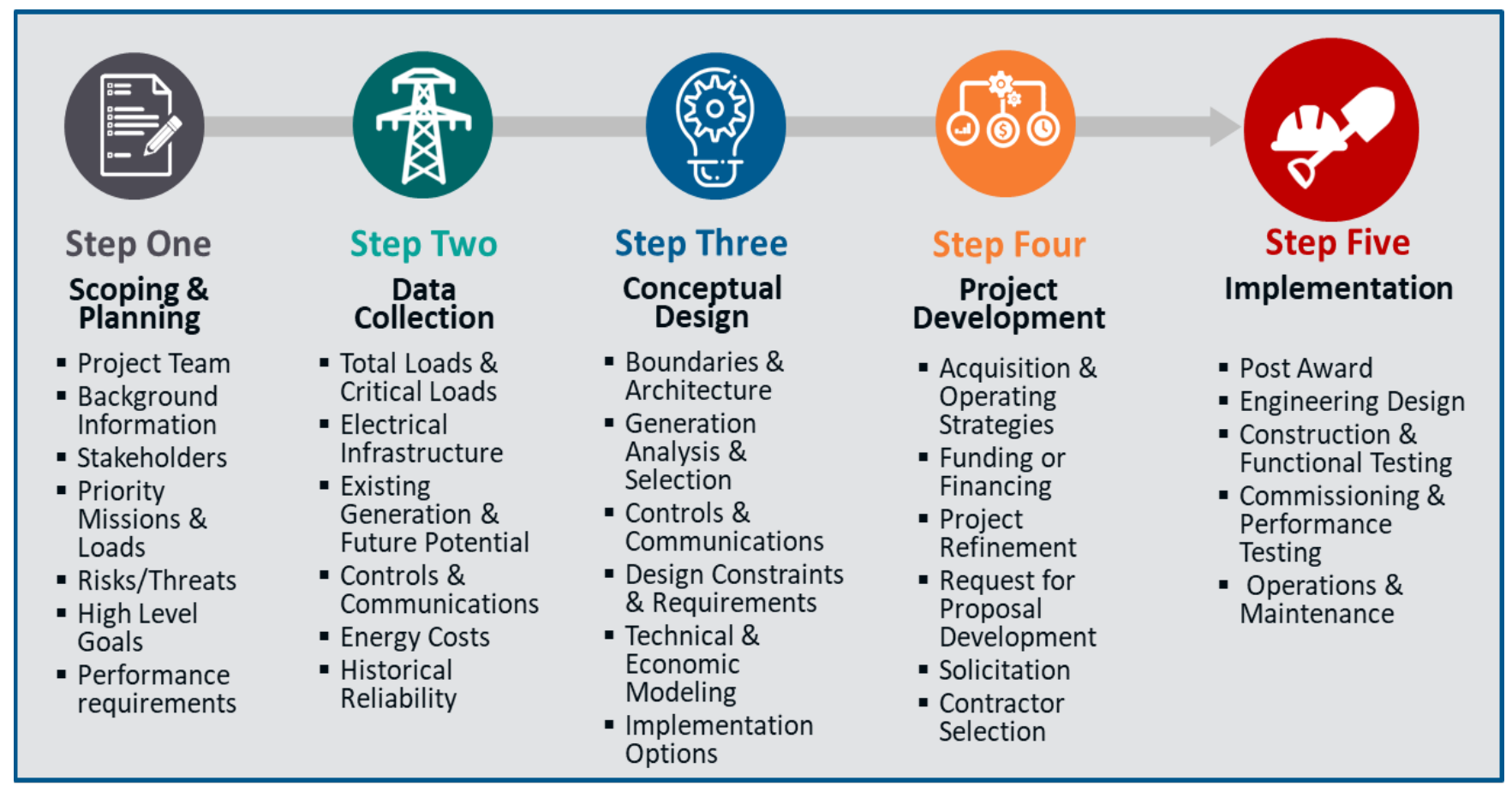

Figure 2. NREL-revised CORE microgrid design process

8 For more information, see "Energy, Resilience and Infrastructure," Concurrent Technologies Corporation, https://www.ctc.com/public/solutions/areasofexpertise/energyandenvironment.aspx. 
This five-step process provides a framework to move from microgrid scoping and planning to implementation. The process provides an overview of the basic steps and high-level information as well as analysis that is required for microgrid assessment. It is not intended to capture every detail of a project but rather to provide a general overview. This report is structured with a specific section for each step that provides additional information, background, recommendations, and lessons from NREL experience. The report is primarily focused on getting a project from an idea to a conceptual design and the execution of Steps 1 through 3 in the CORE process, but Steps 4 and 5 are covered as well.

Before reviewing each of the steps in the CORE process, the next section includes additional background on the energy project collaboration between Marine Corps Air Station Miramar and NREL, which is the source for many of the lessons in the report.

\subsection{Miramar Microgrid Background}

NREL has been supporting energy project assessment and development at Miramar since 2009. Initial assistance focused on renewable energy and energy efficiency projects in support of the installation's net-zero energy goals. ${ }^{9}$ In 2012, NREL completed an assessment of a microgrid at Miramar. The approach taken for that assessment followed the CORE process detailed above to develop a conceptual design for a microgrid. After the conceptual design was completed, the installation secured funding for a microgrid project from the DoD's Energy Conservation Investment Program. NREL supported the development of solicitation documents and proposal reviews for the microgrid project. The microgrid solicitation was a design-build project and was awarded to a joint venture of Schneider Electric and Black and Veatch in 2016. Engineering design for the project was completed in 2017, and construction started in 2018. Construction completion and project commissioning are both expected in 2019. NREL has been supporting the United States Navy and the United States Marine Corps with implementation of the microgrid project through design and construction, and that support will continue through commissioning and performance testing. This report captures and shares experiences and lessons from the Miramar assessment, conceptual design, solicitation, engineering design, and construction process as well as from other microgrid projects supported by NREL.

9 For additional information, see Booth et al. (2010). 


\section{Project Scoping and Planning}

General energy resilience assessment and planning is important for all DoD installations. Energy resilience planning includes a broad look at the threats, vulnerabilities, and risks for an installation and can be utilized to prioritize risk mitigation strategies. Microgrids are one possible risk mitigation strategy to increase energy resilience and the decision to conduct a microgrid assessment should be part of a broader effort to increase energy resilience and should also include an analysis of other options.

Once it has been determined that a microgrid will be part of an overall resilience strategy for an installation, developing a team that understands the high-level project goals and expectations of the stakeholders before conducting a microgrid design analysis is essential. It is suggested that (1) background information and past studies be reviewed before starting an analysis and (2) multiple consultations be conducted with stakeholders to define the high-level goals of the project. Taking these two steps will help ensure the analysis will be worthwhile and that the solutions developed will meet the needs and expectations of the project stakeholders. This section reviews information, recommendations, and examples related to team development, background information reviews, stakeholder consultations, determinations of priority missions, project risks and goals development.

\subsection{Developing a Project Team}

The first key step in conducting a microgrid analysis is the development of a project team to conduct the analysis. Typically, for a DoD installation, this involves a mix of onsite personnel such as the energy manager and the Director of Public Works, who have knowledge of the installation and access to information, as well as subject matter experts with the technical expertise and time to conduct the analysis required. The ultimate goal of the project team is to successfully analyze potential microgrid projects, and if they appear to be feasible and desirable, to develop a single conceptual design that can be used to start project implementation. When developing a project team, it is also essential to define key aspects of the microgrid analysis such as scope, schedule, budget, roles, and responsibilities. Once the key members of the project team have been determined and the key aspects of the study established, the team can begin with the design analysis process.

\subsection{Reviewing Background Information}

If outside experts are going to be the primary entity responsible for conducting the microgrid design analysis, it is important they become familiar with the installation and review basic background information, such as past energy resilience, renewable energy, or reliability studies, site master planning documents, electrical one-line diagrams, energy resource information, installation maps, and load data. Typically, the outside organizations will have a specific data request at the beginning of a project; an example of a data request from a recent NREL microgrid project is shown in Appendix A. An installation will likely not have all the data requested, but NREL experience has been that is most effective to request a comprehensive set of data and then to adapt the analysis as needed to the available data. The key data includes electrical drawings, information on critical loads, utility load information, and utility cost information. Once the background information has been reviewed, the project team should begin initial stakeholder consultations. 


\subsection{Consulting with Stakeholders}

Implementing a successful microgrid requires participation by many stakeholders. Initial briefing and planning meetings should be held with as many stakeholders as possible to discuss the project purpose and identify requirements, goals, and risks related to the proposed microgrid project. Table 1 lists common stakeholders for DoD projects.

Table 1. List of Stakeholders

\begin{tabular}{|l|l|}
\hline Stakeholder Groups & Roles \\
\hline Installation and Mission & Installation leadership \\
& Mission owners \\
& Emergency management personnel \\
& Installation security \\
Legal
\end{tabular}

Ideally, all these stakeholders would be provided with a brief overview of the planned microgrid functions and then have the opportunity to provide input and advise about key features of the analysis such as, what needs to be included, which loads and/or missions are critical, what challenges might be encountered, and how to mitigate risks.

In discussing the potential project and analysis with stakeholders, it can be important to understand which aspects of the project pertain to the area of responsibility or interest for a particular stakeholder and tailor the discussion appropriately. For example, environmental staff 
will likely be principally concerned with issues such as the environmental impacts of new construction, fuel handling and storage, noise and air pollutant emissions from generators, while personnel more actively involved in the mission of an installation will likely be concerned with very different issues such as which loads will be included, whether the project will cause any electrical outages, and how their existing backup generators might be affected.

Based on the information gathered during these meetings, a rough concept of the microgrid can be developed and circulated within the installation leadership to build consensus about the specific aspects of the proposed microgrid project and the evaluation to be conducted by the project team.

\subsection{Identifying Priority Missions and Loads}

To identify priority loads to be considered for inclusion in the microgrid, the team should determine the critical loads on the installation. Critical loads can often be identified through critical facility lists, emergency readiness and response plans, and/or information on standby generators. If this information is not available during the beginning phases of a project, it should be part of the initial data gathering and stakeholder consultation process; and mission owners should be interviewed to identify facilities required to maintain a mission function during a contingency situation. Sometimes it can be helpful to further classify critical loads based on their priority to the installation mission, the energy requirements, and reasonable down-time thresholds. This categorization allows microgrid designers to focus on providing the highest level of reliability to the most critical loads and establishing system requirements. In practice, most mission teams on DoD installations view their function as critical and requiring backup power from a microgrid; therefore; it is sometimes necessary for either a decision maker (e.g., the project team with input from the installation leadership) or higher headquarters command to determine which loads and missions to include in a particular project. Flexibility in microgrid design is another way to address these issues as shown in the example in Text Box 1.

\section{Text Box 1. Example of Load Prioritization Strategy for Miramar Installation Microgrid}

For the Miramar microgrid, loads are categorized into priority levels by the microgrid control system on an electrical feeder-by-feeder basis. In the event of a utility grid disturbance and the microgrid system not having enough generation to power all the critical loads, the protective relays associated with each feeder will shed load in reverse order of prioritization so that the lowest priority loads are shed or turned off first. The control system also allows the microgrid operators to change the prioritization order, as conditions may change over time or because the type of emergency (e.g., a natural disaster versus a terrorist attack) may change which loads are most critical for a given situation or mission.

In some microgrid projects, the microgrid serves the entire installation load. This could be for several reasons such as: the entire installation load is deemed critical, the microgrid generation assets are owned by a third party and serve other entities in addition to the DoD, there are potential cost savings, economies of scale or reductions in the project duration. For example, the microgrids designed for MCAS Yuma and for the Army's Schofield Barracks both contain diesel power plants, on DoD land, owned by the local utility company and utilized for their purposes 
during normal grid operation but with agreements to supply power to the DoD installation in the event of a contingency situation.

It should also be noted that while this report is focused on grid connected microgrids, the DoD has many isolated grids that serve as the primary power supply for an installation and power all the installation loads some examples include Diego Garcia, Guantanamo Bay, and Kwajalein. ${ }^{10}$

\subsection{Identifying Risks}

Understanding the likelihood of potential threats and impact of vulnerabilities within an installation is important for evaluating risks and identifying mitigation strategies (such as a microgrid) to enhance resilience. Some installations already have a good understanding of existing risks that a microgrid should be designed to mitigate; for others a risk assessment could be part of the microgrid design analysis.

Anything that can expose a vulnerability or damage, destroy, or disrupt an asset is considered a threat. Threats can be natural or human-caused hazards. They are typically not within the site's control and can include wildfires, hurricanes, storm surge, or cyberattacks. Known or predicted threats must be identified to understand the potential impacts to the base and the microgrid design. For example, if a site is likely to experience flooding, microgrid components should be placed above the floodplain. If a site is prone to high winds, distribution lines in the microgrid could be placed underground. Threats can be identified in many ways such as literature reviews, physical observations, interviews with base staff, local community or state hazard assessments, and discussions with local emergency operations staff.

Vulnerabilities are weaknesses within infrastructure, systems, or processes that can be modified and mitigated to either prevent a disruption from occurring or lessen the impact of a disruption. Vulnerabilities are identified through stakeholder interviews, as well as through review of planning documents. Vulnerabilities relevant to microgrid design could include locations prone to flooding or fire, lack of back-up systems or single points of failure in electrical lines, electrical poles in disrepair, vulnerabilities in fuel supply chains or fuel storage, lack of redundant communication systems, lack of cybersecurity defenses, or lack of staff with knowledge of microgrid operation. Knowledge of these weaknesses early on can help the microgrid design team mitigate these vulnerabilities.

\subsection{Defining High-Level Goals and Requirements}

The primary goal for microgrid projects is to increase the energy resilience and enhance the ability to serve an installation's electrical loads during a contingency situation. Defining the other overall goals and high-level requirements for a microgrid project in the early stages of scoping will help ensure that a good system design is reached in an efficient manner. To determine the proper microgrid design, a broad goal (e.g., increasing resiliency) requires specific details and metrics to make it actionable. For example, regional threats could drive various durations of electrical outages that a microgrid system must endure depending on its location.

10 The DOE microgrid definition utilized in this report required microgrids to be grid connected and does not include isolated microgrids. However, many industry stakeholders and practitioners do consider isolated systems as microgrids. 
The duration a system is required to survive can have a large impact on microgrid design, as long duration outages could require large fuel storage on-site or increased renewable energy usage, both of which would impact overall design and project economics.

In addition to resiliency metrics and goals, most projects also have other goals and priorities. For example, some installations may want to develop projects that also provide cost savings so that they can seek private sector financing, while others may want to maximize on-site renewable energy or cybersecurity.

Some of the high-level goals and requirements that should begin to be defined at this stage are:

- Order-of-magnitude critical electricity load estimate (kilowatts or megawatts) ${ }^{11}$

- Duration the microgrid should be able to operate in island mode (e.g., for hours or days, or indefinitely) with or without fuel resupply.

- Outage transition thresholds (e.g., the acceptable amount of time from a grid outage to when a microgrid can independently power loads, which range from a seamless transition with no power outage to a short or long duration outage prior to a microgrid starting)

- Assumption about whether off-base fuel supply chains will be available during a contingency. For example, will pipeline natural gas be available and will diesel fuel deliveries from outside or inside the installation be available?

- Does the installation have a preference or preclusion for certain kinds of generation? For example, the installation prefers renewable generation but has a preclusion to wind turbines because they could interfere with flight operations.

- Preferred strategies and mechanisms for implementation, operation, and maintenance of the microgrid.

Examples of initial project requirements from the Miramar Microgrid are shown in Text Box 2.

\section{Text Box 2. Example of Microgrid Requirements at Miramar}

- Upon loss of utility power and receiving confirmation from Miramar and NAVFAC personnel to proceed with microgrid operation, the system will provide electrical power to the designated critical loads on base.

- The microgrid will be operational and provide power to the critical loads for at least two weeks with on-site fuel.

- Upon restoration of utility power, critical loads will be seamlessly reconnected to the utility grid.

- As much of the existing clean energy as is technically feasible will be incorporated into the microgrid.

- Utilize microgrid assets to improve project economics through opportunities from cost savings with generation and grid-connected services.

11 It could also be useful to plan for tiers of criticality or other ways of prioritizing which installation loads are most critical and cannot be moved or transferred to a different installation. As well as which loads require seamless power, versus which loads can tolerate brief outages. 
Some of these high-level goals and requirements can be complex and nuanced, and it could be difficult for a project team to make a final decision on some of them early in the project without more information. Therefore, some of these items could require further analysis from the project team to be resolved, but they should be discussed at the initial meetings and the project team should endeavor to make as many initial decisions as possible in order to reduce the complexity, scope, and duration of the analysis. For an issue that cannot be initially decided upon, an action plan for decision-making should be developed. For example, the project team may agree to research an issue, hold another meeting after additional information has been obtained or analysis has been conducted, and then use that meeting to decide and move forward with the microgrid analysis.

After gathering background information, conducting stakeholder consultations, reviewing risks and threats, and determining high-level project goals, the next step in the microgrid design analysis is gathering data and conducting a detailed review of the existing site conditions. 


\section{Data Collection}

At this stage of microgrid planning, an understanding of the existing conditions on an installation should be expanded in a robust data collection process. This part of the process aims to inform microgrid design by developing a more complete understanding of the loads, existing systems, generation resources, energy costs, and historical reliability at a site. When a team understands existing conditions and planned projects, it can more easily integrate a microgrid into the site's overall master plan.

\subsection{Load Data Collection and Analysis}

Understanding the magnitude and trends of the existing electrical loads on a site is essential for generation analyses and sizing during the conceptual design phase. To fully understand the needs of a future microgrid, a significant amount of data is required. Ideally, electric meters should be recording and archiving data at 1-minute, 15-minute, or 60-minute intervals at the individual building level, and three years of data would be available. In practice, however, this level of data is rarely available. From the background data gathering phase, the project team should have a rough idea of the total loads at a site and the level of data available. Annual total consumption data are generally collected by every DoD installation for reporting. Additionally, most installations have at least energy demand data collected every 15 minutes for a single utility master meter, or the utility company can provide it upon request. Electric utility meters are sometimes also located at the substations, distribution feeders, or the individual building level to provide more information.

The collection of detailed load data (e.g., 15-minute load data) at more granular levels (e.g., at the feeder or building level) at DoD installations is less common. NREL experience has been that some installations have this level of data, but many do not. An electric meter with data logging capabilities may be installed to record and archive consumption data for the desired interval. Historically, electric meters were used only for billing purposes on military installations, so monthly consumption data may have been collected for buildings, but the practice of collecting and storing granular electric data over long periods was uncommon and often impractical in many locations, as the metering capability for this did not exist. However, the DoD has been investing heavily in smart meters and advanced metering infrastructure over the last several years, and the recent desire for energy resiliency improvements is driving a shift toward broader collection and storage of electric meter data across the DoD.

Electric meter data can be analyzed to identify key information such as the peak electrical demand, mean consumption, and minimum demand. These values are important to collect and understand, as they are important parameters for microgrid design. Figure 3 shows total installation load data for Miramar. 


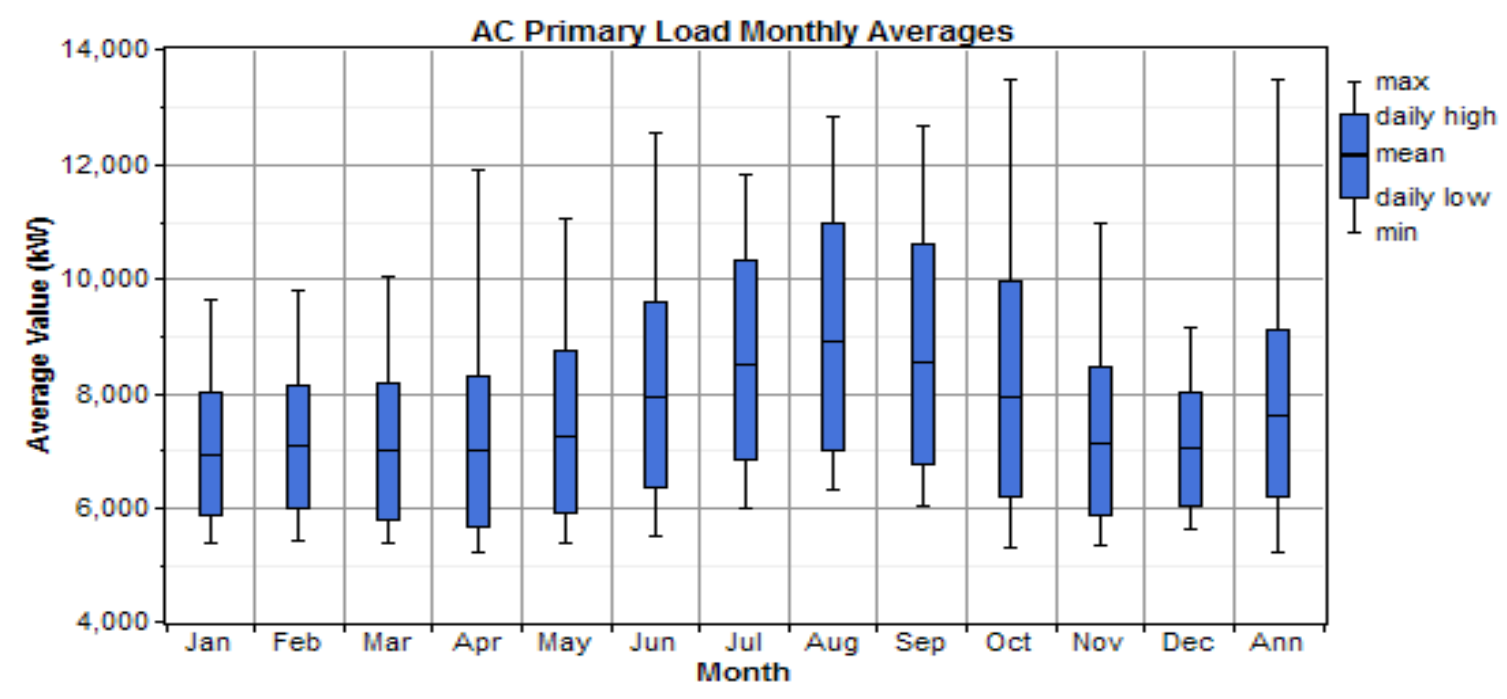

Figure 3. Miramar load data ${ }^{12}$

From this figure, we can see peak loads of about $13,500 \mathrm{~kW}$, mean loads of about 7,000-9,000 $\mathrm{kW}$, and minimum loads of about $5,000 \mathrm{~kW}$. If a microgrid were designed to power the entire installation at all points throughout a year, it would need to be able to power all these loads. This information would be sufficient to understand overall loads on the system but not individual building or feeder loads, or which loads were critical. For Miramar, the critical loads were analyzed separately using feeder and switch-level data to determine their magnitudes. The critical loads at Miramar are only about half of this total load and the microgrid was designed to power only the critical loads initially, but with the ability to be expanded if desired.

\subsection{Electrical Infrastructure}

Reviewing electrical infrastructure drawings and maps helps the microgrid design team to understand the existing infrastructure design and condition and identify key isolation and connection points.

\subsubsection{Drawings and Maps}

A review of electrical drawings should have begun during the background information stage of a project, and a more detailed review should continue as part of the additional analysis and site visit. Electrical one-line drawings and infrastructure maps assist with understanding the existing system as it was constructed. Electrical drawings for an installation should be updated as new projects add or change system components; installations generally maintain updated drawings, but key components on drawing should be validated during the site visit to ensure accuracy. Having access to editable engineering drawings can reduce the cost and time required to develop conceptual microgrid designs. Electrical drawings on military installations are typically grouped into the following electrical areas:

\footnotetext{
12 The blue boxes on this chart indicate average daily highs or lows for the month, the lines indicate maximum or minimum single values for the month.
} 
- Building “one-lines” (commonly $120 \mathrm{~V} / 208 \mathrm{~V}$ or $277 \mathrm{~V} / 480 \mathrm{~V})$ ):

- Will often include information on building-tied standby generators

- May include service transformer, secondary distribution and supervisory control and data acquisition (SCADA) connections

- Distribution one-lines

- Substation/switching station one-lines (commonly include power transformation equipment and switching and protection devices)

- Subtransmission or transmission one-lines (commonly held by the utility)

- Installation map with distribution system and building numbers (commonly includes locations for manholes, poles, switching devices, and building transformers).

By analyzing the electrical drawings and infrastructure maps, an electrical engineer can identify some major items such as loads and means of connecting to the distribution system, generation sources, line ratings, protection and switching devices, available physical space, and equipment spare breaker locations available for future connections such as new microgrid components. All these items are critical when considering power system upgrades that will lead to a successful microgrid. Table 5 outlines some high-level correlations between electrical components and their impact during microgrid planning.

Table 2. Major Components of an Electrical Drawing that are Relevant to Microgrid Assessments

\begin{tabular}{|l|l|}
\hline Component & Microgrid Applicability \\
\hline Load connections & Identify electrically coupled loads and logical systems to island \\
\hline Generators & $\begin{array}{l}\text { Identify existing sources of generation, or upgrades required to delay } \\
\text { existing backup power system from coming online or transferring load back } \\
\text { to the grid }\end{array}$ \\
\hline Protection and switching & $\begin{array}{l}\text { Identify existing devices that could be isolation or sectionalizing points for } \\
\text { the microgrid, or upgrades required to operate the microgrid safely }\end{array}$ \\
\hline Conductors (distribution) & $\begin{array}{l}\text { Identify power carrying capabilities of existing conductors, or upgrades } \\
\text { required if a larger capacity is desired }\end{array}$ \\
\hline Transformers & Consider power flow capacity \\
\hline Utility feeds & $\begin{array}{l}\text { Identify incoming utility connection/s, including capacity and short circuit } \\
\text { contributions }\end{array}$ \\
\hline
\end{tabular}

\subsubsection{State of the Existing Distribution System}

A microgrid using the installation's distribution system to connect generation and loads will be heavily impacted by existing system limitations. When considering a microgrid, the existing distribution system must be adequate and must not become a likely failure point for the system. Previous microgrid efforts have been halted or slowed due to aging, failing, or undersized infrastructure. Before pursuing a microgrid, it is highly recommended to assess the existing distribution system that will support the microgrid to identify weak points and plan for upgrades to be completed before or during the construction of the microgrid. Text Box 3 describes the upgrades required before a microgrid could be pursued at an Air Force base. 
The Air Force initiated an effort to pursue a microgrid at a specific installation. The project team was tasked with developing a microgrid conceptual design and it quickly began doing so using electrical information available at the time. The proposed microgrid would use portions of the existing subtransmission system on the base to route power to priority loads. As the project progressed, a previously unidentified project to upgrade the installation's $60-\mathrm{kV}$ subtransmission system was brought to the project team's attention. The installation's wood poles, which were in poor condition, had previously caused outages. This revelation caused the microgrid project team to pause the design until the design of the new subtransmission infrastructure was complete. If this upgrade to the existing system had not been completed before pursuing a microgrid, the subtransmission network could have failed, causing the microgrid to not function as intended. Additionally, not identifying these issues early in the process delayed progress.

\subsubsection{Isolation Points}

To safely isolate a microgrid from other electrical systems during contingency scenarios, isolation points must be identified. As a starting point, the point of common coupling (PCC) between the installation and the external utility's power system must be established. An installation could have multiple PCCs, and some PCC points could be in a normally open position, with no power flowing during normal conditions. Some large installation microgrids have used existing switching or protection devices as the isolation point at the PCC, but upgrades could still be required. As part of the existing conditions review, potential isolation points should be identified on the drawings and examined during the site visit. Isolation for the microgrid could occur further down the distribution system from the PCC if the microgrid were going to include only a subsection of the installation loads, such as one particular feeder.

\subsection{Existing Generation}

A microgrid must be able to supply enough generation to match electrical load requirements at all times. Evaluating existing on-site generation options (e.g., on-site PV, energy storage, cogeneration, and back-up generators) is the first step in developing a strategy for the microgrid to power loads. Using existing generation sources is generally preferred over building new generation assets, as it is usually more cost-effective and faster to develop. The two main types of generation are:

- A dispatchable generation source is a power generation facility capable of controlling real and reactive power output. It often has a source of on-site or regional fuel storage that corresponds with a time frame of expected power availability, excluding unexpected mechanical and system failures. Examples include diesel and natural gas engines or turbines, fuel cells, geothermal, and some hydropower. Battery energy storage systems (BESS) are another example of a dispatchable generation source. They have unique benefits in that they can respond more quickly than other sources to a utility outage or change in microgrid load. See Appendix $\mathrm{C}$ for additional discussion on BESS. 
- Variable Generation Source - An energy generation facility whose output is dependent on ambient conditions that can change with weather conditions, time of day, and season. Some renewable energy generation sources, such as wind and solar energy are examples.

Microgrids require a dispatchable generation source to follow load so that generation can be matched to the load. Additionally, the main dispatchable generation source for a microgrid generally serves to maintain the power quality of the electrical system by supplying both real and reactive power and maintaining voltage and frequency within established limits.

At a minimum, DoD installations often have backup diesel generators that are an emergency power source for critical loads. These generators are typically connected to the electrical feed for a single building and power that building or a subset of the building's loads in the event of a grid outage. Load is generally transferred to these generators utilizing an automatic transfer switch, but manual transfer is sometimes used as well. These generators typically do not have the ability to operate in parallel (at the same time) with the main electrical grid or to a microgrid. Modifications are required for these generators to be used in a microgrid, including control modifications, paralleling switchgear, and communications equipment for remote microgrid control interface. Additionally, these generators are often only permitted for use during grid outages because of local environmental and/or air pollution requirements, thus they cannot be used for economic savings while grid-connected, but only for contingency situations.

Many installations also have dispatchable generation sources that are available for prime or continuous use such as combined heat and power plants. ${ }^{13}$ These can be excellent generation sources for a microgrid, as they often provide savings over purchased power or thermal energy, and they have fewer operating restrictions than backup diesel generators.

Many locations also have renewable energy generation sources such as PV panels or wind turbines that provide variable power output. These can be good resources to add into a microgrid to improve the ability to sustain long outages, as they do not depend on fuel deliveries and they increase the overall sustainability of the system. However, their variable nature can cause some technical challenges, and systems need to be designed appropriately to accommodate them in a hybrid system.

All existing generation sources should be evaluated for inclusion in the microgrid. Some key items for consideration when evaluating existing generation sources for suitability with a future microgrid include.

- Size relative to microgrid load

- Operational condition and attributes such as controllability

- Physical location and associated electrical connection and communications connections

- Expected remaining lifetime

- Type of fuel used and consideration of existing reserves, external supply chains, and onsite refueling plans

- Air pollution and noise emissions

13 Prime or regular use refers to frequent usage during grid-connected operations. 
- Cost of operation and maintenance (O\&M)

- Economic savings potential

\subsection{Future Generation Considerations}

When reviewing existing installation conditions, the microgrid design team can begin assessing key considerations to identify future generation options.

\subsubsection{Location Availability}

Physical space is a key factor when determining the potential for new generation sources. For example, PV requires available rooftop or carport space with good exposure to the sun and a roof or carport in sufficient structural condition. It also requires a land area, roughly 5-10 acres per megawatt or a body of water for a newer option of placing floating PV systems on water. New conventional generation sources would likely require available land to build a power plant building and a connection to a local fuel supply. However, if a power plant already exists it may be possible to add additional generation to that facility if space exists. Consult the site master planning document and base personnel for possible siting options. Available locations must also account for environmental factors related to land use and the National Environmental Policy Act; installation personnel should be aware of such considerations and can provide input about the general feasibility of certain locations as well as the environmental studies required. When determining a location, noise is also a potential consideration. Many fossil fuel generators are loud, and if they are going to be operated frequently for grid connected economic savings, they must meet specified noise limits. Depending on the proximity of nearby buildings and location specific requirements, they may require specialized noise reduction equipment or facilities at an increased cost.

\subsubsection{Fuel Supply}

Microgrids are designed to reduce the effects of an electrical outage, but microgrids that depend on outside fuel supply such as a pipeline supply of natural gas or delivered diesel fuel risk not having fuel for their engines if supply is unavailable. This section discusses considerations for both natural gas and diesel fuel supply as these are the primary fuels for DoD microgrids that require a fuel supply from outside the installation. Other fuels such as propane would have similar considerations but are not discussed specifically.

Information about existing natural gas transmission and distribution capacity, and the proximity of gas lines to the proposed power generation facility could inform the potential gas-powered generation sources to be used in a microgrid. If this infrastructure is accessible and sufficiently sized, it could provide a cost-competitive fuel supply to drive new or increased generation capacity for the microgrid. The construction of new natural gas infrastructure could be costprohibitive for new generation sources. By gathering information about these considerations during early stage analysis, the option of new natural gas generation can be either pursued or ruled out. Also, the type and reliability of the natural gas supply to the installation could drive this decision as natural gas is typically not stored on-site. Deciding whether to fully or partially rely on the availability of natural gas is a site-specific decision that depends on factors such as the anticipated reliability of gas supply, the criticality of the load, the purpose of the microgrid, and the location of the microgrid. Some related examples and considerations are discussed in the text box 4 below. 


\section{Text Box 4. Examples and Considerations for Natural Gas Based Microgrids}

During Super Storm Sandy in 2012, natural gas pipelines in New York remained operational and several microgrids were able to operate, including Princeton University's. Most natural gas pipelines on the East Coast of the United States are underground and supplies to large customers are very reliable. Also, they are typically not as susceptible to damage by earthquakes compared to sites in California.

Earthquakes in California can cause electrical system outages, and natural gas supply pipes in many California locations are required to contain earthquake shutoff valves for safety that turn off the gas supply in the event of seismic activity. If a microgrid operator in California wants to be able to operate during an earthquake, installations should consider their options and strategies for this scenario, including:

○ Developing alternative generation options such as diesel generators, energy storage systems, or renewable energy sources

○ Having qualified personnel on-site to test for natural gas leaks and reset valves if needed

○ Employing duel-fuel generators

○ Implementing on-site bulk natural gas storage

Many DoD organizations are planning for long duration electrical grid outages (e.g., up to two weeks in many cases). Outages of long duration in the US are rare and something catastrophic would likely have to happen to cause lengthy power outages. In a catastrophic scenario, in may not be prudent to rely on natural gas pipelines for critical DoD missions.

The considerations for diesel fuel supply are generally quite different than natural gas as diesel fuel can easily be stored on an installation. Generally, the considerations for diesel fuel involve the amount of storage and considerations for resupply. For fuel storage the sizing of fuel tanks is the key consideration and tanks are generally sized for some amount of continued operation of the microgrid. For resupply the key consideration is whether to assume fuel tank refueling during a contingency situation is possible or not. Some factors impacting this decision include, how fuel is delivered to an installation e.g. by fuel supply truck or tanker ship, the distance fuel needs to travel, and the potential for alternative sources of fuel during a contingency such as fuel flown into an air station by a DoD aircraft if necessary.

\subsubsection{Economic Viability and Incentives}

Many locations have economic incentives such as grants, rebates, or tax credits for installing certain kinds of generation sources. It can be helpful to explore the availability of these for a project either before or during the site visit to determine eligibility requirements and to discuss the details of them with relevant parties, such as the local utility company or appropriate state agency during the site visit. Some locations may have higher utility rate tariffs, demand response, or ancillary service markets that allow on-site generation options like PV or storage to 
provide added value during normal grid-connected operation. An initial economic analysis early in the microgrid design process will help identify the most cost-effective new generation options.

\subsubsection{Electrical Interconnection}

Three main factors will determine potential interconnection locations of new generation assets in a microgrid.

- Distance - The distance required to connect the generation asset to the distribution system of the microgrid is the simplest factor and it should be reduced to minimize capital costs.

- Available Infrastructure - To minimize the number of upgrades required for the microgrid, spare existing equipment such as a circuit breaker could be used, if available and adequately sized. In some scenarios, running a longer distribution line to an available connection point may be less expensive than the cost of new electrical equipment.

- Infrastructure sizes and rating - An assessment of the existing sizes and capacities of distribution equipment will identify potential locations or bottlenecks that would inhibit the interconnection of an asset at a specific location. For example, a proposed generator might be too large and generate current above the rating of existing wiring. In this case the interconnection point may need to be moved, or upgrades completed on the distribution system.

\subsection{Utility Control Systems}

Many DoD installations have one or multiple existing utility control systems. Most commonly, some type of supervisory control and data acquisition (SCADA) system is used to help ensure reliability of the existing system. These systems use a networked control system to monitor and control electrical equipment such as breakers, protective relays, and generation. Often, some or all of the existing control system can be used for a microgrid project, and it is important to understand the existing system and its capabilities. For example, many SCADA systems can already remotely open and close distribution circuit breakers and this functionally can be used to create microgrid isolation points. Having an existing SCADA system is not a requirement for microgrid development, but it can be useful.

\subsection{Communications Infrastructure}

Information on existing communications networks will inform the use of existing equipment or identify constraints that need to be considered during the design. The microgrid controller will need to utilize existing or new communications mediums to coordinate and control points in the microgrid such as breakers, generators, and solar PV systems. One option is using spare fiber optic strands in existing cables; this is a low-cost strategy that has been used for some DoD microgrid projects. Other projects have installed new fiber optic cable in existing spare ducts. The cost of installing new duct banks and fiber optic cable for a microgrid could be very costly, so using the existing available infrastructure should be considered whenever possible. Another consideration could be wireless or radio frequencies available for communication or control. Many DoD energy projects avoid using these methods of communication, but some have used them successfully. To use them, coordination with and approval by installation communications personnel is required. 
Cybersecurity is a critical consideration when evaluating communications systems and selecting a communications method. Microgrid control systems, which are categorized as industrial control systems, or ICS, require cybersecurity certification from the DoD (see Section 4.7). The cybersecurity requirements can vary based on several factors, including the type of network, the other uses of the network, the type of information traveling across the network, proposed new information technology/operational technology devices and their locations, and the type of communications methods and protocols used.

\subsection{Energy Cost Assessment}

When reviewing existing conditions and gathering data, it is important to understand the current energy costs at a site for all electrical sources, including utility purchases and on-site generation. When analyzing utility purchases, utility bills are often required to understand the nuances of an installation's rate structure, such as charges for time of use or peak demand. For on-site generation, fuel costs (e.g., the cost for natural gas) need to be understood, as do other costs (e.g., operation and maintenance of the generation sources). Understanding current costs and rate structures helps establish the baseline for the analysis of future generation options and their ability to provide cost savings relative to existing options. It is also helpful to understand the other local energy market opportunities and constraints.

\subsection{Existing Resilience and Reliability}

During stakeholder discussions and the assessment of site conditions, it is important to understand the existing resilience strategies and historical electrical reliability of the site to ensure proposed solutions increase the reliability and resilience of the system. Additionally, installations should assess the causes of outages to distinguish what issues can easily be fixed without a microgrid. For example, trimming of trees near power lines can reduce distribution system outages in many wooded areas.

Solutions that military installations commonly use to increase electrical system reliability include alternate transmission feeders (external grid connections), building-tied standby generators, and central on-site generation facilities. During the site visit and when reviewing electrical drawings, the project team needs to review and understand whether or how any of these systems are being used and how a microgrid project might support them. For example, building-tied standby generators could be used in the microgrid, and the microgrid control system should ensure all external grid connections are unavailable before entering an islanded microgrid situation.

Routine maintenance of electrical and mechanical equipment that supply critical systems will mitigate many common sources of failure and improve reliability. Poorly maintained generators may not start, circuit breakers may not open or close, cable insulation may fail, or other systems and components may limit the ability to keep buildings energized. Coordinated maintenance budgeting and effective planning will provide large dividends to facilities during a major utility outage.

Metrics used to characterize electric utility reliability can be used to help estimate the potential for a grid outage. Two common metrics used for this analysis by electric utilities are the system average interruption duration index (SAIDI) and system average interruption frequency index 
(SAIFI).$^{14}$ Often, the values for these metrics are publicly available and can be reviewed for the utility company serving a site, but they are often unavailable at a site-specific level. So, while they can provide useful insight into overall utility company reliability, they are of limited value in determining the exact history of electric reliability at an installation. Meter data can sometimes be used to help understand historical reliability, but it is important to distinguish what might be a meter error or maintenance outage from what is an actual electrical outage for the installation. Discussions with site personal about outages are also useful when determining roughly how often they occur, how long they last, and their causes. Installations should be collecting this data and reporting it as part of the annual DoD energy report. One common cause of an electrical outage on a site is often a failure in the on-site distribution system rather than a full utility outage, so these need to be distinguished as well. It is useful for installations to analyze reliability and to understand what reliability issues they can easily fix such as trees near power lines without a microgrid. Understanding these commons points of failure and durations of historical outages can provide useful insights into microgrid design in terms of the likelihood and potential cause of a future outage.

14 Major event days are also utilized as a metric in some cases. Installations should also consider utilizing statistics that include major event days. 


\section{Conceptual Design}

At this stage, the system requirements have been outlined, existing conditions have been analyzed, and the conceptual design can begin to form around those constraints. The first step in developing a conceptual microgrid design is defining electrical isolation points for either the microgrid or the loads that will be included in the microgrid. Selecting one of these allows the other to be identified and the conceptual design to continue. If preferred, several possible microgrid designs can be developed and reviewed with stakeholders to help make this critical decision. After load and isolation points are determined, generation requirements and options can be evaluated along with corresponding studies, communications, cybersecurity and operational requirements. Techno-economic analysis of the capital costs, savings, and financial return of various microgrid options may inform the ultimate design. As solutions, barriers, and cost or economic constraints are uncovered, the project requirements may need to be adjusted; thus, it could be useful to revisit previous steps. The relationship between initial assumptions, defining system parameters, and design is cyclical and often requires refinement. For example, some loads may need to be excluded from the microgrid project to fit capital costs within a defined budget. This section discusses the key conceptual design steps in detail.

\subsection{Definition of Microgrid Boundaries}

The logical boundaries of potential microgrids begin to emerge once information has been gathered on critical loads, existing generation, and existing electrical systems and equipment. These boundaries group existing loads and generation (if any) behind either new or existing electrical isolation components such as switches or breakers in the distribution system to inform (1) which electrical isolation point or points will be used for the microgrid and (2) which loads, both critical and noncritical, are downstream from this electrical isolation point (and thus included in the microgrid). Figure 4 shows various levels of common microgrids in an example distribution system. The white boxes represent switching or protection devices that could be used to isolate the new microgrid. 


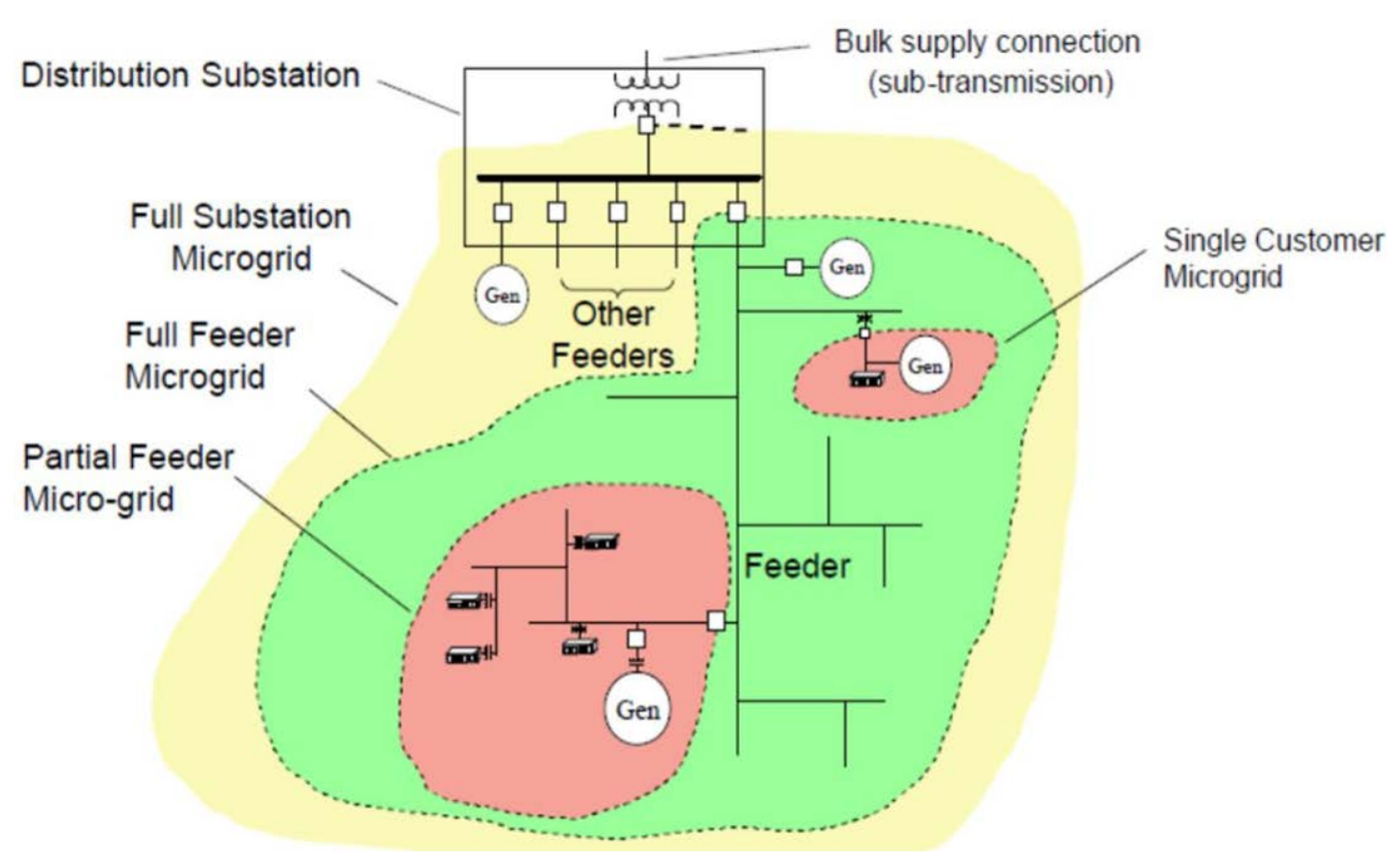

Figure 4. Examples of types of common DoD microgrids

Source: EPRI, 2016.

Depending on the overall goals of the project, the locations of critical loads may or may not drive the selection of the electrical isolation point. For example, in some microgrids, an isolation point that includes all critical loads may be required. In other projects, the isolation point may be selected based on other considerations such as cost (utilization of existing components will be more cost-effective) or the location of existing generation. Key considerations in selecting an isolation point include:

- Location of Critical Loads: Typically, a primary goal of a microgrid at a DoD installation is to provide more resilient power to critical loads; thus, these critical loads must be included in the microgrid and they are a key driver of the isolation point. Often, the optimal microgrid system design includes most but not all critical loads. Some critical loads may be located far from other more clustered critical loads and connecting them would require connecting a large number of noncritical loads. In this instance, the distant critical facilities may remain on backup generators, during a grid outage.

- Available Infrastructure: To minimize the number of upgrades and new construction required for the microgrid, a spare circuit breaker bay or cabinet within a pad-mounted switch could be used, if an adequately rated one is available. In some scenarios, running a longer distribution line to an available connection point may be preferred to paying the potentially high upgrade cost required to construct a new busbar or install other new infrastructure.

- New Generation: The boundaries of the microgrid will depend on the physical and electrical connection location for proposed new generation or storage sources. In some instances, the boundary may expand to include the new sources, while others may force a higher-cost generator connection to be included in the predefined boundary. 
- Existing Generation: If there is existing generation or storage on an installation, including this generation in the microgrid may reduce costs, even if doing so means selecting a less optimal electrical isolation point.

Once the critical facilities to be included in the microgrid are selected, the loads of these facilities can be used to further inform the generation capacity requirements. The examples in Text Box 5 show some types of boundaries and loads included in current DoD microgrid projects. Funding sources for these projects included, the DoD's Environmental Security Technology Certification Program (ESTCP) program, the DoD's the Energy Resilience and Conservation Investment Program (ERCIP), and an Enhanced Use Lease (EUL).

Text Box 5. Examples and Definitions of Loads Covered in Microgrids Listed by Increasing Boundary Size (see figure 4 above)

1. Miramar Building-Level Microgrid (Funded by ESTCP): This microgrid included a single building (the Public Works building) along with carport solar PV and energy storage. This could be considered a single customer microgrid

2. Joint Base Cape Cod Otis Microgrid (Funded by ESTCP): Approximately onehalf of one circuit is included in the microgrid. Some critical loads were electrically moved from one feeder to be included in the microgrid. This microgrid is considered a partial feeder-microgrid.

3. Pacific Missile Range Facility Microgrid (Funded by ESTCP): This project will connect two feeders of the distribution system: one has a diesel generating plant with critical loads, and the other has administrative buildings with rooftop solar PV and battery energy storage systems. This microgrid is considered a full feeder microgrid.

4. Miramar Installation Level Microgrid (Funded by ERCIP): This microgrid is designed to provide power to the critical facilities on the installation and covers about $50 \%$ of the total installation load and feeders. However, the microgrid could cover the entire installation if additional generation or load management controls are integrated in the future. This microgrid is considered a full feeder microgrid that covers multiple feeders.

5. Fort Drum Biomass (EUL Project): A biomass power plant is connected to the subtransmission feeders serving Fort Drum. The entire installation load can be met with this facility, making it a full-substation microgrid.

Pacific Missile Range Facility Microgrid (EUL): A project in development where the utility would own a large PV and battery system located on Navy land, it would support the utility under normal operating conditions but provide power to the installation during a contingency situation. This is a full-substation microgrid.

When defining microgrid boundaries and selecting which loads will be included in the microgrid, it is necessary to review the electric demand for buildings under consideration, if this was not previously done. This refined electrical load data will be used to determine generation 
requirements for the microgrid. If data are available from building-level smart meters, distribution system components (e.g., pad-mounted switches with metering), or other means (e.g., utility meters), the design team should use this information to develop an updated load estimate. If no data are available, the design team may need to make some assumptions of load based on ratings of equipment (e.g., the size of transformers or backup generators) or install meters to record load data. Estimation of load is a less accurate method but may be necessary to move the project forward while more-detailed load data are collected by installing permanent or temporary metering devices.

Critical loads are often only a fraction of the typical load (e.g., 50\%), however the noncritical load cannot always be omitted from the microgrid. To omit loads from the microgrid, additional electrical isolation must occur beyond the main point of isolation by opening a switching or protection device either manually or through automated operation. This level of additional isolation is technically possible, but it is often not cost-effective, as it requires new electrical devices and new communications lines to the main microgrid controller. Details and drawings for possible load management options can be found in Appendix D. Often, it is less expensive to add generation to power noncritical loads than it is to remove them, but this is a project-specific consideration. Text Box 6 highlights this trade-off in one project.

\section{Text Box 6. Example of a Cost Analysis of New Isolation Points versus Additional Generation}

NREL conducted a microgrid analysis for a U.S. Army installation. In this project, multiple microgrids were examined. One of the microgrids was on an installation with a mix of critical and noncritical loads on the same electrical feeder that were not easily isolated from one another. To add building-level electrical isolation points to remove noncritical loads with a new controllable breaker and new fiber optic cable would have cost approximately $\$ 25,000$ per building, principally for new fiber optic cable and underground duct banks. New generation capacity for this project was about $\$ 700 / \mathrm{kW}$. Using a simple calculation that does not account for other potential benefits of isolating individual buildings, we found a breakeven point of about $35 \mathrm{~kW}(\$ 25,000$ per building / $\$ 700$ per $\mathrm{kW})=35 \mathrm{~kW}$ ). Above this size of building, it would be less expensive to remove the load rather than add new generation to power it in islanded mode. Similarly, below this size, it would be less expensive to add extra generation to power the building rather than add the equipment required to remove it.

The best way to estimate the future power requirements of the microgrid is to analyze or record data for the specific loads and introduce a contingency above the peak load. ${ }^{15}$ Other key considerations for understanding loads include power factor and system harmonics caused by nonlinear loads. See Appendix B for details on these considerations. Section 4.2 addresses how to use load data to estimate power requirements.

15 The level of contingency will be a project specific decision depending on considerations for unmet load, load growth, and reliability requirements. 


\subsection{Power Requirements}

The load characteristics of the microgrid are the key driver of generation sizing, along with related considerations such as the level of redundancy required. The peak load of the microgrid to be islanded is typically the most significant consideration when selecting and sizing the generation portfolio. The available capacity of generation sources that can be fully controlled and dispatched by the microgrid (e.g., engines or batteries rather than variable resources such as PV) should be greater than the peak load requirements of the microgrid. The generation resources must also be able to meet other requirements, such as the ability to ramp down to minimum loading. Some common additional considerations are:

- Redundancy: Enough dispatchable generation must be available to meet spinning reserve and non-spinning reserve requirements. In many high reliability applications, not only is enough generation to meet load required, but spare generation capacity in the event of a failure of a generator is also needed. This is commonly referred to as $\mathrm{N}+1$ or $\mathrm{N}+2$, where $\mathrm{N}$ is the largest-sized generator in the system. In an $\mathrm{N}+1$ scenario, the system must have enough spare capacity to absorb the loss of this generator. And in an N+2 scenario, the system must absorb the loss of the two largest generators. ${ }^{16}$

- In-Rush Currents: Enough dispatchable generation must be available to ensure transient inrush currents from transformer energization and motor-start currents do not overload the generators or trip protective devices. During startup of the microgrid, the generators must be capable of energizing the connected transformer capacity, and many generators can do this at a rating above their normal capacity known as an overload rating. A conservative rule-ofthumb is that 1.0 million volt-amperes (MVA) of diesel generation can energize 2.0 MVA of unloaded transformers, 1.5 MVA of natural gas engines can energize 2.0 MVA of transformers, and 2.0 MVA of inverter-based generation can energize 2.0 MVA of transformers. These are rules-of-thumb and must be validated with the manufacturer for each specific system. If the system is brought online in steps and there is load on some of the previous step's transformers, the generator must be sized to be large enough to meet both the online load and the new transformer capacity.

- Reactive Power: Generation sources must be able to supply the load requirements for both real and reactive power. Not all generation sources (e.g., older PV systems) can supply reactive power, so this could be a key driver of generator selection depending on the reactive power needs of the system. See Appendix B for an additional discussion of reactive power.

- Contingency and Load Growth: To size a generator to a load, an engineer typically adds a contingency factor of $15 \%-20 \%$ to the peak load to account for unexpected load spikes or future load growth. Future load growth can be estimated from an installation's master plan, but analysis of load growth also needs to consider energy efficiency projects to reduce load. But careful attention should also be paid to the minimum load, as operating diesel and natural gas generators at a significantly reduced output can result in extremely poor efficiencies or even damage to equipment from wet stacking. A common threshold for minimum diesel generator operation is approximately $30 \%$ before wet-stacking conditions occur, but this

16 The simultaneous loss of two generators in a system could result in an unstable power system and a system shutdown or loss of load. If this happens, the system should be able to be restarted with the available generators, but it would see a temporary outage. 
could be higher or lower based on timing of low load conditions and generator specifications. This may result in a need to have more generators rather one large generator, at an increased cost.

- Harmonics, Nonlinear Loads, and Balancing: In a system with large amounts of nonlinear loads or unbalanced loads, the generation sizing may need to be adjusted beyond peak loading and contingency requirements. Harmonics occur when the current waveform is distorted by nonlinear loads whose resistance is not constant, resulting in current pulses, and these pulses create harmonic currents in addition to the original current. Harmonic currents and loads that are not evenly distributed can lead to distribution system and system balancing issues that may need to be considered when sizing generation.

- Seamless Transition: If the installation requires a seamless transition (e.g., no loss of power) into microgrid mode; specific generation sources and equipment for rapid load pick up are required. These typically come at additional cost, compared to a manual transition.

\subsection{Generation Analysis}

Selecting generation sources ${ }^{17}$ for a microgrid is one of the most critical design decisions for a project team. During operation of the microgrid, the generation sources (and potentially loads acting in a demand response function) will be operated to maintain stability and power quality on the system. The ability to successfully operate the microgrid is paramount, but often, multiple generation design options could successfully accomplish this. The final choice of generation sources is often determined by several factors, such as the power requirements, available renewable energy resources, existing generation assets, regionally available fuel sources, air emissions, and economic return. The selected generation options will likely be a balance of technical ability to meet load along with an optimization of other project priorities such as costs, sustainability, and redundancy.

Many advanced microgrids combine generation sources into hybrid systems that can dispatch and curtail generation as needed and can capture some of the benefits of both dispatchable and variable generation. For example, a system may be designed to optimize the output from renewable resources to minimize operating costs, but these resources would be curtailed as needed to maintain the power quality of the system. Hybrid power systems can be far more complex than microgrids with a single generation source. Table 3 provides an overview of general characteristics of hybrid power systems with varying levels of renewable energy.

17 See Section 3.5 for definitions of generation sources. 
Table 3. General Characteristics of Microgrids Operating in Islanded Mode with Renewable Energy

\begin{tabular}{|c|c|c|c|c|}
\hline \multirow[t]{2}{*}{ Level of Renewable Energy } & \multirow[t]{2}{*}{ Operating Characteristics } & \multicolumn{2}{|c|}{ Variable Renewable Contribution to Load } & \multirow[t]{2}{*}{ Level of Maturity } \\
\hline & & Peak Instantaneous & Annual Average & \\
\hline Low & $\begin{array}{l}\text { - Dispatchable generation runs at all times } \\
\text { - Renewables reduce net load on dispatchable } \\
\text { generation } \\
\text { - All renewable energy goes directly to load. } \\
\text { - No control system in many cases }\end{array}$ & $<30 \%$ & $<20 \%$ & $\begin{array}{l}\text { High, many examples at } \\
\text { large and small scale }\end{array}$ \\
\hline Medium & $\begin{array}{l}\text { - Dispatchable generation runs at all times. } \\
\text { - Renewables reduce net load on dispatchable } \\
\text { generation. } \\
\text { - At high renewable energy contributions, additional } \\
\text { load is added, or renewable energy is curtailed to } \\
\text { avoid overgeneration and/or insufficient loading on } \\
\text { dispatchable generation. } \\
\text { - Basic control system is typically required. }\end{array}$ & $30 \%-75 \%$ & $20 \%-50 \%$ & $\begin{array}{l}\text { High, many examples at } \\
\text { large and small scale }\end{array}$ \\
\hline High (with energy storage) & $\begin{array}{l}\text { - Renewable energy and storage can power load } \\
\text { without need for engine generators. } \\
\text { - If engine generators are in the system, they can be } \\
\text { shut off unless needed, for example, to charge the } \\
\text { battery during periods of low renewable energy } \\
\text { resource. } \\
\text { - Requires basic control system at a minimum } \\
\text { - In this case, renewable energy generation can be } \\
\text { greater than the peak loads on the system. When } \\
\text { this happens energy storage acts as a load to store } \\
\text { excess energy. }\end{array}$ & $50 \%-100 \%$ & $50 \%-100 \%$ & $\begin{array}{l}\text { High, many examples } \\
\text { but most at small scale }\end{array}$ \\
\hline High (without energy storage) & $\begin{array}{l}\text { - Engine generation can be shut down or become a } \\
\text { spinning reserve when renewable energy can meet } \\
\text { load. } \\
\text { - Additional components are required to ensure } \\
\text { power quality when the engine generator is off. } \\
\text { - Requires sophisticated control system }\end{array}$ & $50 \%-100 \%$ & $50 \%-100 \%$ & $\begin{array}{l}\text { Low to medium, few } \\
\text { examples, and most are } \\
\text { at small scale }\end{array}$ \\
\hline
\end{tabular}


Currently, for installation-scale microgrids in DoD, most projects include medium or low levels of renewable energy. Several projects with high levels of renewable energy have been developed and successfully executed at DoD installations, but these are typically at smaller scales. For example, a 100\% renewable building-level microgrid at Miramar was built and tested. ${ }^{18}$

As the costs of renewable energy and energy storage decrease and microgrid technology matures, we could see future installations of microgrids with high levels of renewable energy. Additional considerations for generator selection are discussed in Sections 4.3.1-4.3.2.

\subsubsection{Existing Prime Power Dispatchable Generation and Variable Generation}

Using existing generation in a microgrid minimizes new capital costs. If the team's review of existing conditions found existing generations sources that seemed promising, they should be further analyzed during the design analysis. Any existing systems must be assessed for their suitability in connecting to the microgrid by analyzing several key factors, including:

- General Characteristics: Information on the existing assets is required including type of generation source, size of generation source, operating restrictions, and historical reliability. Existing generation that is near the end of its useful life or is not very reliable may not be a good option for the microgrid.

- Generator Ownership: If the generation source is owned and operated by the installation, it is fully available for use if desired. In many cases (e.g., the microgrids at Miramar and Fort Carson), part of the generation systems for the microgrid are owned and operated by a third party under a power purchase agreement (PPA). Typically, PPAs do not contain provisions for operation when islanded from the commercial grid and would require technical as well as contractual modifications to enable this mode of operation.

- Location on the Distribution System: Existing generation must be located within the electrical island of a microgrid, behind the electrical isolation point in order to be available for use by the microgrid. Often, the generation on an installation is located in a different area than the critical loads, and the isolation point must be carefully selected to include both. The location of generation sources may also drive the decision about how they connect and communicate with a microgrid control system, as the control system generally needs to be able to monitor and control generation sources if they are to play a significant role in the microgrid.

- Controllability: Microgrid generation assets must be controllable by the microgrid control system. Many existing generation sources are not controllable, and overall controls and communications will need to be added in most cases. In some cases, it may not be possible or cost effective to retrofit controls onto an existing generator.

- Economic Dispatch: To increase the economic viability of the microgrid, an installation may want to use microgrid generation assets to provide economic benefits while gridconnected, such as peak shaving or grid services. Certain generation resources will be more likely to provide grid-connected value due to lower operating costs (e.g., natural gas is a less expensive fuel source than diesel) and fewer operating restrictions (e.g., diesel generator operation may be limited due to air permitting).

18 See Faries et al. 2016 for more information on this project. 


\subsubsection{Paralleling Existing Standby Generators}

Using existing central or standby generation assets in a microgrid is one pathway to increase the capacity of the microgrid while minimizing capital costs. A generator's ability to operate in parallel with a microgrid must be considered, as most standby generators do not have the appropriate governor/excitation controls or paralleling switchgear required to operate in cooperation with a microgrid, and this equipment must be added at a cost to the project along with communications infrastructure. This consideration is similar to the discussion of isolation points in Section 4.1.1 in terms of the cost and benefit of upgrading a generator, as the upgrades required could exceed the cost to install a new generator. Options for standby generators to pick up load, including electrical diagrams are shown in Appendix E.

Air permitting of generators is another important consideration. In some locations such as California, backup generators can generally only be used in an emergency scenario because of emissions restrictions. These restrictions depend on the type of generator and its emission control systems, for example diesel generators with Tier 4 emissions controls can be utilized in grid connected mode in California but this equipment increases costs and is not typically found on back-up generators. This consideration may limit the value of including them in a microgrid for economic, testing, or research applications, but it would not impact operation of the microgrid in a contingency situation. Other potential considerations for this scenario include generator controls and compatibility, automatic transfer switch characteristics, system protection settings, and local utility interconnection requirements.

If standby generators are deemed feasible for use as a generation source in the microgrid, a do-no-harm scenario should be defined to minimize concerns of increased risk of damage to these stand-by generators from operating with the microgrid and in addition to their stand-alone functionality. For example, if the communications from the new microgrid fails, or a fault occurs on the distribution system, the existing backup systems should properly operate as a stand-alone asset during an outage scenario.

\subsection{New Generation Sources}

In many cases there may not be enough suitable existing generation for a microgrid, and new generation sources must be added to meet project needs. When selecting new generation sources, there are numerous considerations for the overall project. The following subsections discuss some new generation options and related considerations. Additional background on types of generation can be found in Section 3.5

\subsubsection{New Dispatchable Generation Assets}

As discussed in Section 3.3, a dispatchable generation source is required to meet the power needs of a microgrid. If sufficient generation to supply load does not exist, the simplest way to size a new dispatchable generation source is to analyze the peak load and subtract any existing dispatchable generation that would be used to meet these loads; the remainder is the new minimum dispatchable generation size requirement. With this size, additional considerations, as discussed in Section 4.2, can be considered, including in-rush currents, provisions for future growth, and redundancy requirements. 
In some projects, the microgrid system owner may be willing to risk not meeting peak load in certain situations. For example, sometimes peak loading might be infrequent (e.g., a large peak during a few hot summertime days). In such cases, some installations may decide to reduce their peak load requirement to only meet peak loads some fraction of the time (e.g., 99\% of the time). If they have an outage during those $1 \%$ highest peak load times, they would reduce load by removing some less critical buildings, removing less critical systems, or reducing building loads though other means, such as increasing air conditioner setpoints. This decision is a case-specific but taking this type of approach can lower overall generation costs.

For example, Miramar is implementing a $1.6 \mathrm{MW}$ load shedding system applied to their central heating, ventilation and air conditioning control system. This capability has a rough cost of $\$ 450,000$ or $\$ 280 / \mathrm{kW}$, compared to a higher cost for new generation capacity. This strategy will provide flexibility for the microgrid system at a lower cost than additional generation.

When considering generation options, it is also necessary to understand the fuel supply options as discussed in Sections 2.5 and 3.6. For example, natural gas may be available on certain installations, but the capacity and supply pressure of the natural gas system needs to be evaluated to determine its ability to supply the generators.

If existing fuel sources cannot be used or are not present, the team should analyze options for bringing in a new supply of fuel. One publicly available resource for transmission-level location data for natural gas, oil, and electricity infrastructure is the Homeland Infrastructure FoundationLevel Data website. ${ }^{19}$ This database — along with discussions with local utility providers - could help the project team determine the viability of a new fuel supply. Other options, such as landfill gas or hydrogen supply and storage could also be considered. Hydrogen can be used both as a fuel for fuel cells and by fleet vehicles if desired.

The economics of new generation sources should be considered and will likely be a key component of generation selection if project cost savings are desired. To achieve greater cost savings the generation components may need to operate while grid connected and provide a reduction in energy bills.

\subsubsection{Renewable Generation Assets}

Adding renewable generation assets to an installation can have many benefits including lower energy costs, reduced environmental impact, and an on-site energy resource that does not require outside fuel. There are several key considerations when evaluating options such as location, renewable resource, technology type, permitting, off-take agreements, and financing. As discussed in Section 2, several of these variables should have been examined during the site visit providing a preliminary understanding of renewable energy options. The key considerations for developing renewable energy projects are well documented. ${ }^{20}$ Additionally, several tools can be used to help evaluate the technical and economic feasibility of renewable energy projects, including:

19 "Homeland Infrastructure Foundation-Level Data (HIFLD)," U.S. Department of Homeland Security, https://hifld-geoplatform.opendata.arcgis.com.

20 See Springer 2013 for more information. 
- NREL's System Advisor Model (SAM): https://sam.nrel.gov/

- NREL's Renewable Energy Optimization Tool (REopt): https://reopt.nrel.gov/

- The Canadian government's RETScreen tool: https://www.nrcan.gc.ca/energy/softwaretools/7465.

- HOMER Pro: https://www.homerenergy.com/products/pro/index.html

Renewable generation sources such as wind and PV have multiple benefits. In grid connected operations they can provide cost savings. When microgrids are operated under contingency scenarios, renewable energy provides a generation source that does not require refueling. Because of this benefit, renewable resources are often seen as offsetting other generation sources that require refueling. Some of the limitations are the variability of the power production for wind and PV, though these can be forecasted. Microgrids can be powered solely by renewable energy, but this approach generally requires energy storage. The capability and features of modern inverters have made using renewable energy sources in a microgrid much simpler over the last several years. Many features that allow for integration with microgrids used to be rare or require customization, however many are now commonly available in most inverters, especially the larger ones. These features include the ability to control several settings and functions on demand from a microgrid controller such as:

- The amount of power delivered (e.g., adjustable power output from $0 \%$ to $100 \%$ of potential system output at any given time) as well as regulation of the ramp rate of how fast power output can increase.

- Reactive power delivered (e.g., adjustment to the power factor of the power delivered by the inverter to provide both real and reactive power)

- The ability to adjust the settings of the inverter so that it can still provide power during grid disturbances (e.g., changing the voltage setting at which an inverter stops delivering power to a microgrid).

The Miramar microgrid ESTCP project demonstrated several of these features including the ability for a microgrid controller to adjust power output and reactive power in a PV inverter. An example of PV control is shown in Figure 5.

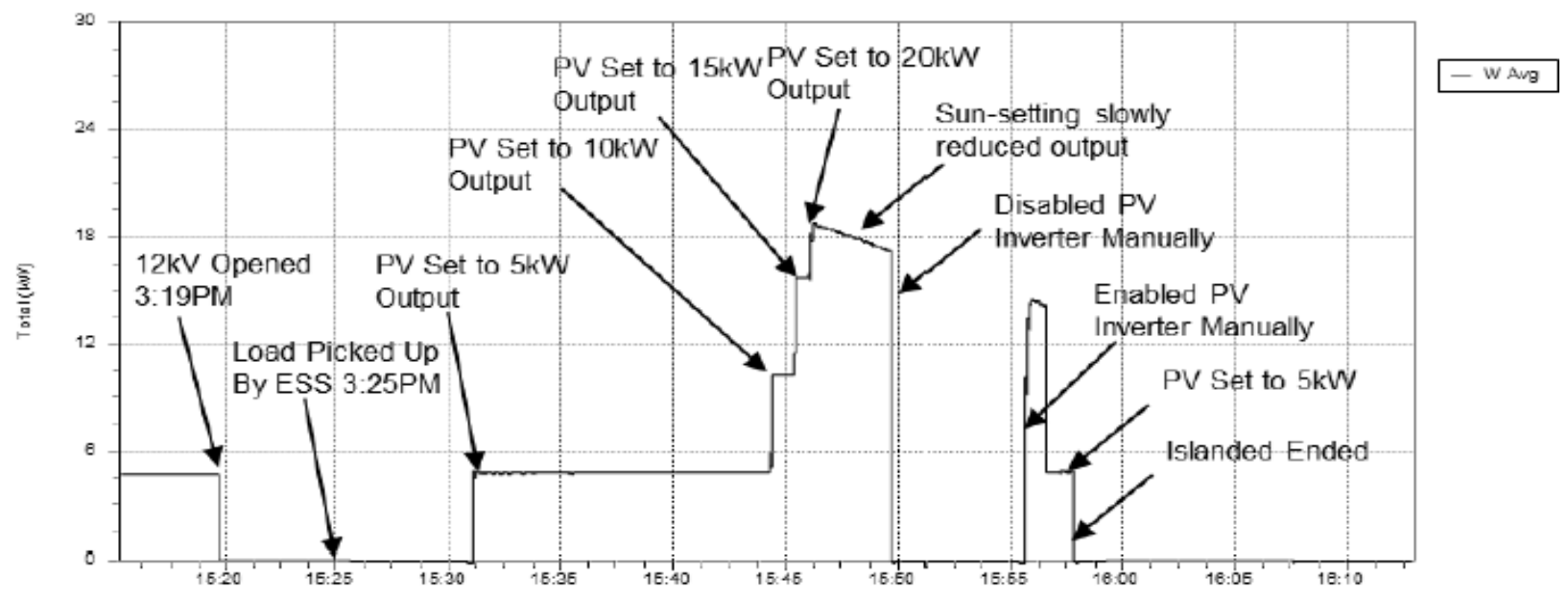

Figure 5. Power output data and control signals from PV at Miramar during islanding test

Source: Faries et al. 2016 


\subsubsection{Energy Storage}

There are many types of energy storage (pumped hydro, compressed air, etc.) but the most common in a microgrid is a BESS. Batteries can provide several benefits to a microgrid. Traditional generation sources such as diesel or gas generators do not have an instantaneous capability of responding to sudden load changes, and this latency in generator response can impact system frequency, which in turn affects utilization equipment at the building level. A BESS of sufficient size that is connected to the microgrid can provide an immediate response to sudden changes in system frequency (i.e., following loss of another generation unit) and thus maintain stability until appropriate load shed techniques can be employed.

A BESS can also be used to black start the microgrid or even a power plant if needed. A large BESS could be utilized as a large interruptible power supply for seamless transition to microgrid mode if desired.

Potential revenue-producing activities for a BESS include peak shaving, energy arbitrage, demand response, and various ancillary services. If the BESS were used for economic purposes, special attention would need to be placed on the state of charge of the system along with associated resiliency requirements, and the site would need to toggle this setpoint based on the desired use. See Appendix C for more information.

\subsubsection{Matching Generation and Load}

The timing of loads and generation in a microgrid is an important consideration when selecting new generation resources. When the microgrid is operating in grid connected mode the controller can perform economic optimization. When the microgrid is operating in islanded mode, the microgrid controller must maintain balance between generation and load and ensure voltage and frequency remain within the established boundaries. Balancing load and generation can be difficult, as the load profile seen by microgrid energy resources is dynamic. Reasons for this include but are not limited to:

1. Building mechanical systems contain equipment that are continuously starting and stopping.

2. Lighting and plug loads change according to building occupancy.

3. Solar irradiance variations change PV generation, which directly affects loads.

4. Some emergency generators transfer their loads to the utility grid after power is restored.

The available microgrid energy resources must meet these dynamic load variations while keeping a reserve margin for contingencies.

For a design analysis, it is useful to conduct system modeling to match microgrid loads with generation on an hourly, 15-minute, or 1-minute basis. This type of modeling can provide a detailed look into how a microgrid can supply loads from different generation sources at each time step throughout the course of a year. To conduct this modeling, detailed load data are needed (e.g., hourly interval data for one year). With these load data, a modeling program such 
as REopt or HOMER ${ }^{21}$ can be used to conduct an hourly analysis to provide information on the ability of generation to supply load, the cost of supply, and the amount of fuel required.

Figure 6 shows two examples from REopt of this type of analysis. The top chart in the figure shows an example installation load being met under normal grid operation. In this example the load is being meet by a combination of sources including utility power purchases, on-site PV, and energy storage. The purpose of the optimization in this case is to show how microgrid assets can be utilized to provide grid connected value. The solar PV meets load reducing the need for purchases of energy. The energy storage both stores PV generation and strategically supplies power to reduce peak utility purchases. The bottom chart shows an example of modeling for an islanded scenario and the ability for microgrid assets to be used to survive an outage. The chart helps illustrate the length of time an example installation can survive an outage, at $90 \%$ probability, given various types and sizes of microgrid generation assets (diesel, solar, and storage) and a fixed diesel fuel supply. Outage survivability is shown as a probability because it depends on the load, solar generation, and battery state of charge when the outage occurs. The charts do not show all of the possible analysis that could or should be conducted for a project but simply provide two examples of the usefulness of this type of modeling during a design analysis.

21 https:/www.homerenergy.com/ 

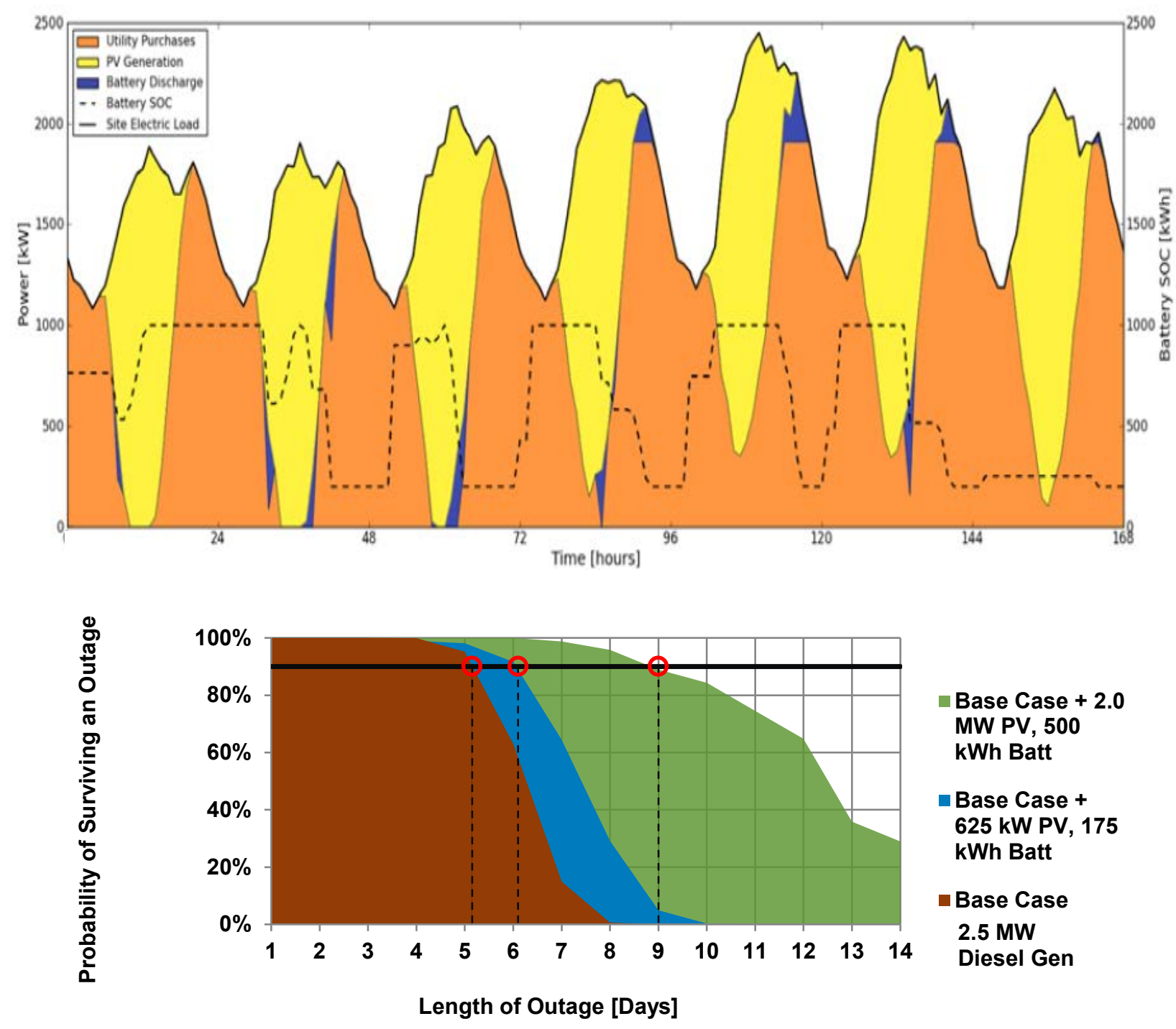

Figure 6. Examples of REopt analysis

\subsection{Electrical Modeling and Studies}

Because microgrids operate independently of the utility in islanded mode, detailed analysis is sometimes required to model the microgrid to ensure the proposed solution can adequately maintain power quality and system stability. These models provide detail beyond what REopt or HOMER can analyze. Electrical models for microgrids support three types of analysis: (1) steady state under normal conditions such as power-flow (or "load-flow"), short circuit, protection, harmonics, and arc flash; (2) dynamic stability; and (3) transient analysis. These analyses cover different time frames.

Power-flow studies typically cover time spans lasting one minute or more, dynamic stability studies typically cover time spans of one second to several minutes, and transient studies cover intervals of less than one second. 
Each of these study types help verify system functionality in different ways and are discussed in more detail below.

- Power-flow analysis is performed to calculate steady-state bus voltages, phase angle, real and reactive power, and currents carried on conductors and supplied to loads in an electrical power system. In microgrid analyses, these power-flow solutions are useful for determining voltage drops and line losses, bus voltages at nodes, conductor ampacity requirements, reverse power flow, and coordination of protective device settings, under different microgrid configurations. The amount of short circuit current available to activate protection devices may be significantly less during island operation. To help mitigate this issue the protective devices at Miramar have two settings, one for grid connected operation and one for islanded operation. The protection coordination portion of this analysis is essential to safe microgrid operation.

- Dynamic stability analysis is primarily performed to investigate generator stability under changes in generation or load in a power system. For two reasons, dynamic stability is particularly important to analyze when planning a microgrid. First, changes in load or generation within the microgrid can represent a large percentage of the rating of the microgrid generator(s). Second, voltage and frequency must be regulated by at least one generator in the microgrid (as opposed to the utility in grid-connected mode); this further necessitates dynamic stability analysis to properly tune the generator controls. A key part of this analysis is to understand rotor angles changes between different generators in the microgrid, and to ensure that they do not become unstable and trip offline.

- Transient analysis is performed primarily to account for fast electrical transients that arise from in-rush currents caused by inductive loads such as transformers or induction motors. Other reasons to perform high-resolution studies are to account for highbandwidth power electronic control algorithms and to analyze harmonics arising from the switching action of inverters.

Text Box 7 discusses the modeling undertaken for the Miramar microgrid during the conceptual design analysis process and its results. Further modeling for the project was conducted during the engineering design phase. 
To analyze possible islanded microgrid scenarios during conceptual design, modeling of the electrical systems for Miramar was performed in two stages. In the first stage, a model was used to perform power flow analyses on the microgrid. In the second stage, a time-domain analysis tool was used to perform dynamic analyses on the microgrid.

\section{Results}

1. A central diesel plant of sufficient size to carry the planned load will likely handle all expected disturbances, including starting all feeders without subdivision. However, some large disturbance events (e.g., faults and loss-of-feeder) could create sufficiently large frequency or voltage disturbances that could affect some sensitive equipment.

2. A scenario with only natural gas generators will likely be unable to manage all expected disturbances due to the slow response times of natural gas engines.

3. A minimum of two power plant generators are needed for maintaining stability during microgrid operation, and one of these must be diesel.

4. Turn-down of electric loads prior to load pickup by building energy management system control, controlled load transfer of standby generators, and/or possibly controlling building and feeder level switching equipment has a significant positive impact to reduce disturbances during load pickup.

The size of the frequency and voltage disturbances will likely necessitate adjustments to the protection settings within the microgrid during islanded operation.

\subsubsection{Interconnection Application and Studies}

In addition to engineering studies for a microgrid, the local utility may also require additional electrical studies or analysis for interconnecting the generation sources with the utility grid. These are determined by the utility based on their system characteristics, design standards and policies, and operating procedures. Many utilities have a well-documented process for distributed generation interconnection that can be followed for any generation sources that would be added.

Most utilities do not have many microgrids connected to their systems and do not have an established process for connection of or coordination with microgrids. It is recommended that the microgrid design team engage with their utility early and throughout the design process to understand any additional requirements the utility may have for the microgrid. It may also be useful to discuss with the local utility to identify potential design aspects that offer co-benefits to the installation's and utility's systems (e.g., grid services or demand response).

\subsubsection{Protective Relaying and Selective Coordination}

During utility-connected conditions, the electrical distributor's distribution system (often called the "infinite grid") is a significant contributor to fault current magnitude. In islanded modes 
of microgrid operation, the available fault current in the distribution system is reduced, as the available energy resources typically do not have the capacity or inertia to contribute substantially to faults. As a result, islanded electrical systems must be evaluated for total fault current and protective relay settings may have to be adjusted when the system is in this state to ensure selective coordination between protective devices. Typically, these device settings become more sensitive to faults during islanded operation. Modern protective devices have multifunction capabilities and can receive a control signal from a microgrid controller to change their settings according to system conditions.

As part of the microgrid design, an electrical engineer will need to determine the available fault currents in the islanded system and perform a coordination study to determine the appropriate settings for the protective devices in both utility grid-connected and islanded modes of operation. The microgrid controller informs the distributed multifunction relays of the current state (utilityconnected or islanded).

\subsection{Microgrid Controls}

A critical component of microgrid design is controls. The microgrid controller is the "brain" of the microgrid and it must communicate with all devices that monitor and control distributed equipment or systems. The controller and associated components that together comprise the microgrid management system include main control hardware and software, power supplies, UPS, racks, data historian and other servers, work station/monitors, and Ethernet switches for interfacing with existing systems (e.g., SCADA, cogeneration [cogen] plants, PV systems, and advanced metering infrastructure) and new systems such as building-level diesel generator controls, building load shed circuit breakers, distribution system sectionalizer switches, and controllers at other sites.

A microgrid management system is an integrated real-time power distribution management system unifying SCADA functions, energy resource controls, and load management, with a common user interface. The system functions in both utility-connected and islanded operating modes to ensure effective monitoring and control of the electric power system for reliable and safe operation.

Features or capabilities provided by the microgrid management system could include:

- Performing frequency and voltage control or support within the network

- Providing real and reactive power balancing

- Ensuring sufficient spinning reserve and step load capability are available

- Short-term and long-term weather and renewable generation forecasting systems that can predict impacts on site loads and generation and enable operators to act if necessary

- Priority-based load shed schemes

- Historical data archiving and analyses for predicting site loads, reporting, system planning, etc.

- Monitoring generator availability including both planned maintenance and unscheduled shutdowns

- Supporting the microgrid restoration process, including black-start capability and protocols for energizing the network 
- Seamless transfer to/from the utility connection

To ensure compatibility with other systems, the controller should use simple and nonproprietary inputs and outputs and common communications protocols.

Generator control modes describe how the electric machine interacts with the power system to which it connects. A power system is characterized by two steady-state variables: voltage and frequency. These variables are maintained within a small bandwidth to enable the successful operation of generators and loads connected to the power system. Four typical generator control modes are base (fixed) output, variable (uncontrolled) output, isochronous, and droop control. Generators in microgrids will typically provide power under one of these control modes and the overall microgrid controller will likely need to balance and control generation with different control modes. For example, in the islanded microgrid at Miramar, the PV systems operate as variable output (i.e., they change according to time of day and clouding events), the landfill gas generators operate as base load, and the power plant generators operate in isochronous load share mode. See Appendix B for more details on control modes.

\subsection{Communications and Cybersecurity}

Adding microgrids to protect from outages can also introduce new cybersecurity vulnerabilities. One enabling feature of a microgrid, in fact, is the two-way data communications among the microgrid participants (e.g., generation sources and controllable loads) and - in some caseswith the grid to which it is connected. Those control and communication functions can create vulnerabilities by increasing the microgrid's attack surface, presenting portals for cyber intrusions.

Providing reliable and secure communications among the microgrid components and between the microgrid and base facilities is a functional requirement. The speed of communications or system latency can be a limiting factor for some microgrid operations and must be considered when designing systems. For example, building management and control systems cannot be used to maintain power quality in the microgrid by balancing load and generation because they do not response fast enough to changes. They can however be used for longer term load reduction such as reducing the total magnitude of critical loads during an outage.

For cyber security of particular concern are the communications supporting the microgrid control systems. Securing these communications involves restricting both physical and logical access. Microgrid systems in DoD must follow the risk management framework (RMF) for cybersecurity review and accreditation. An overview of the RMF process is shown in Figure 7. 


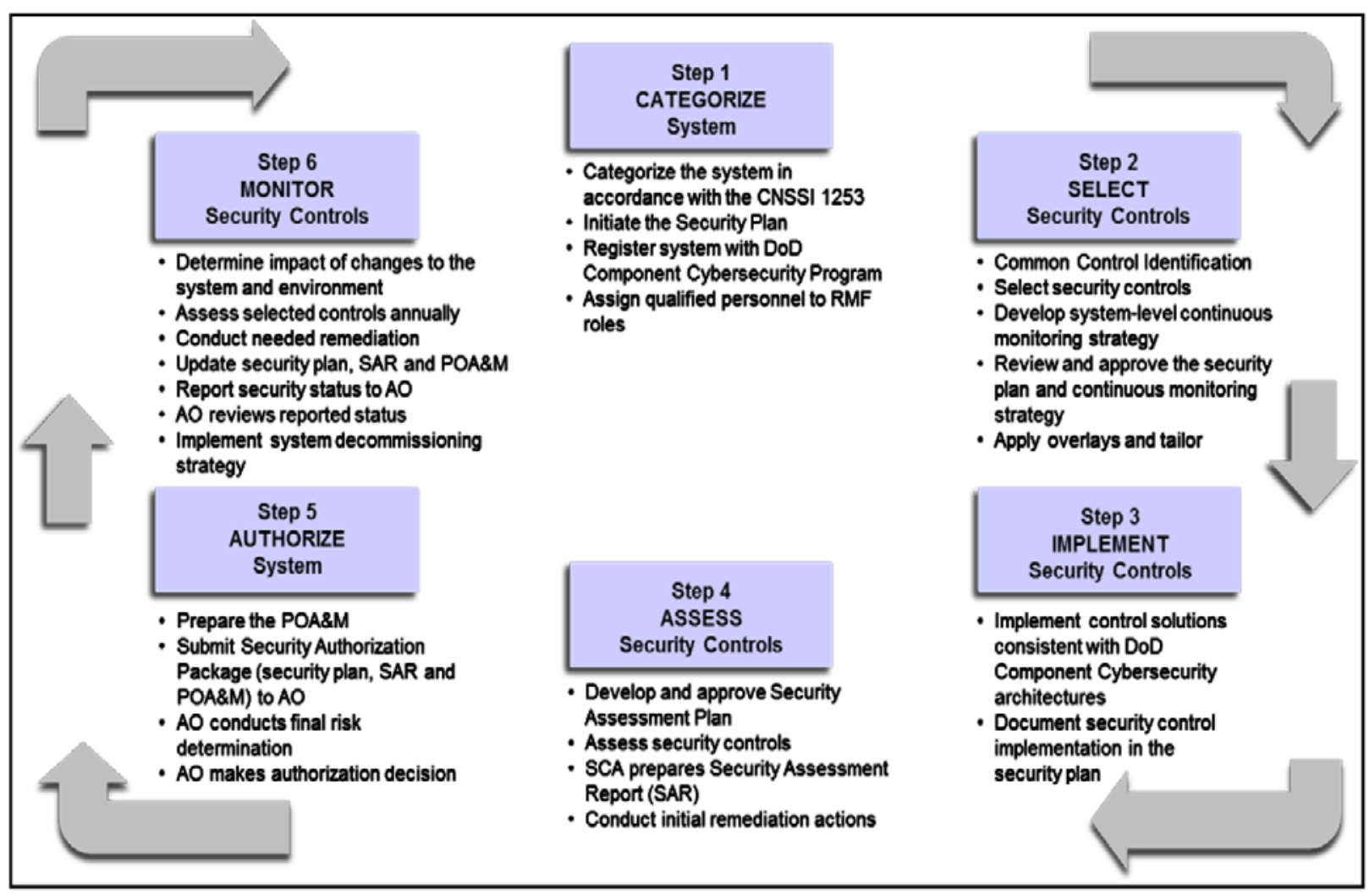

Figure 7. DoD RMF typically applied to microgrids

Source: DoD instruction 8510.01, 2017

For more information on the RMF, see DoD Instruction $8510.01 .^{22}$ See also Appendix F for additional specific information on cybersecurity provisions for microgrids and additional resources.

Implementation of a microgrid requires the integration of communications to enable the control architecture necessary for safety, security, reliability, sustainability, and cost-effectiveness.

22 “DoDI RMF 8510.01 for DoD IT,” DoD CIO, 28 July 2017.

http://www.esd.whs.mil/Portals/54/Documents/DD/issuances/dodi/851001_2014.pdf. 
This can be a challenging process within the RMF; see Text Box 8 for the example of Miramar and Otis Air National Guard challenges and solutions.

\section{Text Box 8. RMF Examples for Miramar and Otis Air National Guard Base ESTCP Projects}

At Miramar, the key lesson learned is that adopting a command-level solution or framework for cybersecurity is essential before making the RMF a requirement of the contractor. Much of the RMF requires government input and organizational decisions that will impact the final control system solution. For instance, it is critical to know the Categorization level within the RMF in order to know which security controls must be implemented and this could impact the microgrid software. In the best-case scenario, the command information technology office has a framework with which the microgrid control system software can integrate to enable the required security controls.

One goal of the Joint Base Cape Cod Otis ESTCP microgrid is to demonstrate a cyber-secure microgrid that can participate in regional ancillary service markets. Market participation in the ancillary service market requires a communications interface with the external utility. This project was particularly challenging in that the microgrid included a connection to the outside utility. The RMF package for the project has been developed, but approval and granting of an official authority to operate are still in process and will likely be the responsibility of the Air Force after the demonstration period.

\subsection{Additional Design Requirements and System Integration}

A microgrid is a complex engineering system with multiple power generation, distribution, and protection devices. Although the design is generally focused on the electrical engineering, there must also be considerations of many other factors for a successful system such as fuel supply, water supply, environmental considerations and permitting, information technology, physical security, and O\&M. Some of these factors may impose additional design considerations or constraints on the microgrid design or operation and need to be considered as part of the design analysis. These considerations are generally very specific to the particular project.

One additional design requirement of considerable importance is systems integration. Integrating the various microgrid components, systems, and communications methods is very challenging. In many microgrid projects, this is the most complicated and difficult task for the engineering team.

\subsection{Microgrid Technoeconomic Analysis}

A component in the microgrid design analysis is often a techno-economic assessment that analyzes capital costs for a system, opportunities for cost savings, and financial return. Typically, microgrid projects require this analysis to seek funding for project implementation so that costs, savings, and returns are well-documented and understood. However, not all projects require technoeconomic analysis and some projects may simply be implemented to meet resiliency requirements or mission needs. This section reviews the components of a technoeconomic analysis, the project team for a microgrid will need to determine what analysis if any is required for a particular project. 


\subsubsection{Cost Estimation}

As part of a design analysis, capital costs for potential microgrid systems and components may need to be evaluated. Examples of typical items to include in a cost estimate both for upgrades and new components include:

- Electrical system components (e.g., new sectionalizing switches, circuit breakers, relays, and cables)

- Energy generation and storage (e.g., new cogeneration and battery energy storage)

- Controls and communications (e.g., fiber optic communication lines and microgrid controller)

- New buildings or renovations (e.g., new microgrid control room)

- System integration (e.g., holistic integration of electrical, mechanical, and building control systems)

- Cybersecurity (e.g., DoD RMF process)

- Operation and maintenance (e.g., costs per hour of operation for diesel generator maintenance)

- Engineering design costs

- System study costs for protection, interconnection, etc.

- Other general components and additions to construction projects, such as considerations for safety, project management, general provisions, overhead, and profit

The exact capital costs for these project components can vary according to several factors, including system size, location, and features. For more information on typical system costs, see Giraldez et al. (2018).

\subsubsection{Economic Savings}

The next step in developing an overall understanding of the economic viability of a microgrid is the calculation of the cost savings that it can provide if any. Typically, during grid-connected mode, microgrids can provide cost savings from self-generation, demand response, peak shaving, or ancillary services. Determining the amount of potential savings is site-specific and should be part of the overall economic evaluation of a project. Many projects can provide some cost savings even if that is not their primary purpose and even if the overall project does not provide a positive financial return. This section discusses potential cost savings opportunities.

\section{Self-Generation}

Potential cost savings from self-generation in a microgrid come from the price difference between purchasing electricity from a utility company and generating it on the installation instead. Many kinds of projects can provide savings from self-generation opportunities and each potential generation source should be evaluated. In many instances, renewable energy projects can provide favorable economics for self-generation as do combined heat and power projects where engines or turbines fueled by natural gas can meet both thermal and electrical loads.

A simplified example is presented to help explain this concept. For a theoretical microgrid, the economic value of natural gas generation in the microgrid is driven by the cost difference for grid electrical energy versus purchased natural gas. At electricity costs of $\$ 0.15$ per kilowatthour $(\mathrm{kWh})$ and natural gas costs of $\$ 12.00$ per million British thermal units it is more costeffective to purchase natural gas generators and use the generators to produce electrical energy 
than it is to buy electrical energy from the grid. However, this analysis should also include operating costs, which will reduce the potential savings and estimates of fuel escalation rates or changes. As the prices of these commodities change, the economic value of the microgrid changes. Additionally, other potential new utility costs that may result from self-generation such as departing load and standby generation charges must be considered.

\section{Demand Response}

In electrical systems it is very expensive for the utility company to supply energy during periods of peak demand. Because of this, utility companies often offer incentive programs for customers to reduce their loads during these periods. These are commonly known as demand response programs. Generally, these programs require customers to sign a contract to reduce their load when called upon by the utility company during peak system demand or when the utility is experiencing generation or transmission issues. Customers are paid on a per-kilowatt basis for providing the service. Some of these programs require customers to reduce load by taking actions such as increasing setpoints on air conditioning systems. Other utilities allow customers to utilize existing dispatchable generation sources such as batteries or engine generators to reduce their load on the utility system. ${ }^{23}$

\section{Peak Shaving}

Utility bills can be quite complex, and many contain a charge related to the peak power demand or usage of a customer during certain days and hours. In this scenario, utilities track a customer's energy usage throughout the month and the maximum value is multiplied by a dollar-perkilowatt $(\$ / \mathrm{kW})$ charge to create a peak demand charge. A microgrid supervisory control system and generation resources can be used to monitor peak demand at the installation and utilize the microgrid generation to reduce peak demand.

\section{Ancillary Services}

Many locations have markets for energy or the services that energy generation could provide. Generation that is part of a microgrid could be used to sell energy or services into these markets. For example, the California Independent System Operator has an open market for energy sales and PJM Interconnection has a market for frequency response. The barriers to entry to participate in these markets can be high, as they often require sophisticated and expensive metering equipment, including a connection to an outside entity, which represents a cybersecurity risk. Additionally, some markets have minimum sizes for generation, and many smaller microgrids may not meet the market requirements.

\subsubsection{Lifecycle Cost Analysis}

After costs and potential savings have been determined, the next step is to determine the overall economic savings, if any, from a microgrid project. Overall savings are assessed by analyzing the lifecycle costs and savings from a project; to calculate the overall financial metrics such as

23 For additional information on the demand response programs for SDG\&E, Miramar's serving utility, see "SDG\&E Programs that Reward Your Business for Reducing Energy Use," SDG\&E, https:/www.sdge.com/businesses/savings-center/energy-management-programs/demand-response. 
net present value, rate of return, or savings to investment ratio. A basic formula for a microgrid project with a positive economic return is:

Value of Energy Revenue Streams $>$ Capital Costs + Operations Costs + Maintenance Costs

Because there is extensive information in the public domain on how on how to conduct economic analysis for energy projects, this report does not cover these in detail. Also, several tools have also been developed to help with this type of analysis for microgrids. Examples include:

- Distributed Energy Resources Customer Adoption Model by Lawrence Berkeley National Laboratory; see https://buildingmicrogrid.lbl.gov/projects/howaccess-der-cam.

- Microgrid Design Tool by Sandia National Laboratories; see https://www.energy.gov/oe/services/technology-development/smart-grid/role-microgridshelping-advance-nation-s-energy-syst-0.

- Renewable Energy Optimization Tool by NREL; see https://reopt.nrel.gov/tool.

- Hybrid Optimization Model for Electric Renewables (HOMER), by HOMER Energy; see http://www.homerenergy.com/

A few observations and lessons from NREL project experience with microgrid analysis are that:

- Many energy resiliency projects do not have a positive financial return when economic savings are analyzed.

- A microgrid project can have a positive financial return, but this requires a unique combination of installation location, financial incentives, and existing infrastructure.

- If resiliency is a mission requirement, a project does not necessarily need to have cost savings, rather the microgrid could increase the installations capability, reduce risk, and/or provide additional insurance for the mission

\subsection{Implementation Options}

Microgrid projects in the DoD typically follow one of three general project implementation pathways. These include appropriations-funded projects, privately financed or funded projects, and demonstration projects.

\subsubsection{Appropriations}

Appropriated funds are those financial resources provided by the U.S. Government budget such as Military Construction (MILCON) funds and a subset of MILCON the ERCIP Program.

Typically, a DoD installation must apply for funding under one of these programs with information about the project, such as capital costs, expected savings, and a narrative of other benefits. Once appropriated funds have been obtained, the DoD installation can follow the wellestablished DoD acquisition process for design and construction to build a microgrid project; see Section 5 for details.

\subsubsection{Alternative Financing}

Appropriated funding is quite limited and several types of privately financed sources of funding can be used for microgrid projects, provided the project meet certain requirements. These funding sources include energy savings performance contracts (ESPC), utility service contracts 
(USC), utility energy service contracts (UESC), power purchase agreements (PPA), enhanced use leases, inter-governmental service agreements, and utility privatization, where applicable. The DOE Federal Energy Management Program ${ }^{24}$ provides many services and resources related to alternative financing.

ESPCs and UESCs are important financing mechanisms that support over one billion dollars per year in verified energy efficiency cost savings for the federal government (Stuart et al. 2013). A typical ESPC or UESC may include resiliency measures if the combined set of energy conservation measures (ECM) is economical. This involves bundling projects with high return on investment with projects that have lower return on investment. This is a straightforward and common approach to including less cost-effective resiliency measures within a performance contract. The current federal ESPC statute (42.U.S.C. 8287) allows energy conservation measures (ECM) with short payback to be bundled with long term payback ECMs.

A simplified cost justification can be conducted to show that any resilience energy conservation measure can be included in a larger ESPC, as long as the entire ESPC is cost-effective in the contract term. This approach avoids the complicated analysis that would be required to quantify and attribute the cost savings that could come from effective resilience measures, but which are by their nature difficult to identify, quantify, and properly attribute. For example, the costs associated with microgrid controls and communications are difficult to justify on their own, but they could be bundled with a combined heat and power plant within an overall ESPC or UESC.

\subsubsection{Demonstration Programs}

Multiple advanced microgrid projects on DoD installations have been funded by technology demonstration programs in order to help advance technology development and deployment. Examples of programs include the DoD ESTCP program, California Energy Commission grant programs, the State of Connecticut's microgrid program, and Department of Energy grants. These programs need to be evaluated on a case-by-case basis, as the opportunities within each program change frequently and vary substantially, and long-term O\&M funding sources must be considered. However, these programs can be especially good opportunities for installations to learn, as they can help advance new microgrid technologies and they do not result in loans that require repayment.

24 See for more information (https://www.energy.gov/eere/femp/federal-energy-management-program) 


\section{Project Development}

Either after or during the microgrid conceptual design process, a preferred implementation method should be selected. Once this is done, additional steps can be taken to help develop the project appropriately for the selected implementation option. While this report focuses primarily on conceptual design, key project development considerations and lessons learned are discussed briefly in this section.

\subsection{Acquisition and Operating Strategy}

Each of the various implementation mechanisms in Section 4.10 will have its own considerations for acquisition and operations, and these will vary considerably by the method selected. A few lessons from NREL experience are offered below.

\section{Acquisition}

- Generally, appropriations-funded projects are split into separate contracts for design and construction. This is a well-established system for buildings and a potential avenue to reducing project costs. However, this can be problematic for microgrids, as they are very complex systems that include items such as customized control software that does not necessarily fit well into the design-bid-build acquisition process. Design-build contracts may be more appropriate for microgrid solutions, as the intention is to have operational requirements with flexibility in the technical solution for most microgrids.

- Competition for projects is generally desired and can lead to better overall results for a project if multiple technical solutions and bidders are options for selection teams. However, care must be taken to ensure the bidders are prequalified and have the appropriate microgrid project experience. Generally, DoD has contracting preferences that support contracting with small businesses, which make contracting faster and easier. These initiatives are very useful for most construction contracts and regular facilities work; however, microgrids are large and complex projects that require specialized expertise across many disciplines and contracting avenues that use full, and open competition between bidders may yield better projects even though they require special approval within DoD.

- Generally, the DoD also has contracting preferences that favor "lowest price technically acceptable" decisions for selecting contractors, which makes contracting faster and easier. These initiatives can be useful for some construction contracts but, as stated above, microgrids are complex projects and a best-value approach to contractor selection may yield better projects even though it requires special approval within DoD.

\section{Operations and Maintenance}

- Some implementation avenues such as an Energy Savings Performance Contract (ESPC) also include plans or solutions for O\&M, as they require savings that can be measured. Other mechanisms, such as appropriations do not come with funding for O\&M and they require an installation to plan for this with a different source of funding. Planning for O\&M should begin in the overall project planning process but be updated based on the acquisition process and requirements. 


\subsection{Project Refinement and Funding and Financing}

In many cases, a project will need to be refined or modified during the development or implementation phases as new information comes to light or conditions change. Where a project is in the process will determine the methods by which this can be accomplished and the difficulty and cost of making refinements.

As an example of the refinement required, for the Miramar microgrid, funding to implement all the desired project options was unavailable. To match the funding available, the project scope had to be reduced and certain components such as energy storage had to be removed from the initial implementation. ${ }^{25}$

Funding limitations and other considerations can also yield a phased approach to microgrid design, wherein components in the system or capabilities of the microgrid can be built out over time as warranted and as funding is available.

\subsection{Solicitation, Selection, and Award: Lessons Learned}

Once a conceptual design has been established and a procurement mechanism has been decided upon, the next step in the development of a project is often to prepare a solicitation or request for proposals (RFP) for the project. The specifics of the solicitation process depend on the procurement mechanism; for example, ERCIP projects follow a very different process than alternatively financed projects. Generally, however, the goal of the processes is the same: to select a qualified contractor by reviewing several proposals from various contractors. The proposals should be from qualified contractors with experience in the design, construction, and commissioning of complex microgrid systems. Numerous qualified organizations can respond to DoD microgrid RFPs, and competition for projects is typically robust. The following subsections present some lessons learned from the Miramar solicitation process, which was an appropriations-funded project.

\section{RFP Process}

- It is often useful to establish a two-stage process for DoD microgrid projects, where an initial request for interest or a request for qualifications is used to down-select contractors. This approach can ensure only qualified bidders respond. It can also be used to limit the distribution of sensitive information, such as installation electrical drawings to a select number of contractors.

- The design-bid-build procurement process common in construction projects may not be a good fit for implementing microgrids. Microgrid projects could benefit from changes to the standard RFP template and from common DoD design-bid-build project specifications.

- Holding "industry days" before final RFPs are developed can allow potential contractors to provide input to improve the overall solicitation and process.

- A successful project team must be multifaceted. Microgrid project experience is essential, but experience with cybersecurity, government projects, and system integration are also very important.

25 Miramar subsequently received a grant from the California Energy Commission to include energy storage in the overall project. 
- Some contractors tend to utilize low bid subcontractors or vendors in order to save money and win the project award. It can be valuable to develop detailed performance specifications or standards for key microgrid components to ensure quality products, installation, and commissioning.

\section{RFP Technical Requirements}

- Microgrid RFPs tend to have many specifications. It could be simpler for contractors to comply with RFP specifications if specifications were clearer and if they did not contain both performance and prescriptive requirements. In practice, this is difficult, as the government has prescriptive requirements (e.g., uniform facilities criteria), but it often wants to allow contractors to have the freedom to be creative in other areas (e.g., microgrid control options) and thus uses more performance-based requirements for certain project aspects.

- The development of microgrid design criteria or specifications could help with project standardization and could potentially lower overall project costs.

- More mechanisms (e.g. industry days) for discussing proposals and projects with contractors to facilitate more-creative solutions to meet government requirements or intent could be helpful. It could also improve the process and provide the government with a better project at a lower cost.

- Project options can be a useful mechanism to indicate items the government would like but which are not required for the overall execution of the project. Using the option process, the Miramar microgrid received additional desired project attributes.

- Resolving as many potential project issues before the solicitation is a best practice. For example, Miramar extensively studied the air permitting process and requirements before determining a technical requirement for the microgrid RFP.

- The request for information process during solicitation is critical in that many project decisions or information are required to be assembled in a timely manner. Ensuring the government team is ready to address items fully and clearly is essential to having a good consolidated RFP upon award.

\section{RFP Contractual Requirements}

- Government RFPs are very long and complex, and the allowed response time is often very limited. More time to prepare bids could allow for better contractor responses.

- The timing allotted for some design and construction activities in government contracts is not tailored for microgrid projects, and it is not very flexible. This could be adjusted to allow increased timing for certain activities, such as microgrid design and stakeholder consultation.

- Software development required for microgrids does not fit well into the government process for design and construction, which, again, is more tailored to buildings.

\section{Selection}

- Following a best-value approach rather than a "lowest price technically acceptable" approach to microgrid contracting is advised, as microgrids are complicated systems.

- Full and open competition for micro-grid projects in terms of the type of contractors that can bid on projects is preferred. 
Cybersecurity

- If the government could risk-categorize the microgrid system in the RMF process before releasing the RFP, the contractor could save considerable time in the RMF process with minimal effort on the government's part.

- DoD should clearly describe the government's and the contractor's responsibilities in the RMF cyber security process.

Once the solicitation process is completed and the project is awarded to a qualified contractor, the project can move into implementation, which is addressed in the next section. 


\section{Implementation}

Once a microgrid project has been awarded, it must be designed, constructed, commissioned, and tested to ensure effective operation. While this report focuses principally on conceptual design, this section provides a general overview of implementation along with lessons learned.

As part of the implementation process, many DoD installations have found it helpful to have subject matter experts available to support project components such as design reviews, construction oversight, and system testing as DoD staff may not have the experience, expertise, time, or resources to fully support the efforts. National laboratories, owners' engineers, and consultants directly reporting to the DoD have served as subject matter experts to assist with past and ongoing microgrid projects.

\subsection{Post-Award Period}

After project award and prior to the engineering design phase, there is a contract initiation and post-award project period in which the project team forms. This part of the process has been short in some DoD projects and is critical for stakeholder engagement and background research. Some lessons from the DoD microgrid post-award process include the following:

- One key lesson from the Miramar microgrid project is that the project team would have benefited from a longer post-award project period. This part of the project was very short, and it did not allow the contractor to conduct detailed analysis or hold discussions of previous analysis at the installation or to conduct significant stakeholder outreach. A longer post-award period would have allowed for this and would have improved the overall project by saving the project team time and effort in the long run.

- Many key stakeholders in the post-award process were not well-informed about the RFP requirements and the contractor's proposed solution. Greater awareness and information sharing on the part of both the government and the contractor teams would have improved initial discussions. It is recommended that both sides hold internal kickoff briefings and meetings before the official project meeting.

- Stakeholder lists and organization lists - from both the contractor and the governmentwould have been helpful, as would clarification of everyone's roles and responsibilities in addition to information on who has authority for decision making.

- Having installation leadership engaged in the post-award process can be a valuable way to show support for the project.

\subsection{Engineering Design}

The engineering design process may include: conceptual, schematic, design development, prefinal, and 100\% design and construction documents. This effort requires research, analytical simulations, engineering calculations resulting in predictive outcomes with solutions for potential operating scenarios, additional metering on site as appropriate, power system and mechanical system studies, design reviews, and delivery of final sealed drawings and specifications for construction. 
Some lessons from some DoD microgrid engineering design processes include:

- It is recommended that before the microgrid design begins, detailed system modelingas described in Section 4.4.3 - be performed. The results of these analyses will predict electrical behavior in the microgrid. Such analysis should include more specific information on the generator/engine parameters and control algorithms, the load control capabilities, monitoring and microgrid devices, and system latency to accurately predict electrical behavior. Such studies would include, but not be limited to power flow, short circuit, protective device coordination, transient stability, mechanical infrastructure, economic, environmental, and other efforts.

- The electrical systems power flow model should be used for several different analyses. In particular, the model should be used to perform parallel protection studies. In this case, "parallel" refers to that fact that two complete protective device coordination studies must be carried out: one in grid-connected mode and one in islanded mode. The parallel protection studies should be used to determine new settings for the distribution system protective relays and protective devices.

- The control modes of dispatchable generation must be examined as part of the microgrid design; microgrids require generators that can operate both in parallel with the utility grid as well as isolated from the utility grid. For engine generators, this often means a switch in control modes. This could involve, for example, switching from a current source to a voltage source or switching into isochronous or droop control mode. For inverters, this often means having a dual mode inverter that needs to switch modes as well operate with or without the electrical grid.

- Coordination with the local utility should be conducted during the design process to ensure that the project meets utility interconnection requirements.

\subsection{Construction and Testing}

A next step in the microgrid implementation process is construction, and it is followed by various types of testing.

\subsubsection{Construction}

The level of construction for a microgrid project will vary considerably depending on the amount of new infrastructure required. If a lot of new infrastructure such as generation equipment, communications lines, and electrical equipment is required, the construction process can be quite long and involved. In comparison, if the microgrid is simply a new control system to integrate existing equipment, the process could be much shorter and not as complex.

For the Miramar microgrid, the construction process was quite extensive as the joint venture was required to build new components, including:

- New fiber optic communications lines

- A new power plant building with diesel and natural gas engines

- A retrofit of existing office space to contain a new energy and water operations center

- Installation of motor-operated medium voltage switching equipment

- A new microgrid control system with custom software, redundant servers, and three control stations along with a training simulator 
Lessons learned from the construction process in DoD microgrids include:

- Construction requirements and submittals should be discussed and clarified together by the government and the contractor before the start of construction. Sample forms and templates can help contractors understand government processes.

- The document control process for drawings, reviews, approvals, etc. should be established and well understood by both the contractor and the government.

- As a result of the shop drawing review and approval process, the design documents evolve during the construction phase. Redlined drawings on site need to reflect these changes and should be referenced in the commissioning process.

- Utility companies generally do not have a process for interconnection of microgrids, and this can be challenging, as the utility company may be unsure of how to proceed with microgrid related projects or who within the utility is responsible for approval of the project interconnection agreement. Early and frequent discussions with the utility and establishing a single point of contact from the utility to support the process can both be useful.

\subsubsection{Laboratory/Factory Testing}

Testing of components and systems prior to site delivery and installation is a critical step in the quality assurance process. Scenarios can be simulated, and results can be determined to verify design criteria and performance expectations.

A combination of factory, laboratory, and field testing is needed to verify that a particular piece of equipment has met project requirements.

Ideally, testing would occur in a scaled test bed environment with an appropriate level of system framework, including representative power generation sources, loads, control devices, software, hardware, networking components, and associated communications equipment. The test bed would be used as a proof of concept that would confirm design-phase performance expectations. The specific tests and the amount of equipment that needs to be physically present for a test as opposed to simulated will vary by project and risk tolerance. The range of options includes full simulation, controller hardware in the loop, power hardware in the loop, and full system testing. The cost of testing needs to be appropriated balanced with the risk reduction that it provides and the specific requirements of a particular project.

Examples of tests include, simulated load step changes, sudden loss of generation equipment, ground faults, controller functionality, islanding sequences, equipment functions, and other contingencies in grid-connected and islanded microgrid modes.

\section{Independent Validation and Verification}

Though the individual components of a microgrid are often simple and common, the complexity of these components in an integrated system leaves many opportunities for critical items to be overlooked. To ensure all operational, cybersecurity, and economic goals are met, and that the system ensures safe operating conditions, it can be helpful to have an unbiased third-party review and support projects. There are many organizations that can provide this validation, verification, and testing support, some examples include private companies, DoD laboratories, DOE national laboratories, and universities. 
Text Box 9 provides examples of testing for microgrid projects.

\section{Text Box 9. Examples of Microgrid Testing}

The ESTCP microgrid demonstration project at the Navy's Pacific Missile Range Facility aimed to integrate an existing diesel generation plant, existing rooftop solar PV arrays, and battery energy storage systems into an economic and cyber-secure microgrid. Cybersecurity penetration testing occurred at NREL's Energy System Integration Facility to identify potential threat vectors and to make recommendations that led to securing previously unsecured entry points into the control system prior to integration with the microgrid. This penetration testing is not currently a part of the DoD RMF cybersecurity process, but it could support a reduction of risk presented by new control systems on military installations.

For the Miramar ESTCP microgrid project, controller hardware-in-the-loop testing took place at NREL's Energy System Integration Facility to test Raytheon's microgrid controller. The testing helped improve controller function and reduce risks before deployment at Miramar.

For the installation scale microgrid at Miramar factory acceptance testing for key equipment such as generators and switchgear was conducted and witnessed by the project team.

Controller hardware in the loop testing was conducted at Schneider Electric facilities and witnessed by project team. The purpose of both tests was to reduce risks, verify functionality, and refine the system as needed prior to deployment.

\subsubsection{Site Acceptance Testing (Non-Energized)}

After equipment has been installed, but before electrical power is applied, acceptance testing procedures should be followed in accordance with national standards and manufacturer's recommendations. These procedures will identify components that may have been damaged or loosened during transportation to the site and setting in place.

The standard test procedures are defined by the National Electrical Testing Association (NETA) in the ANSI/NETA publication Standard for Acceptance Testing Specifications for Electrical Power Equipment and Systems, 2017 (or latest) edition. Test personnel should be certified in accordance with ANSI/NETA ETT Standard for Certification of Electrical Testing Technicians, 2018 (or latest) edition.

The manufacturer's recommended test procedures should be submitted for project team review along with the proposed safety plans of the system integrator (including all subcontractors).

\subsubsection{Testing Lessons Learned}

It is beneficial to test components in a laboratory setting prior to deployment at DoD installations. A robust testing process helps ensure that components will work properly when installed reducing overall project time and additional site costs. Successful testing requires an environment that mimics some or all the site conditions and equipment plus a clear test plan with established processes and goals. 


\subsection{Startup and Commissioning}

Upon satisfactory completion of electrical and mechanical acceptance testing, components and systems are energized, and equipment startup occurs in accordance with manufacturer's recommendations. System commissioning then begins in a simulated manner, i.e., control signals are confirmed, data acquisition speed and accuracy is verified, etc. The system integrator then proceeds with commissioning as described in the approved Commissioning Plan.

Verification of equipment status, control signals, load data, etc. includes the following:

1. Monitoring of status and control of circuit breakers

2. Control of dispatchable generation sources

3. Load control

4. Metering and communication infrastructure

5. Coordination of microgrid controller functions

6. Additional field tests will include (but are not limited to):
A. Test the generators e.g. in isochronous mode or base load mode, as appropriate
B. Test remote configuration of the protection devices
C. Test any human-machine interface and visualization tools
D. Test of communication UPS devices and backup generators
E. Test the networks and servers.

\subsubsection{Demonstration}

After successful commissioning of the system, the system integrator will then demonstrate the microgrid under different operating scenarios. Demonstration of the microgrid includes the final performance measurement and validation procedures. The microgrid demonstration period should include a variety of scenarios to demonstrate the functionality of the system. High level examples are list below.

1. System response to differing load levels and operation during different times of day to account for variables such as PV generation

2. Functionality of economic savings components such as peak shaving

3. Loss of generation during microgrid operation

4. Loss of communication signals

5. Introduce simulated conditions (i.e., faults in system, different operating scenarios/system configurations, sudden loss of utility)

\subsection{Microgrid Testing}

After implementation, the islanding operation should be regularly tested to assure it is operationally ready when required. Depending on the location conditions, some or all 
components of the microgrid may seldom be utilized. Therefore, in addition to regular maintenance, a regular testing plan needs to be developed and exercised.

Generally, standby generation that is started but not loaded is less reliable than a system that is regularly exercised at full load. Further, when supervisory controls are seldom utilized — a typical case - evolution of the controlled assets or degradation of communications presents a constant operations and maintenance (O\&M) challenge. It is therefore recommended that a rigorous O\&M schedule be implemented, including live load testing of the system at regular intervals such as quarterly or semi-annually. The frequency of testing required will likely be project specific and subject to considerations such as does testing require a utility outage, how frequently is the microgrid system used in grid connected mode, and what loads are connected. Some existing emergency power systems such as back-up generators in hospitals are typically required to conduct monthly testing. There are several test scenarios which could be utilized:

- The ideal test scenario is to regularly island the microgrid and operate for a period during which normal load variation can be exercised. This type of test verifies the complete system, including operation of breakers, communication, control system, and generation.

Unfortunately, such tests are not without hazards, as the chance of an outage during the test is a constant possibility - indeed, it is the reason for the test - and will doubtless cause concern among microgrid users.

- A less ideal, but often more workable, test plan is to engage all systems - supervisory controls, communication and generation - to bring the microgrid to "net-zero import." This method tests nearly all operational system components while maintaining a grid connection in the event of unforeseen issues. For this method to be effective, the supervisory controls should include the capability of measuring import/export and actively controlling generation to maintain a set level during the test period. Maintaining this state while intentionally varying loads within the microgrid provides a solid test of (1) communications links, dispatch and load balancing between generation units, and (2) control of other assets, such as building energy management systems or standby generation. However, this method does not test the operation of breakers, load pickup (often the most problematic system state), or other potential key system functions such as sectionalizing loads.

- If neither of the preceding test strategies is acceptable, individual assets should be tested regularly at reasonable load levels. For example, centralized generators should be brought to full load levels, turn-down of building energy management systems should be exercised via remote control, and sectionalizing breakers should be operated by remote control. Such testing reduces the most common failures in standby systems, but it neglects some systems and functions, which can cause problems during contingency operation.

\subsection{Operations and Maintenance}

After the design, construction, testing, and demonstration of a microgrid project, the system will be turned over to the government for ongoing operations and maintenance (O\&M). Prior to this point, the government should have established strategy, personnel, and funding for O\&M. Some lessons from DoD microgrid projects related to O\&M include.

- Government O\&M personnel are generally not experienced with microgrid O\&M. Thus, either training or contractor support is required for successful O\&M. 
- Operation and maintenance for a microgrid involves many different disciplines, including facilities, electrical, and mechanical. These need to be coordinated into an overall O\&M strategy with someone who is responsible for overall supervision.

- The DoD cybersecurity process requires regular reviews and updates to remain compliant. A qualified DoD representative needs to be responsible for this.

- Having a training simulator for microgrid operator training is a valuable tool for training new operators and reducing the risks of them learning on the actual operating system.

- O\&M decisions such as who is responsible for O\&M (e.g., government or contractors), how the microgrid will be operated (i.e., manually or automatically), and how the plant will be staffed (e.g., 24 hours a day, 7 days a week versus weekdays during business hours) have large implications on both the cost of O\&M as well as the response time and readiness of the microgrid during a contingency situation.

The microgrid operator can perform several different functions that can provide economic benefits, including actively managing the system for demand response and self-generation, ongoing review and understanding of the utility's rate structure for new opportunities, and scheduling maintenance for PV and other generation systems to ensure maximum uptime. 


\section{References}

Black \& Veatch. 2016. Microgrid Design and Execution Handbook. Overland Park, KS: Black \& Veatch. REV 2016-04. https://www.bv.com/docs/energy-brochures/microgrid-design-ampexecution-handbook.pdf.

Booth, Samuel, John Barnett, Kari Burman, Joshua Hambrick, Mike Helwig, and Robert Westby. 2016. Targeting Net Zero Energy at Marine Corps Air Station Miramar: Assessment and Recommendations. Golden, CO: National Renewable Energy Laboratory. NREL/TP-7A4047991. https://www.nrel.gov/docs/fy11osti/47991.pdf.

DoD (Department of Defense). Instruction: Installation Energy Management. Originally published December 11, 2009 and last updated August 31, 2018. Number 4170.11. https://www.esd.whs.mil/Portals/54/Documents/DD/issuances/dodi/417011p.pdf

Electric Power Research Institute. 2016. Microgrids: Expanding Applications, Implementation, and Business Structures. https://www.epri.com/\#/pages/product/000000003002008205/?lang=en-US

ERDC CERL (U.S. ARMY Engineer Research and Development Command). 2011. SPIDERS Microgrids for Enhanced Mission Assurance and Renewable Energy Utilization. Presented at the Partners in Environmental Technology Technical Symposium \& Workshop, November 29December 1, 2011, Washington, D.C. http://www.dtic.mil/get-tr-doc/pdf?AD=ADA554422.

Faries, Ryan, Mick Wasco, Tom Stepien, Bob Riel, and Bob Butt. 2016. Final Report: Zinc Bromide Flow Battery Installation for Islanding and Backup Power. ESTCP Project EW-201242. El Segundo: Raytheon. September 2016. https://www.serdpestcp.org/content/download/40963/391544/file/EW-201242\%20Final\%20Report.pdf.

Giraldez, Julieta, Francisco Flores-Espino, Sara MacAlpine, and Peter Asmus. 2018. Phase I Microgrid Cost Study: Data Collection and Analysis of Microgrid Costs in the United States. Golden, CO: National Renewable Energy Laboratory. NREL/TP-5D00-67821. https://www.nrel.gov/docs/fy19osti/67821.pdf.

Jensen, Richard, Jason Stamp, John Eddy, Jordan Henry, Karina Munoz-Ramos, and Tarek Abdallah. 2015. Methodology for Preliminary Design of Electrical Microgrids. Albuquerque, NM: Sandia National Laboratories. SAND2015-8433. https://pdfs.semanticscholar.org/0cc2/f8805f9acbd56c5f29492164c84e7867115a.pdf.

Marqusee, Jeffery, Schultz, Craig, and Robyn, Dorothy. 2017. Power Begins at Home: Assured Energy for U.S. Military Bases. Noblis for the Pew Charitable Trusts. https://www.pewtrusts.org/ /media/assets/2017/01/ce_power_begins_at home assured energy for_us military bases.pdf

National Renewable Energy Laboratory. Continuously Optimized Reliable Energy (CORE ${ }^{T M}$ ) Microgrid. July 2013. https://www.nrel.gov/docs/fy13osti/57744.pdf 
Naval Facilities Engineer Command. 2017. Installation Energy Security Framework. July 13 ${ }^{\text {th }}$, 2017.

ODASD(IE). (Office of the Assistant Secretary of Defense for Energy, Installations, and Environment). 2018. Department of Defense Annual Energy Management and Resilience (AEMR) Report Fiscal Year 2017. July 2018. https://www.acq.osd.mil/eie/Downloads/IE/FY\%202017\%20AEMR.pdf

ODASD(IE). (Office of the Assistant Secretary of Defense for Energy, Installations, and Environment). 2017. Department of Defense Annual Energy Management and Resilience (AEMR) Report Fiscal Year 2016. July 2017.

https://www.acq.osd.mil/eie/Downloads/IE/FY\%202016\%20AEMR.pdf.

ODASD(IE). (Office of the Assistant Secretary of Defense for Energy, Installations, and Environment). 2016. Department of Defense Annual Energy Management Report Fiscal Year 2015. June 2016. https://www.acq.osd.mil/eie/downloads/ie/fy\%202015\%20aemr.pdf

Secretary of the Army. 2017. Army Directive 2017-0: Installation Energy and Water Security Policy. February 23, 2017. http://www.asaie.army.mil/Public/ES/doc/Army_Directive_201707.pdf.

Springer, Robert. 2013. A Framework for Project Development in the Renewable Energy Sector. Golden, CO: National Renewable Energy Laboratory. NREL/TP-7A40-57963. https://www.nrel.gov/docs/fy13osti/57963.pdf.

Stuart, Elizabeth, Peter H. Larsen, Charles A. Goldman, and Donald Gilligan. 2013. Current Size and Remaining Market Potential of the U.S. Energy Service Company Industry. Berkeley CA: Lawrence Berkeley National Laboratory. LBNL-6300E. https://emp.lbl.gov/sites/default/files/lbnl-6300e 01.pdf.

Ton, D., and M. Smith. 2012. “The U.S. Department of Energy’s Microgrid Initiative.” The Electricity Journal 25(8): 84-94.

United States Air Force. 2017. Energy Flight Plan 2017-2036. January, 6, 2017. https://www.safie.hq.af.mil/Portals/78/AFEnergyFlightPlan2017.pdf?ver=2017-01-13-133958$\underline{503}$ 


\section{Appendix A. Example Data Request from NREL Microgrid Project}

This appendix provides an example of some data that could be requested for a microgrid assessment it has been adapted from previous NREL requests.

1. One-line diagrams and site distribution plans as available (e.g., high level, including power generation and energy storage resources, main distribution switchgear, feeders, and building transformers) of the different systems

2. Communications infrastructure drawings

3. Background information on existing utility control systems

4. Fifteen-minute load data for utility/main meters, three-year dataset preferred; moregranular data are preferred, if they are available

5. Utility rate schedule/structure information, including energy, demand costs, power factor or other penalties as applicable; utility cost profiles/bills for the past three years

6. Information on demand response opportunities or potential with the local utility

7. Documentation related to historical electrical utility outage information or other power quality issues; other utility outage information (e.g., natural gas lines and communications)

8. Site build-out master plan, including buildings, infrastructure, key systems; include project list for new/upcoming planned or funded projects in critical load area

9. Data from any software models of the electrical distribution system that have been developed; this could include medium voltage distribution system data such as transformer ratings and impedances, conductor info for overhead and underground systems - sizes, material (CU or AL), and cable lengths, plus source (utility) impedance and fault current

10. Mission critical/microgrid load identification and characterization:

F. Facilities to be included in the microgrid

G. Critical facility/building load information

i. Fifteen-minute load data for buildings - three-year data set preferred; more granular data are preferred, if they are available

ii. Peak loads, types of loads, typical load profiles

iii. Large power loads (for example, large equipment or large building complexes connected to single point)

iv. Building numbers/locations identified on site plan

v. Type of distribution system (overhead, underground, or mixed) 
H. Information on controllable loads in critical area (i.e., loads in a building management system, direct digital-controlled facility, or other automated system) that could interface with the microgrid controller

I. Information on curtailable loads that could be shut off in an islanded scenario (important enough to be in the microgrid but would be the first to go if systems conditions require immediate load shed) this leads to a priority scheme in the microgrid

11. Information, consumption data, and drawings related to the existing hot water, steam, and chilled water distribution systems

A. Any information on proposed steam-to-hot water conversion

12. Distributed resource availability and characterization

A. Existing cogen and standby generator ratings/nameplate data and information (including make/model, size, age, machine impedance data, building location, automatic transfer switch timer settings if applicable) generator control systems currently in place (i.e., stand-alone/isolated system, dedicated facility backup/open transition automatic transfer switch, or closed transition paralleling switchgear)? Fuel tank size and fuel type or types

B. Co-generator production, daily logs for past three years for electricity, heating, and cooling

C. Cogeneration gas and fuel oil costs; monthly or hourly fuel use, output and runtime for multiple, recent years

D. Schedule and costs of O\&M (including any generator overhauls)

E. Energy storage systems, if applicable (grid-scale or building UPS), size (kW), capacity ( $\mathrm{kWh}$ ), voltage, location, etc.

F. Project list for renewables: planned, funded, and/or installed; PV system nameplate size, system locations, and production for each system

G. Any other processes or heat requirements that can make use of cogen waste heat

13. Duration the microgrid needs to operate when islanded from the utility with and/or without fuel resupply via truck or pipeline (e.g., two weeks)

14. Identification of known, strategic or mandated technology or configuration preferences

15. Definition of extent of cybersecurity requirements

16. Utility cost escalation rates (\%/year) for both electricity and natural gas, discount rate and inflation rate 


\section{Appendix B. Reactive Power, Harmonic Distortion, and Control Modes}

\section{Reactive Power and Power Factor}

Motors, transformers, and other inductive equipment require reactive power in order to operate properly. Reactive power, or volt amperes reactive (VAR), can be provided by the utility, power factor (PF) correction capacitors, inverters, dynamic VAR compensators, or by other means. Reactive power in islanded mode is typically provided by connected generation equipment. However, some substations include capacitors for PF correction equipment that is installed at the transformer secondary distribution equipment. Substations can have capacitors with various steps with controls based on load PF setpoint. Some systems use fixed capacitors at substations to offset transformer inductive losses.

These distributed capacitors provide a benefit in island mode by reducing the amount of reactive power that is needed by generation sources. They also reduce system losses by suppling reactive power near the loads that need the VAR's.

Generators typically are rated for 0.8 power factor (PF) (i.e., a 1,200 kW/1,500 kVA machine can supply up to 900 [kilovolt amperes reactive] kVARs to a load with lagging PF). In a system with leading PF (more capacitive loads than inductive loads), generator capacity becomes constrained and stability may be compromised. Ideally, the total loads in the system are close to, but slightly lag, unity PF. The islanded mode PF should be evaluated as part of the engineering design analyses.

\section{Harmonic Distortion}

Many devices that are connected to the electrical power system, such as computer equipment, adjustable speed motor drives, and inverters that are used as part of PV generation facilities, generate current harmonics that are injected into the electrical network. Harmonic currents flow from the polluting sources back to the power source. These harmonic currents will aggregate into the utility electric system and flow toward the source. These harmonics distort the supply voltage waveform, possibly causing sensitive equipment to not operate correctly.

Under utility-connected conditions, the source impedance is small enough that harmonic effects are not significant. However, the problem can be amplified when the power system network is supplied by diesel or gas generators, where the impedance of the source is much higher (resulting in higher voltage drop from harmonic sources back to generators). The aggregated harmonic currents can potentially bring generators offline.

Harmonics, by their nature, are higher frequencies than the fundamental power system frequency (50 or 60 hertz). The more common harmonics are the third, fifth, seventh, and ninth, although the specific harmonics and their magnitude depend on the extent of single-phase nonlinear equipment (e.g., laptops) and three-phase (e.g., adjustable frequency drives) devices. Higher harmonics are attracted to capacitors because the impedance is inversely proportional to frequency, $1 / \mathrm{j} \omega \mathrm{C}$, where $\omega=$ frequency and $\mathrm{C}=$ capacitance. Because capacitive reactance is inversely proportional to frequency, unfiltered harmonic currents in the power system find their 
way into power factor correction capacitor banks. These capacitor banks act like a sink, attracting harmonic currents and thereby becoming overloaded.

The use of harmonic filters, both passive and active type, help improve the overall power quality of the network. An assessment of harmonic-producing equipment, together with the magnitude of harmonics that are produced, is typically required to determine filter size and characteristics as well as determining optimal filter locations. Filters located at selected distribution substations would likely provide more benefits because the harmonic currents do not flow very far before they are mitigated.

Sometimes existing generations sources have tolerance levels with respect to the amount of harmonic current distortion that they can tolerate, and it is recommended that these data be requested from the generator's manufacturers if this might be a concern.

Additionally, an engineering study should be conducted at the substation secondary level with data logging instrumentation to determine the extent of the harmonic contribution from nonlinear loads. The study will then provide the most appropriate harmonic mitigation technique for each substation. This will be advantageous as it will mitigate harmonics before going into the $20-\mathrm{kV}$ distribution system. Some possible harmonic mitigation options are:

- Option 1-Passive Filters: Passive filters consist of reactors and capacitors set up in a resonant circuit configuration. The configuration is then tuned to the frequency of the harmonic order to be eliminated. A system may be composed of several filters to eliminate several harmonic orders. Alternatively, if available existing substation capacitor banks in conjunction with appropriately sized reactors could be used to create these harmonic filters.

- Option 2-Active Filters: These devices constantly measure current flow and inject a harmonic current spectrum in phase opposition to the measured spectrum. This has the effect of canceling the original harmonic currents. Active filters can be stand-alone or built within a battery energy storage system. Placement of filters is critical in order to prevent harmonic currents from flowing back to generators.

An engineering assessment of utility or advanced meter data could provide information on the level of harmonic distortion that exists for an installation or location. Although the worst-case scenario for harmonics is typically during islanded mode of operation, during utility-connected operation, the location for the harmonic filters will still provide benefits in addition to maintaining a stable, robust microgrid.

\section{Control Modes}

This section details the following possible generation control modes:

- Base load: The generator provides constant real power at a fixed power factor and is synchronized with the utility or another generator source that determines the frequency of the alternator.

- Variable load: The generator provides real power at a fixed power factor and is synchronized with the utility or another generation source. Power is produced on a variable and non-consistent basis, such as with solar or wind energy. 
- Isochronous mode or isochronous load-sharing mode (commonly referred to as swing machine or swing group of machines): The generator in isochronous mode has the ability to return to the original speed after a change in load and will maintain the same fixed frequency regardless of the load it is supplying up to the full load capabilities of the generator. In isochronous load-sharing mode, a group of generators is connected and has a load-sharing control on top of the individual governor controls that proportionally splits the change in load among the group of generators to maintain a target fixed speed and act as a frequency reference. In this mode, the generator(s) act like the power supplied by the utility grid and are used in isolated power systems where the isochronous generator(s) are responsible for maintaining consistent system frequency.

- Droop mode: The generator speed varies linearly with the load. Frequency droop is a decrease in frequency or speed proportional to the load and is expressed as the percentage reduction in frequency versus the frequency set-point that occurs when the generator is fully loaded versus the frequency that occurs when the generator is unloaded. If the frequency set point, droop characteristic, and grid frequency are constant when connected to a utility generator(s) in isochronous mode, the generator output will remain constant. In isolated systems, if all the generators are in droop mode, the isolated system frequency will also change as the load changes, and a change in the droop governor control frequency set-point is required to return the system to the original frequency. 


\section{Appendix C. Battery Energy Storage Systems}

A battery energy storage systems (BESS) can provide several benefits that to the electrical distribution system and microgrid. This appendix provides additional considerations and applications for these key resources.

Traditional generation sources such as diesel or gas generators do not have an instantaneous capability of responding to sudden load changes, and this latency in generator response impacts system frequency, which in turn affects utilization equipment at the building level. A BESS of sufficient size that is connected to the microgrid can provide an immediate response to sudden changes in system frequency (i.e., following loss of another generation unit) and thus maintain stability until appropriate load shed techniques can be employed. Though response times vary somewhat by the specifics of the battery with differences related to battery chemistry, battery manufacturer, application that the battery was designed for, etc. most batteries can provide this response. The most common battery deployed for DoD microgrid applications is one of the two most common types of lithium ion batteries, either lithium iron phosphate or lithium nickel manganese cobalt oxide. Some general characteristics that sometimes lead projects to select lithium ion batteries include, fast response, lower technology risk, lower cost, and higher energy density than some alternatives.

Some PV systems are sensitive to grid power quality and will shut down during a minor grid disturbance, but with stable voltage and frequency, these resources will remain connected. The BESS can act as a "spinning reserve" to manage dynamic load changes, and some conventional generation (gas or diesel) that normally would need to be on-line to meet this need could be shut down. A BESS can also be used to black start the microgrid or even a power plant if needed.

A large BESS could be utilized as a large interruptible power supply for seamless transition to microgrid mode if desired. If an event caused the main utility breaker to trip, and depending on the state of charge, BESS could either take over and stabilize the distribution system before other generation comes online. Once other generators were online and picked up the essential loads, the BESS could absorb some of the remaining loads by order of importance.

One major challenge in microgrid designs is that many include solar PV, which is a variable energy resource and could exceed load in certain circumstances. To mitigate this issue, a BESS could be installed, to be charged during periods of excess PV generation and discharged during periods of high electricity demand. A BESS can also dampen the harmonic interference between the conventional generation and PV and can also provide a firm grid reference frequency to allow the PV to operate in islanded mode.

Potential revenue-producing activities for a BESS include peak shaving, energy arbitrage, demand response, and various ancillary services. If the BESS were used for economic purposes, special attention would need to be placed on the state of charge of the system along with associated resiliency requirements, and the site would need to toggle this setpoint based on the desired use. For example, if a goal for the BESS were to prevent exporting electricity to the utility grid and reduce nighttime demand, the BESS could be maintained at a low state of charge $(20 \%)$ at the start of the day. This would require charging the battery during the day and discharging the battery at night. If at another time it is decided to use the BESS for backup up 
power for a specific mission (e.g., as a back-up energy source), the BESS would need to be fully charged as recommended by the manufacturer. The stability, robustness of the distribution system would be the overarching factor considered under this mission assurance mode of operation; peak shaving or avoiding electricity export to the utility would not be the priority.

During the islanding mode of operations, a BESS can provide a major service by reducing the harmonics components injected in the system. One source of harmonics is often a large amount of power being produced by the PV inverters. Without a harmonic mitigation technique, PV generation is sometimes not recommended during islanded mode, as it creates instability in the installation's distribution grid and some generators are sensitive to them. Reactive power compensation is another common service a BESS can provide in both grid-connected and islanded modes.

\section{Additional Resources}

U.S. Battery Storage Market Trends. U.S. Energy Information Administration. May, 2018. https://www.eia.gov/analysis/studies/electricity/batterystorage/pdf/battery storage.pdf

Lazard's Levelized Cost of Storage Analysis-Version 4.0. Lazard. November, 2018.

https://www.lazard.com/media/450774/lazards-levelized-cost-of-storage-version-40-vfinal.pdf

General information on energy storage including information on the types of energy storage technologies, applications, and case studies. Energy Storage Association. http://energystorage.org/ 


\section{Appendix D. Load Management Techniques.}

One way the load/generation balance can be controlled is through load-shedding techniques. For example, distribution circuit breakers feeding substation transformers that supply only noncritical/essential buildings may be open when the microgrid is islanded (and these buildings remain without power until sufficient generation is available). Furthermore, there are buildings that may not be important enough to be powered up that are connected to transformers that do supply high priority loads. Removing these low-priority buildings from the microgrid could provide some additional load control and stability advantages. For example, a building that requires $200 \mathrm{~A} 3$-phase at $400 \mathrm{~V}$ is a $138-\mathrm{kW}$ load on the microgrid, and 10 of these buildings equate to more than $1 \mathrm{MW}$ of potential load-shedding capability. It should be noted that these load-shedding techniques may not be fast enough to balance load/generation in real time, but they are useful to remove system load below a desired generator capacity setting (typically $80 \%$ ) and allow the generation resources to maintain balance by varying output.

There are several different methods for tripping circuit breakers and removing buildings supplied by those circuit breakers from the microgrid. One labor-intensive process that requires qualified personnel involves the manual tripping and closing of circuit breakers at distribution equipment to remove buildings from the microgrid. This method is costly and typically not advisable except in emergency situations.

A much faster control technique involves electrical shunt-tripping of selected building supply breakers. A trip coil at the breaker is energized when load needs to be shed, and the remotecontrol signal may be from nearby controller. An example of such a modified substation secondary equipment distribution scheme is shown in Figure D-1.

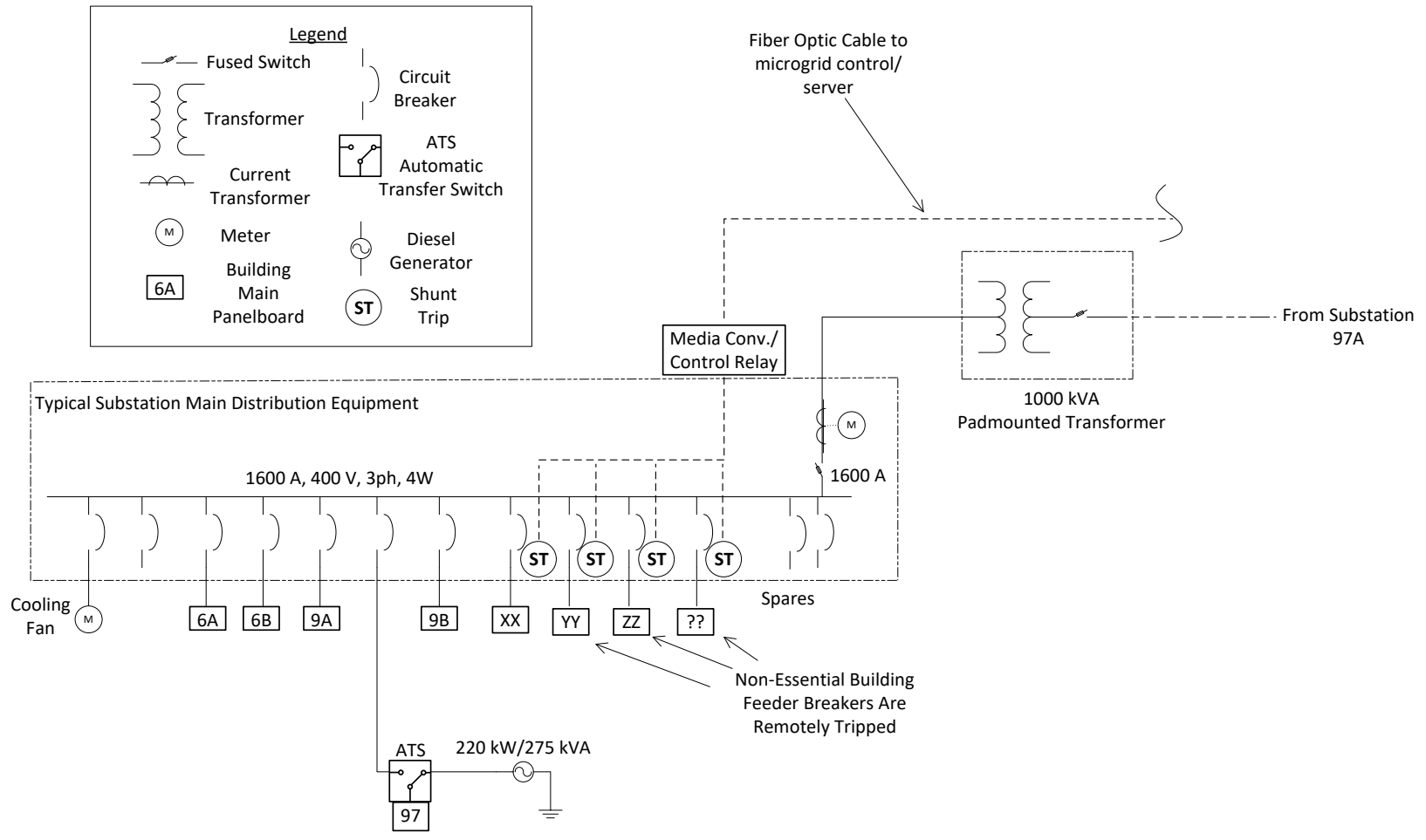

Figure D-1. Substation modification for load management by shunt-trip 
Shunt-trips may already exist on some distribution equipment circuit breakers, or the selected building feeder breakers could be retrofitted with a vendor-supplied kit to enable this functionality. In some cases, a breaker would have to be replaced by one with the needed control capability. A troublesome issue with the shunt-trip concept is that these breakers will have to be manually reset after utility grid power is restored and the shunt trip signal is disabled. Because of this, the shunt trip concept is only marginally better than manual operation of the breakers.

An ideal scenario would have draw-out style power circuit breakers in the substation secondary distribution equipment. These devices have the built-in capability to receive both trip and close remote-control signals, and the breakers can also provide breaker status, load, and other information to the microgrid server. An example of this concept is shown in Figure D-2.

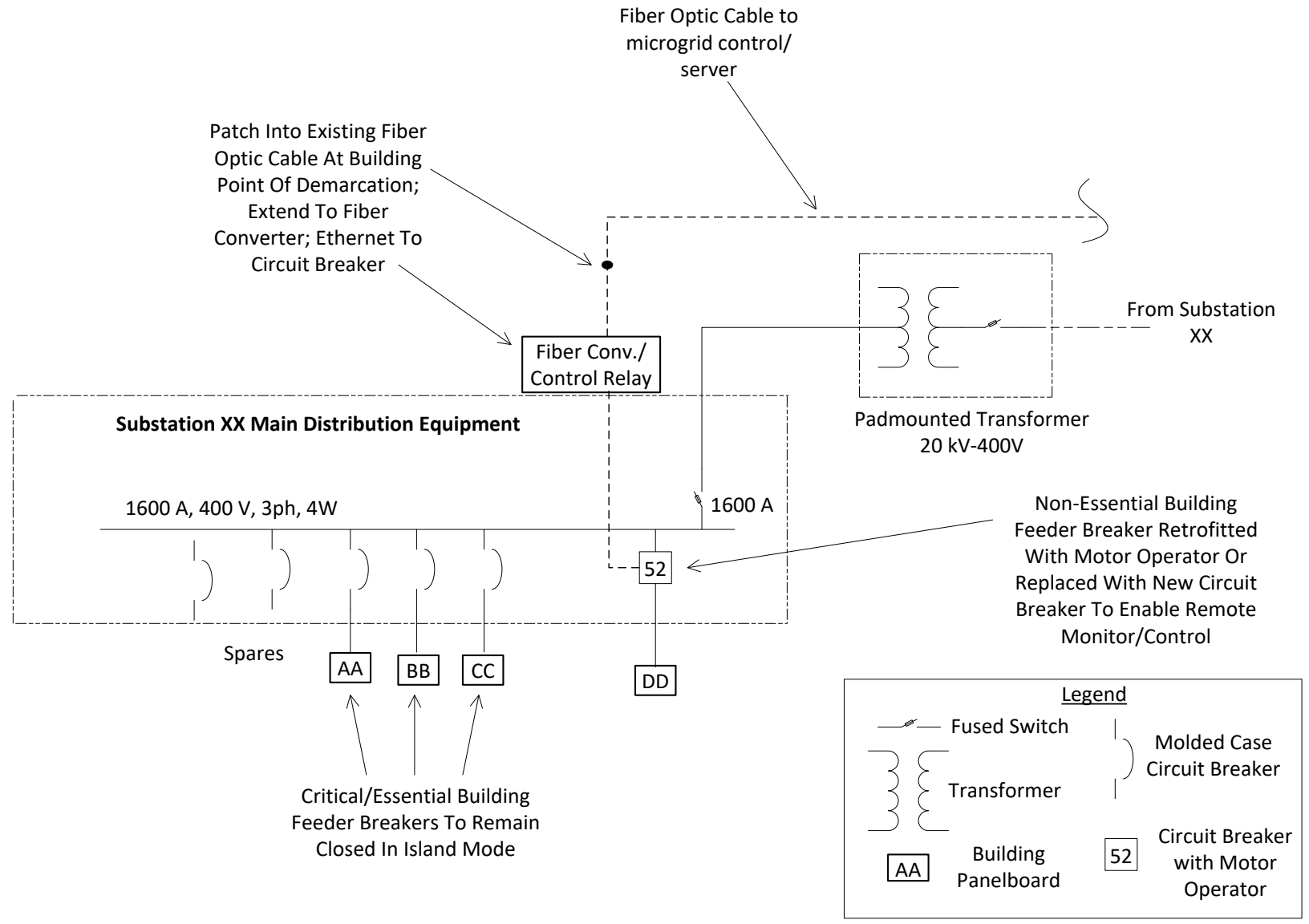

Figure D-2. Draw-out style power circuit breakers for load control 


\section{Appendix E. Generator Transfer Options}

Automatic transfer switches often have open transition between sources (generator and grid), which means the building loads are interrupted when transferring from generator to grid supply. An example of this scheme is shown in Figure E-1. Some transfer switches have the capability of "fast" transfer of sources from the diesel generator to the grid in a "seamless" fashion, when both sources are within an acceptable window.

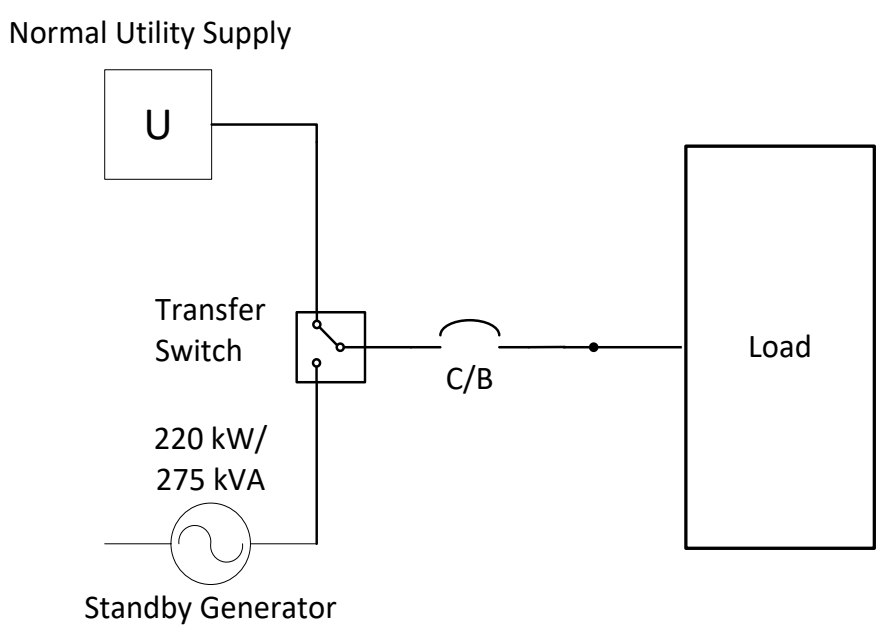

Figure E-1. Typical automatic transfer switch scheme for standby diesel generator

Another scheme, shown in Figure E-2, includes a pair of circuit breakers, each of which is controlled for either single source or parallel source operation. The controller monitors the grid supply and the diesel generator, and it controls the generator speed and voltage to enable parallel operation. When normal grid supply is lost, the controller trips that utility breaker and starts the generator to supply the building loads. When the utility source returns, the generator is synchronized to it, and the utility breaker is closed to parallel the two sources. The diesel generator may transfer the building loads to the utility source or remain connected and support the grid (based on commands from a microgrid controller).

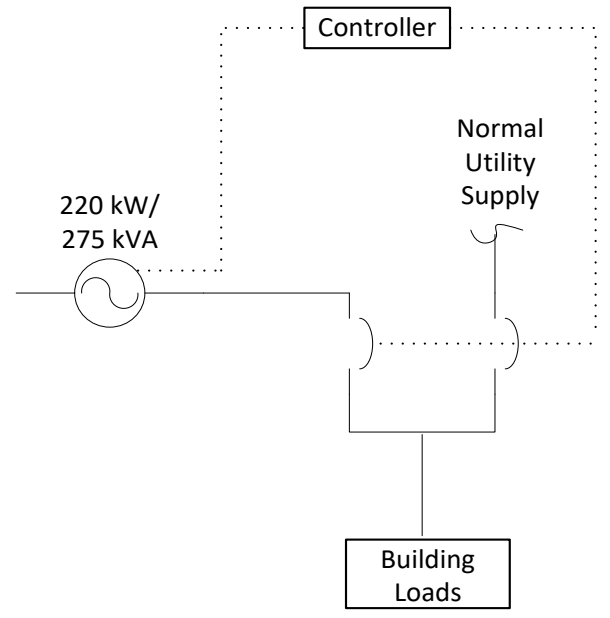

Figure E-2. Paired circuit breakers for standby diesel generators to support load/generation management 


\section{Appendix F. Cybersecurity Provisions}

This appendix presents an overview of cybersecurity previsions and defenses adapted from previous NREL DoD projects.

The first line of defense occurs at the perimeter of the microgrid with the objective of keeping attackers out altogether. Physical access security is the foundation to a defense-in-depth strategy. Cabinets and containers should be secured. Where new or upgraded microgrid controls are added to outdoor generators, cabinets should be padlocked; keys should be stamped (DO NOT DUPLICATE) and controlled.

Hardware hardening, in the form of removing unnecessary software and services, and disabling unneeded communications and data ports on the computers hosting the control software, adds another, host-based layer of "perimeter" security. Where practicable, device and control station universal serial bus (USB) or memory card controllers that are not explicitly required should be disabled. If present, radios (Wi-Fi or Bluetooth) should be deactivated. Operating systems, software, and firmware are hardened by disabling or removing code, protocols, and services that are not specifically required to operate the microgrid. Default services such as Telnet, Secure Socket Shell (SSH), or Remote Desktop Protocol (RDP) should be disabled. Port security should be enabled to restrict only the particular source media access control (MAC) address of the defined networked devices.

Sitewide password policy should be administered, including the management of passwords (e.g., access and storage), adequacy (e.g., length and characters required), privilege (i.e., administrative rights), and expiration (e.g., frequency of change, lock-out, and revocation). Passwords should be enabled to restrict access to only authenticated users.

Appropriate logical network architecture is the basis of a secure microgrid control system. Operational characterization of the microgrid, threat identification, and vulnerability assessment allow the risks to be managed as part of the initial microgrid design. For example, network segmentation and isolation on the basis of functional groups will reduce many vulnerabilities.

Here, a useful start includes firewalls and intrusion-detection systems that also seek to keep intruders out and identify attempts to penetrate the network perimeter. A firewall performs stateful inspection of inbound and outbound traffic. A firewall (e.g., Cisco ASA 5512 or Juniper SRX210) between the microgrid network and any other networks should be configured to deny all traffic except that which is explicitly authorized. Whitelisting is a security protocol where only preapproved devices are allowed system access. Firewall rules should at a minimum provide source and destination filtering (i.e., filter on media access control [MAC] address), in addition to Transmission Control Protocol (TCP) and User Datagram Protocol (UDP) port filtering and Internet Control Message Protocol (ICMP) type and code filtering. Role-based access control (RBAC) should be employed to restrict microgrid user privileges to only those required to perform assigned duties (principle of least privilege). According to base sitewide policy, microgrid firewall logs ("syslogs") should be monitored to ensure all relevant policies are correctly enforced, validate network architecture, and regulate access controls. 
Once the microgrid is commissioned and operational, networked devices should receive timely security patches and updates. Doing so procedure manages or eliminates any security backdoors as they are discovered by the equipment manufacturer. Time-based utilities ("cron jobs") may be configured by base personnel to update the system with the latest firmware and security patches (rather than providing device-level network or physical access to manufacturer's representatives).

Any updates or modifications to the energy management control system (EMCS) and operational technology $(\mathrm{O} / \mathrm{T})$ network shall require a formal "system security plan" that complies with NIST 800, FIPS 140-2, and FIPS 199, as applicable.

\section{Additional Resources}

"IEEE Std 1547.4-2011: IEEE Guide for Design, Operation, and Integration of Distributed Resource Island Systems with Electric Power Systems," Institute of Electrical and Electronics Engineers (IEEE), 2012. https://standards.ieee.org/findstds/standard/1547.4-2011.html.

"NIST Risk Management Framework (RMF) Overview," National Institute for Science and Technology: Computer Science Resource Center, http://csrc.nist.gov/groups/SMA/fisma/framework.html.

"SP 800-53 Security and Privacy Controls for Federal Information Systems and Organizations," National Institute of Standards and Technology, April 2012. https://nvlpubs.nist.gov/nistpubs/specialpublications/nist.sp.800-53r4.pdf.

"SP 800-82 Guide to Industrial Control Systems (ICS) Security," National Institute of Standards and Technology, May 2015. https://nvlpubs.nist.gov/nistpubs/specialpublications/nist.sp.80082r2.pdf.

"UFC 4-010-06 Cybersecurity of Facility-Related Control Systems," Whole Building Design Guide, 18 January 2017. https://www.wbdg.org/FFC/DOD/UFC/ufc 4 _010_06_2016_c1.pdf. 